\title{
Notes on Contributors
}

Carl Lavery is Professor of Theatre at the University of Glasgow. His recent edition of the journal Green Letters, 'Performance and Ecology: What Can Theatre Do?', will be published as a book by Routledge in 2018. He is currently finishing a new monograph, Interrogating the Human: Ecology, Theatre, and Theatricality.

Andrew Lennon is a $\mathrm{PhD}$ candidate at the University of Birmingham supported by the AHRC Midlands3Cities DTP. His research focuses on the mobilisation of documentary strategies in contemporary performance. He completed an undergraduate degree at Trinity College Dublin and studied at the Motley School of Design. He has worked in Ireland and England as a lighting technician and designer.

Anna McMullan is Professor of Theatre and Co-Director of the Beckett International Foundation at the University of Reading. She was Principal Investigator of the AHRC Staging Beckett project, a collaboration between the universities of Reading and Chester, and the Victoria and Albert Museum, London, from 2012 to 2015. McMullan is author of Performing Embodiment in Samuel Beckett's Drama (2010) and Theatre on Trial: The Later Drama of Samuel Beckett (1993), and co-editor of Reflections on Beckett (2009) with Steve Wilmer. She also publishes on Irish theatre and Performance and is co-editor with Cathy Leeney of The Theatre of Marina Carr: 'before rules was made' (2003).

Trish McTighe is Lecturer in Theatre at the University of Birmingham. Previously, she lectured at Queen's University, Belfast and was an AHRC post-doctoral researcher on the Staging Beckett Project at the University of Reading (2012-2015). Her book, The Haptic Aesthetic in Samuel Beckett's Drama, was published with Palgrave in 2013, and she recently co-edited the double volume Staging Beckett in Ireland and Northern Ireland and Staging Beckett in Great Britain (Bloomsbury-Methuen, 2016). She has published in the journals Modern Drama, Samuel Beckett Today/Aujourd'hui, and the Irish University Review, on topics such as Beckett's drama, embodiment, and Irish culture and performance histories. She is theatre reviews editor for the Journal of Beckett Studies.

Sinéad Mooney is a senior tecturer in English at De Montfort University, Leicester. She works on Irish literature, modernism, and women's 
writing. Her previous work on Beckett includes A Tongue Not Mine: Beckett and Translation (Oxford University Press 2011), which won the American Conference for Irish Studies Robert Rhodes Prize.

Brenda O'Connell is a $\mathrm{PhD}$ candidate at Maynooth University, Ireland. Her thesis, entitled: 'Age Matters: Motherhood, Matrixial Theory and the Ageing Female Body in Samuel Beckett's Work', is funded by the Hume Scholarship. Brenda has published on performance art, theatre reviews. and has a forthcoming article on the ageing female body in Beckettpublished by Nordic Irish Studies.

Sarah Jane Scaife, Adjunct Lecturer TCD and Artistic Director of Company SJ, researches and directs Beckett nationally and internationally (London, New York, Greece, India, Malaysia, Singapore, China, Mongolia, America, Japan, and Georgia). Company SJ are currently touring their Beckett in The City series. Research projects include female Irish writers of the early twentieth century and a new Beckett production.

Graham Saunders is the Allardyce Nicoll Chair in Drama at the University of Birmingham. He has published widely on Sarah Kane including About Kane: The Playwright os the Work (2009) and 'Love Me or Kill Me': Sarah Kane and the Theatre of Extremes (2002). He currently publishes on British Brama since 1945, Samuel Beckett, and the relationship between contemporary British dramatists and Elizabethan and Jacobean Drama. He was Principal Investigator on the AHRC-funded project, 'Giving Voice to the Nation': the Arts Council of Great Britain \& the Development of Theatre \& Performance in Britain 1945-1995 (2009-14), a collaboration between the University of Reading and the Victoria and Albert Museum London, and was a Co-Investigator on the AHRC-funded Staging Beckett: the Impact of Productions of Samuel Beckett's Drama on Theatre Practices and Cultures in the UK and Ireland (2012-15).

Derval Tubridy is Senior Lecturer in the Department of English and Comparative Literature at Goldsmiths, University of London. She works on modern and contemporary literature, performance and the visual arts with a particular focus on the intersections between language and materiality. Her monograph Samuel Beckett: The Language of Subjectivity is forthcoming with Cambridge University Press.

Phillip Zarrilli is Emeritus Professor of Performance Practice, Drama Department, Exeter University, and Artistic Director, The Llanarth Group. He is known internationally for his directing and acting in Beckett's later shorter plays. Most recently he directed Footfalls and Play for The National Theatre Company, Costa Rica (2017). 


\section{Editorial: Staging Beckett and Contemporary Theatre and Performance Cultures}

1. Such as the Dublin Gate Theatre Beckett Festival launched in 1991, the Happy Days International Beckett Festival inaugurated in 2012 , or the Barbican Beckett International Festival in June 2015.

2. Michael Gambon

played Hamm in a production of Endgame at the Noel Coward Theatre in 2004, and Krapp in Krapp's Last Tape in the Duchess Theatre in 2010; Ian McKellen played Vladimir with Patrick Stewart as Estragon in the 2009 West End production of Waiting for Godot at the Haymarket, that subsequently toured to Broadway in 2013 Fiona Shaw performed Winnie in Happy Days directed by Deborah

Warner in a touring production which included the National Theatre's Lyttelton in 2007; and Mark

Rylance played Hamm with Simon McBurney as Clov in Complicité's Endgame at the Duchess in 2009.

Further details of these and other UK and Irish productions can be
Once the epitome of experimental, 'difficult', avant-garde drama, at the edge of what is possible in the theatre, the plays of Samuel Beckett are now likely to be presented and indeed to sell out, in international Festivals, ${ }^{1}$ West End, Broadway, or national venues with high-profile actors such as Michael Gambon, Ian McKellen, Fiona Shaw or Mark Rylance. $^{2}$ Tracing the history of this trajectory was one of the aims of the AHRC (Arts and Humanities Research Council)-funded research project Staging Beckett: the Impact of Productions of Samuel Beckett's Plays on Theatre Practice and Cultures in the UK and Ireland that ran from 2012-2015 as a collaboration between the Universities of Reading and Chester and the Victoria and Albert Museum, London. Beckett is now a highly marketable, cultural icon with global brand recognition, but this does not adequately account for the legacies of his work for contemporary theatre and performance practices and cultures, whether national, international, regional or fringe. ${ }^{3}$

The Staging Beckett project set out to bring a range of contemporary practices and critical discourses from theatre and performance studies into dialogue with Beckett's theatre. Beckett's plays remain an important medium for what Herbert Blau termed 'thinking through' theatre and performance, asking fundamental questions about the interrelations between self and other, human and non-human, theatre and the other arts, and between the performing body, voice, technology, space, time, and the ethics of witnessing. ${ }^{4}$ Beckett's work therefore has the potential to open up new creative practices and vocabularies for testing the languages and boundaries of theatre in the twenty-first century. Individual productions, whether through testimony or archival remains, tell us a great deal about shifting practical and cultural interpretations of Beckett at different historical moments and locations. Beckett's work therefore remains a vibrant presence and inspiration for scholars, practitioners and audiences of contemporary theatre and performance. ${ }^{5}$ This issue, though inevitably covering only a small selection of case studies mainly from British and Irish contexts which was the stated focus of the project, aims to explore some of Beckett's 
found by searching the Staging Beckett Database <https:// www.reading.ac.uk/ staging-beckett/> [accessed

3 March 2017]

3. See Nicholas Johnson's meditation on the writer's legacy in 'A Theatre of the

Unword: Censorship, Hegemony and Samuel Beckett' in Ireland, Memory and Performing the Historical Imagination, ed. by Christopher Collins and Mary P. Caulfield (Basingstoke: Palgrave Macmillan, 2014), pp-36-54 (p-38): 'the true legacy of a writer is only contained in the durability of his or her living thought, and the rest is branding'.

4. See, for example, Herbert Blau, Sails of the Herring Fleet (Ann Arbor: University of Michigan Press, 2004), p. 2 .

5. Full details of our outputs including articles edited books and public exhibitions can be found on the bsite as eur publications include, in addition to this special issue of Contemporary Theatre Review, the twin volumes Staging Beckett in the UK and Staging Beckett in Ireland and Northern Ireland, coedited by Trish McTighe and David Tucker, and published by Bloomsbury Methuen Drama in 2016, and a forthcoming special issue of the bi-lingual journal, Samuel Beckett Today/ Aujourd'bui, co-edited by McMullan and Pattie, on Staging

Beckett at the Margins, which includes analyses of productions of Beckett's work in the marginal spaces of cities such as London, Dublin, or New York, as well as national and regional cultures beyond the Euro- living legacies for the discipline of theatre and performance, from his impact on actors, designers or directors $\overline{\mathbf{z}}$ on theatre cultures at national and local levels $\overline{\mathbf{z}}_{\mathbf{z}}$ and on theatre and cultural programming, to the generation of new approaches to theatre and interdisciplinary or intermedial performance and aesthetics, and on our interactions with the performance archive.

The repositioning of the human in relation to the non- or more than human is a fundamental concern of ecology and performance. This is the subject of Carl Lavery's article that develops, using Beckett as a prism, existing work that he and Clare Finburgh presented in their 2015 edited collection, Rethinking the Theatre of the Absurd: Ecology, Environment and the Greening of the Modern Stage. ${ }^{6}$ However, Lavery does not ask us to once again consider Beckett a card-carrying absurdist, whose early work for the theatre such as Endgame (1957) was seen at the time as an expression of post-nuclear anxieties. Instead, Lavery puts forward the proposition that Beckett's theatre becomes a site where the human disappears, or else is subjected to the ravages of time, such as the figures in Play (1963), whose visages have become weathered by the same processes as the urns that enclose them. In this way Lavery argues that Beckett's theatre can be viewed ecologically through the metaphor of a garden. While this has long been used in drama from Shakespeare onwards - in Richard II (1597) as an emblem for misrule, or the marker for the dysfunctional family relationships in Enid Bagnold's The Chalk Garden (1955) - Lavery asks us to view Beckett's theatre in performance as an ecological phenomenon: from the structure of the building itself to features such as the proscenium arch, the drama becomes an affective site through which spectators are 'weathered' through the events they experience onstage. However, Lavery does not equate ecology with nature, but more a relationship between the human and the nonhuman. Far from being 'at home', or at the centre of things, Lavery reminds us that cataclysmic events such as the Indian Ocean Tsunami in 2004, demonstrate that human beings are actively dispelled from the oikos. This precarity is something that Beckett is all too aware of and, using Footfalls (1976) as his main example, Lavery demonstrates, through reference to Jean-François Lyotard's late writings, how this hostility is enacted in a world such as Endgame where it has ceased to rain ${ }^{7}$ and where beyond the sanctuary of the room Hamm bewails, 'Nature has abandoned us'. ${ }^{8}$

Trish McTighe addresses questions of performance and landscape in her article on place and archive in relation to the Happy Days International Beckett Festival that has been held for several years in the Northern Ireland town of Enniskillen. In particular, McTighe is interested in those performance events that take place outside the central locus of the festival itself. Drawing on the early work of Nick Kaye on site-specific performance, McTighe sees geographical sites as forms of archive that, when utilized within the context of a performance, reveal traces of their own history. Yet, crucially, McTighe does not see the use of location in the Happy Days Festival as genuinely sitespecific in intention or effect, or even Beckett's own tenuous association with Enniskillen, through his attendance at the local Portora 
American cultural axis including Korea and Turkey.

6. See Rethinking the Theatre of the Absurd: Ecology, the Environment and the Greening of the Modern Stage, ed. by Clare Finburgh and Carl Lavery (London: Bloomsbury, 2015

7. Samuel Beckett, The Complete Dramatic Works (London: Faber, 1986), p. 94.

8. Ibid., p. 97.

9. See the Beckett Digital Manuscript Project, a collaboration between the Universities of Antwerp and Reading, and the Harry Ransom Humanities Research Centre at the University of Texas at Austin: <http://www. beckettarchive.org> [accessed 18 March 2017].
School. Using as her main example a performance of Ohio Impromptu (1980) on Devenish Island in a small cottage, sited within the ruins of an ancient monastery, McTighe argues that the tourist experience (travelling out to the island by boat and being given the opportunity to explore the ruins after the performance), diminishes the associations of place and performance that most site-specific work deliberately seeks to accentuate. While the town of Enniskillen has many historical associations - from being an early plantation settlement for the English and Scots in the 1600s to the IRA 1987 Remembrance Sunday attack McTighe concludes that for the festival organisers site becomes used more for its novelty value and what she calls the 'resonances of place' than for any commemorative function such locations might hold. However, McTighe's article offers productive ways of thinking about place and landscape as archive.

Indeed, within the landscape of Beckett Studies, archival research has become prominent, including a rise in genetic manuscript study. ${ }^{9}$ With an emphasis not on Beckett's own texts, but on the ephemeral traces of performance, archival work became one of the main strands of the Staging Beckett project, together with an early recognition that to properly assess Beckett's impact on British and Irish theatre cultures the team would need to travel out beyond the showpiece collections housed at Reading University and Trinity College Dublin. Sinead Mooney's article is a mischievous and witty response to this recent 'archival turn' in Beckett Studies that has focused on the discarded drafts and works in progress that the author had-left carefully preserved sinee his death in 1989. Instead, Mooney takes us on a journey to less prestigious repositories of Beckettian materials situated within small theatre collections, public libraries, and city and county council records in order to look at several regional productions of Waiting for Godot performed since the celebrated (and well-documented in performance histories) London production in 1955. Mooney argues that the value of the ephemera located in these collections - scrapbooks, prompt books, financial records and stage managers reports - is of value to scholars of Beckett and theatre historians alike in that these archives move away from the author-centred archives of Reading and Dublin to ones that expose (often in unexpected and amusing ways) the material conditions of performance and give indications of how a celebrated avant garde work such as Godot fared beyond the metropolitan centres of Paris and London to audiences Birmingham, Nottingham and Manchester. Here, Mooney discovers that little regard was paid to Godot's Left Bank credentials, tracing how the play was first made to conform to institutional structures, and more broadly how these Godots from the late 1950s to the mid-1970s charted the decline of the old repertory system and the policy changes instituted through the Arts Council and local authorities that directly impacted on theatre in the provinces from the 1960s onwards. Mooney argues that these networks of less regarded collections represent the vast, invisible 'dark matter' that binds together theatre studies as a discipline in the traces they reveal of backstage conditions integral to the producing of performance itself. 
10. For example, Kene Igweonu, "'The Tree has Four or Five Leaves": Talawa: Britishness, and the First All-Black production of Waiting for Godot in Britain', and John Stokes, "A Price to be Paid": West End Beckett', as well as essays on the history of London and regiona including Scottish productions of Beckett's drama in Staging Beckett in Great Britain, ed. by Tucker and McTighe.

11. Participants included the Artistic Director of Ireland's Druid Theatre Garry Hynes $\overline{\mathbf{z}}$ Gare St Lazare Players Ireland- Pan Pan Theatre (Ireland) $\overline{\mathbf{Z}}_{\mathbf{2}} \mathrm{UK}_{\mathbf{\perp}}$ based directors Ian Rickson and Natalie Abrahami, and actors Lisa Dwan, Tricia Kelly and Ronald Pickup. The transcripts of these are available on the Staging Beckett website <https://www. reading.ac.uk/stagingbeckett / $>$ [accessed 18 March 2017].

12. Interviews with Mitchell and the range of scholarly analyses of her work are too extensive to summarize here. However, interviews I have found particularly useful include those by Maria Shevstova, 'On Directing: A

Conversation with Katie Mitchell', New Theatre Quarterly, 22.1 (2006) 3-18; 'Conversations around Choreography: Siobhan Davies and
In addition to searching for archival traces of performances of Beckett's plays, the Staging Beckett project has invited performance analyses of specific productions through its conferences and publications, in order to reflect on past and present approaches to staging Beckett's work in the UK and Ireland. ${ }^{10}$ In this issue, Andrew Lennon's article looks at the role that darkness occupies within Beckett's theatre in a series of case studies that include the actress Lisa Dwan performing Not I (1973), Footfalls (1976) and Rockaby (1982) at the Royal Court Theatre in 2014; a show collectively entitled Beckett's Ghosts (2007) by Bedrock Productions, Dublin; and Out of Joint's production of All That Fall (1957) performed at the Enniskillen Happy Days Festival. For Lennon, darkness does not simply limit what is seen, but becomes a crucial property that can also be perceived visually. Moreover, complete darkness becomes a property that, Lennon argues, partly through direct observation of audience reaction in these shows, can provoke a new awareness, inducing feelings of intense solecism, unease, and panic.

Throughout the Staging Beckett project, we held interviews and public talks with theatre practitioners, as an integral part of the history of staging Beckett in the UK and Ireland, and an investigation into the living legacies of Beckett's work for contemporary theatre and performance. ${ }^{11}$ In the Documents section of this issue, we have included an interview with Katie Mitchell on her many productions of Beckett's work, and a reflective essay by Irish director Sarah Jane Scaife on her company's site-specific staging of Beckett's plays for female actors.

Katie Mitchell is a well-known and sometimes controversial British director who has worked with major companies and institutions in Europe, including the Schaubühne, Berlin. Her productions include a wide range of theatre genres, from Ancient Greek plays to nineteenthcentury naturalism to contemporary playwrights like Martin Crimp e* Sarah Kane. She also directs opera, from Handel to newly commissioned operas such as George Benjamin's Written on Skin (2012). What links these very divergent texts is her search to create a visceral, urgent and contemporary environment through which they might address audiences. Other concerns are around ecology and technology in performance - her use of live camera from her stage adaptations of Virginia Woolf's The Waves (2006) and Dostoevsky's The Idiot in ... some trace of her (2008), to The Forbidden Zone (2016) have become major reference points in debates about intermedial performance. ${ }^{12}$ She has frequently directed Beckett's work, although scholarship on her practice tends to neglect this strand of her directing portfolio. The interview with Katie Mitchell included here focuses on her productions of Beckett's work in relation to some of the major preoccupations of her broader body of work and approaches to directing. It is particularly valuable for the Staging Beckett project and for this issue, as Mitchell reflects on very different theatre cultures in Britain and in Europe, particularly in Germany.

The site-specific work of Dublin-based theatre director, Sarah Jane Scaife, was the subject of several conference papers of the Staging Beckett project, and also several of our publications. ${ }^{13}$ These outputs 
Katie Mitchell', $(2009-$ <http://www.siobhan davies.com/conversa tions/mitchell/tran script.php> [accessed 7 May 2017]; Summer Banks, 'A Chat with Director Katie

Mitchell', Exberliner, 28 September $2010<\mathrm{htt}$ p://www.exberliner. com/culture/stage/ an-interview-with-katie

mitchell/> [accessed

May 2017]; and

Charlotte Higgins,

'Katie Mitchell,

Britain's theatre's queen in exile', Guardian

14 January $2016<$ http s://www.theguardian. com/stage/2016/jan/ 14/british-theatrequeen-exile-katiemitchell> [accessed May 29 2017]. For an interview specifically on her earlier work on Beckett's plays, see Julie Campbell, 'Julie Campbell interviews Katie Mitchell about her recent production of "Beckett's Shorts"', Journal of Becket Studies, 8.1. (1998)127-39. In relation to Mitchell's intermedial theatre, one of the earliest essays was Louise Lepage, 'Posthuman Perspectives and Postdramatic Theatre:

The Theory and Practice of Hybrid Ontology in Katie Mitchell's The Waves?, Culture, Language and Representation, 6 (2008) -137-149; and 2017 one is Benjamin Fowler's 'Re-Mediating the Modernist Novel: Katie Mitchell's Live Camera Work' in Contemporary Approaches to Adaptation, ed. by Kar Reilly (Basingstoke: Palgrave Macmillan, foming). In relation to the tension between Mitchell's work in British theatre and in European theatre cultures, see, for example, Dan Rebellato, 'Katie Mitchell: Learning from Europe', in Contemporary are informed by Scaife's own oral and published reflections on her work, which offer valuable documentation and insight into her practice and processes of staging Beckett. In her document in this issue, she discusses the Beckett in the City project which her Company SJ initiated in 2009, focusing on the programme of Beckett plays for female actors entitled Beckett in the City: The Women Speak, which premiered in Dublin in 2015. Engaging with Baz Kershaw's argument that traditional theatre spaces are ideologically encoded, Scaife discusses her aim of focusing on the audience's encounter with the performance and, especially, the choice of a site-specific location which aims to foreground the relationship between the performance and its situation in this particular place and contemporary moment. The Women Speak programme was set in the ruins of Dublin's Halla Banba, a collection of Georgian buildings on Dublin's Parnell Square, which includes the former National Ballroom. This location was chosen as these buildings had been used as State institutions, including the neighbouring Coláiste Mhuire, a Christian Brothers School, that had formerly been domestic residences, initially for Ascendancy gentry, and, subsequently, in the late nineteenth century before being taken over by the State, crowded and dilapidated tenement housing. Scaife discusses her search for a site which simultaneously evoked a domestic and a State setting, and how her collaborative preparatory processes focused on the encounter between the audience, the plays and the material features of their location. Her Beckett in the City project sought to engage audiences in a dialogue between Beckett's plays and the contemporary conditions of marginalization and dispossession whose traces were so evident in and around her chosen sites. Her article also complements that of Lennon in foregrounding the sensory and perceptual impact of Beckett's work on audiences.

Derval Tubridy analyses one of Scaife's earlier programmes in the Beckett in the City series along with the work of another Irish company, Pan Pan, who have adapted several of Beckett's radio plays for live performance, including All That Fall and Embers. Inevitably, the restrictions maintained by the Beckett Estate on modifying Beckett's stage directions or texts in performance has limited the scope for experimentation with his plays in areas of the world or metropolitan theatre spaces to which the reach of the Estate extends. Because of this, many practitioners have turned to alternative means of exploring and re-encountering the contemporary relevance of Beckett's work in performance, and adapting Beckett's prose texts has offered some leeway to experiment with staging and to test the boundaries of live performance by introducing modes of perception and audience engagement inherent to other media. ${ }^{14}$ Drawing on analyses of the medium of installation art, which Scaife also invokes, Tubridy considers the ways in which space and technologies of light and sound impact on the audience's sensory response to these works. One of the key findings of the Staging Beckett project is that Beckett's work remains a particular inspiration and testing ground for experimental performance focused on the body, site and technology, and that the intersections between the performance of Beckett's texts and an installation aesthetic 
European Theatre Directors, ed. by Maria M. Delgado and Dan Rebellato London: Routledge, 2010), pp.317-38 13. See essays by Anna McMullan and Brian Singleton in Staging Beckett in Ireland and Northern Ireland, ed. by McTighe and Tucker, pp-103-119 and pp. 169-184 respectively; and Derval Tubridy, 'Installing Beckett: Pan Pan Theatre and Company SJ', in Contemporary Theatr Review 28.1 (2018).

14. Beckett himself collaborated on some stagings of his prose work, where the texts are read or embodied by an actor with minimal set, in the case of Irish actor Jack MacGowran, and director Siobhan O'Casey, for example. See the 'adaptation' entry in The Grove Companion to Samuel Beckett: $A$ Reader's Guide to his Works, Life and Thought, ed. by C.I Ackerley and S.E. Gentarski (New York: Grove Press, 2004) pp. 5-6. There are more experimental adaptations of Beckett's prose, by Mabou Mines for example, as in their productions of The Lost Ones and Imagine Dead Imagine. See Anna McMullan, Performing Embodiment in Samuel Beckett's Drama (London: Routledge, 2010), pp-133-39. For a recent discussion of Irish adaptations of Beckett's prose texts, see Nicholas Johnson, 'The Neatness of Identifications? Transgressing Beckett's Genres in Ireland and Northern Ireland 2000-2015', Staging Beckett in Ireland and Northern Ireland, ed. by McTighe and Tucker, pp. 175-202.

15. Here All Night was included in a Gare St Lazare Beckett in is a growth area. Recent work by Gare St Lazare Players Ireland, such as their piece, Here All Night, where Conor Lovett read sections of Beckett's prose amid the installation 'Hello Sam Redux' by Irish artist Brian O'Doherty and musical compositions by Paul Clark, demonstrates this trend. ${ }^{15}$

Brenda O'Connell continues the discussion of the intersections of Beckett's work with concepts and practices from the performing arts more broadly, through a discussion of how contemporary Irish performance artist, Amanda Coogan, has been inspired by and has reconceived aspects of Beckett's work in her own practice. Coogan has acknowledged Beckett's influence in her work, and with reference to her 2015 Irish Royal Academy series of performances, O'Connell investigates how Beckett's staging of the indomitable need to tell one's story and his focus on reimagining embodiment as part of the staging of marginalized subjectivities, has been reimagined in the work of Coogan.

The actors who have interpreted Beckett's work have often been interviewed in order to mine their experiences of being directed by Beckett in some cases, or to evaluate whether there are specific approaches or skills appropriate to performing Beckett. Phillip Zarrilli contests the longstanding association of performing Beckett as form of torture/trauma, arguing from a theatre practitioner's point of view that performing Beckett offers a range of challenges and affordances to the performer. Like Sarah Jane Scaife, Zarrilli is a practitioner-scholar,and, like her (and indeed Herbert Blau, invoked at the beginning of this Introduction) his writing voice shifts between the academic and the personal. Zarrilli concludes with a profoundly intimate reflection on Beckett's impact on him at a particularly challenging time of his life, but which he in turn channelled into his productions of the Beckett Project. Many of us are drawn to Beckett's work precisely because of this intersection of the aesthetically challenging $\overline{\bar{z}}_{\overline{\mathbf{z}}}$ the invitation to rethink the languages, modes of embodiment, technologies and boundaries of theatre and performance $\overline{\overline{\mathbf{x}}}_{\mathbf{z}}$ and the intimate address, the way in which his work speaks to the vulnerabilities of being human.

Staging Beckett has now concluded the AHRC-funded phase of the project, although the website continues to be updated with interviews and research resources on staging Beckett, including project-related publications and other research outputs and events. Indeed, the project has acted as a catalyst for reconsidering Beckett's relation to contemporary critical discourses and landscapes of theatre and performance, and renewing Blau's challenge to 'think through' Beckett. The project aimed to analyse and foreground the rich legacies of Beckett's work and its contexts of performance for audiences, archivists, theatre companies and practitioners, as well as for scholars. The main finding of the project, however, is that we have only begun to scratch the surface. Independent sister projects include the Beckett Laboratory, which was established as part of Trinity College Dublin's annual Samuel Beckett International Summer School in 2013, directed by Nicholas Johnson 
London programme at the Print Room in May-June 2016. See <http://www.theprint-room.org/pastproductions/beckettin-london/> [accessed 18 March 2017].

16. See 'Beckett Lab', Samuel Beckett Summer School <https://beckettsum merschool.wordpress. com/beckettlab/> [accessed

20 September 2017].

17. Performing Beckett/ Jouer Beckett, organised by Dominic Glynn and Jean-Michel Gouvard, involving two programmes of study days, one in March in Bordeaux and one in London in October 2017. See <https://jmgouvard wixsite.com/perfor mingbeckett>

[accessed 20 September 2017]. and Jonathan Heron, ${ }^{16}$ and, in France, the Jouer Beckett/Performing Beckett project, which is investigating the differences between French and British approaches to staging Beckett. ${ }^{17}$ We look forward to many future dialogues and collaborations.

\section{Funding}

This work was supported by the Arts and Humanities Research Council UK [AHRC grant number: H5147000]. This special issue of Contemporary Theatre Review is one of the outputs of the AHRC-funded project Staging Beckett: the Impact of Productions of Samuel Beckett's plays on Theatre Cultures and Practices in the UK and Ireland 1955-2010. For more details see the About Us section on the Staging Beckett project website: https://www.reading.ac.uk/staging-beckett/ [accessed 3 March 2017]. The Investigators were: Anna McMullan (University of Reading), David Pattie (University of Chester), Graham Saunders (now University of Birmingham) and the researchers were: Trish McTighe and David Tucker (PDRAs) and Matthew McFrederick (PhD researcher).

Anna McMullan and Graham Saunders 


\title{
Ecology in Beckett's Theatre Garden: Or How to Cultivate the Oikos
}

\author{
Carl Lavery
}

1. Raymond Williams, Marxism and Literature (Oxford: Oxford University Press, 1977), Pp-128-35.

2. Carl Lavery and Clare Finburgh

'Introduction: Greening the Absurd', in Rethinking the Theatre of the Absurd: Ecology, Environment and the 'Greening' of the Modern Stage, ed. by Carl Lavery and Clare Finburgh (London: Bloomsbury, 2015), pp-1-58 (pp-16-17).

3. Peter Osborne, Anywhere or Not at All: Philosophy of Contemporary Art (London: Verso, 2013), p. 149 .
In an Introduction, co-written with my colleague and friend Clare Finburgh, for the publication Rethinking the Theatre of the Absurd: Ecology, Environment and the Greening of the Modern Stage (2015), I suggested that the work of the playwrights loosely associated with Martin Esslin's problematic category, the Theatre of the Absurd, might be rethought historically rather than existentially. This led me to claim that so-called absurdist writers (whose names include Samuel Beckett, Eugène Ionesco, Arthur Adamov, Jean Genet and Harold Pinter) were able to articulate a 'structure of historical feeling', ' in Raymond Williams's understanding of the term, that was characterised by a nascent but deeply felt sense of anxiety regarding an impending form of ecological crisis. ${ }^{2}$ In my reading, the anxiety was dependent upon two factors. First, the explosion of the two atom bombs over Hiroshima and Nagasaki in August 1945, quickly followed by the invisible terrors of radiation sickness, cancers and birth defects in the bodies of survivors; and second, the appearance of new modes of ecological knowledge that came into being in the 1950s, and which were popularised by Rachel Carson's eco-best-seller, Silent Spring (1962), a text that highlighted the disastrous effects of chemical pesticides on bird populations as well as on the larger ecosystem in general. The great irony here, of course, is that many of the playwrights associated with the Theatre of the Absurd, in particular Samuel Beckett, rejected naturalist depictions of history altogether. Paradoxically, by deliberately constructing his work so that it could occupy what philosopher Peter Osborne, after Gilles Deleuze, has called 'any-space-whatever', 3 Beckett has arguably proved the most historically astute and adaptable of all twentieth-century playwrights; the one whose work foreshadows, darkly, the general and specific 
4. Alan Read, Theatre in the Expanded Field: Seven Approaches to Performance (London: Bloomsbury, 2013) p. xix.

5. As well as changing the geomorphology of the earth through drilling and excavation practices, the industria processes of capitalist modernity have increased the amount of carbon in the atmosphere and so warmed the planet, which, in turn, has impacted on tectonic plate movements. They have also left trace elements in sand, rock and soils through toxic sludge and other forms of chemical pollution. Even the most remote places on earth, areas once designated wilderness, now show signs of human interference through the presence of airborne particles in soil sediments.

6. This attempt to undo binaries and exclusions resonates with Bruno Latour's critique of modernity in We Have Never Been Modern trans. by Catherine Porter (Cambridge,

MA: Harvard University Press 1993). dilemmas of our own environmentally troubled age, the playwright who, to use Alan Read's language, continues to irritate us, having the ability to get under our skin. ${ }^{4}$

But what does this irritation consist of, and why does it affect us in the age of what many geologists and climate scientists are now calling the Anthropocene, a new geological epoch in which western modernity has embedded itself into the very rock strata of the planet as a result of industrialisation, nuclear testing and the burning of fossil fuels? ${ }^{5}$ Possibly because, as I wager in this article, Beckett's plays purposefully set out to deconstruct the teleological triumphalism inherent in some narratives about the Anthropocene. In Beckett's hands, theatre is no longer a space where the essence of the human appears; on the contrary, it is a site where the human dis-appears, subjected, as it is, to a series of 'more than human' flows and temporal processes that challenge its muchvaunted exceptionalism and apparent omniscience. To be a spectator at a Beckett play is to find oneself overwhelmed by the shimmering presence of a strange and estranging world, a world that no longer makes linguistic sense, and where the dangerous binary between 'nature' and culture is troubled, without, for all that, ever being dissolved completely. ${ }^{6}$

In order to unearth the ecological potential that remains latent in the temporal and affective aspects of Beckett's work, I propose, in this article, to adopt an oblique method of approach. Instead of engaging in direct analysis, in simply displaying the textual evidence for my claims and parcelling out knowledge, I intend to read Beckett's theatre indirectly through the metaphor of a garden. The reason behind this figural move is to find a new way of engaging with the ecological affects of Beckett's theatre, the sense in which, as in a garden, actors and spectators are subjected to a kind of 'weathering', to the elemental impress of time. The overall objective is to offer an alternative approach to the ecological dimension of Beckett's theatre that draws on two, as of yet, divergent strands of contemporary Beckett scholarship - namely, the ecocritical and the phenomenological or haptic. Additionally, I am concerned with how we might write ecological affect in response to Beckett's plays, a stylistic ambition that necessitates a different form of theatre criticism by experimenting with a subjective register of discourse. For if, as I argue below, Beckett's work insists on a mode of embodied participation, in which spectators are included in the event, the only way to capture the affective charge of that experience in writing is to fashion metaphors, images and rhythms as much as ideas, concepts and terminologies.

\section{Ecology}

Given its relative marginality, to date, within the disciplines of Theatre and Performance Studies, it seems important, from the outset, to qualify my comments on ecology, and to define how I seek to use it in conjunction with Beckett's theatre. The first point to note is that ecology is not necessarily about 'nature' (whatever that means) and neither is it limited to a scientific or cybernetic study of a given ecosystem or communication network. ${ }^{7}$ Rather, as I use it, ecology is a mode of operating that seeks
Timothy Morton'

argument in Ecology

Without Nature:

Environment

Aesthetics (Cambridge,

MA: Harvard

University Press,

2007). It also explains

why nature in this

article is always placed

in inverted commas. 
8. For more on how ecological thinking is a thinking of connection, see Timothy Morton, The Ecological Thought (Cambridge, MA: Harvard University Press, 2010), p. 1.

9. Wendell Berry, Home Economics: Fourteen Essays (Berkeley, CA: Counterpoint, 1987) pp. 54-75.
10. In this context, see Carl Lavery and Simon Whitehead's critique of Heideggerianinspired ecocriticism 'Bringing It All Back Home: Towards an Ecology of Place', Performance Research, 17.4 (2012), 111-19.

11. For a reading of Harold's Pinter drama through Lyotard's notion of the oikos, see Mark Taylor-Batty and Carl Lavery, 'The Secluded Voice: The Impossible Call Home in Early Pinter', in Rethinking The Theatre of Absurd, ed. by Lavery and Finburgh, pp. 219-40. connections, and which attempts to problematise, without ever collapsing, the borders between the human and non-human, the socius and bios. ${ }^{8}$ Ecology, then, is a marginal discourse by itself, a discourse of the inbetween, the composite: it fluctuates, swerves and troubles. Crucially, it is also a discourse about what it means to be at home. In its etymology, for instance, ecology is a word that derives from the combination of the Greek prefix oikos (home, house or hearth) with the suffix logos (law, order, economy). In a literal sense, then, to be ecological is to engage in what the ecocritic and poet Wendell Berry calls 'home economics', a practice that would, from Berry's perspective at least, privilege planning, the management of supply and demand, and the return to equilibrium all things that policy makers and government think-tanks are so concerned to quantify and centralise.

While I want to keep the etymological link that would tie ecology to a thinking about home and homecoming in this article, my understanding and usage of the term differs quite radically from Berry's; and we could say, for that matter, from much of the first wave of ecocritical writing, which relied heavily on Heideggerian notions of dwelling and homecoming. In my understanding, by contrast, ecology is a mode of operating that troubles the contours of the human subject by revealing the extent to which the entwined concepts of homecoming and dwelling are not only philosophically dubious but environmentally and socially harmful. This is because such thinking tends to place the subject at the very centre of the world by assuming that the human being is the only creature that can dwell poetically. ${ }^{10}$ There is nothing, for instance, in Heidegger's discourse of dwelling to suggest that the earth has its own autonomy, and/or that 'nature' is something that dominates us as opposed to being something that we are charged to care for. Ultimately, an ecology founded on a dwelling-perspective is unable to respect the alterity of the earth, the fact that it does not exist for 'us', so to speak. Additionally, such a philosophy offers little help in allowing us to live in a world that very obviously and directly questions human supremacy, such as we saw, for example, in the Indian Ocean Tsunami in 2004 or the earthquake in Haiti in 2010. The difficulty with an ecology of dwelling is that it can transform, quickly, into an ecology of despair and rage in those moments when the world refuses to play a subservient role in the human drama.

Therefore, instead of an ecology that surreptitiously seeks to master the earth, I want to argue for an oikology that undoes the human subject by placing it - the anthropos - in an immanent world that it is unable to dominate. From this perspective, homecoming, the search for the oikos, would be a paradoxical process, something that is doomed, in advance, to failure, a realisation that human being, contra its designated place in western metaphysics, is always a deferred or impossible being. In ecological terms - and this is why Beckett's work is so important - there might be more to be learnt in accepting our absence than in clinging to our presence.

My understanding of ecology draws much from the thinking of JeanFrançois Lyotard who, in his late work - especially the collection of essays The Inhuman: Reflections on Time (1992) - posited the oikos as something that was fundamentally opposed to economic and cybernetic systems as well as to metaphysical values. ${ }^{11}$ Playing on the etymological root that 
12. Jean-François Lyotard, 'Oikos' in Political Writings, trans. by Bill Readings and Kevin Paul Geiman (London: UCL Press, 1993), pp.96-107 (p.105).

13. Ibid., p. 102 links ecology with economics (oikonimikos or oikonomikon), and which he associates with the 'public sphere', Lyotard proceeds to offer an unconventional and ontological reading of the oikos that emphasises its strangeness, privacy and resistance to communication:

I simply mean that, for me, 'ecology' means the discourse of the secluded, of the thing that has not become public, that has not become communicational, that has not become systemic, and that can never be any of these things. ${ }^{12}$

For Lyotard, the oikos is absolutely not a place where one can dwell; it lies beyond representation and cognition as a shadow, a secret, something working away at the centre of identity, undoing it, making us marginal to ourselves:

My oikeion is an otherness that is not an Umwelt at all, but this otherness is in the core of the apparatus. We have to imagine an apparatus inhabited by a sort of guest, not a ghost, but an ignored guest who produces some trouble, and people look to the outside to find out the external cause of the trouble. But probably the cause is not outside at all. [...] That is the reason why I connect ... this topic of the oikeion with a writing that is not knowledge at all and that has, properly speaking, no function. ${ }^{13}$

To be ecological in a progressive sense, Lyotard believes, is not, then, in the first instance, to turn towards the Umwelt or outside environment. Rather, it centres on the human being's capacity to find a way of living with this internal alterity, this ignored guest that troubles us, but which we can never transcend because it constitutes the paradoxical core of our humanity. As Lyotard puts it in a different text the destiny of 'humankind ... is to be inhabited by the inhuman'. ${ }^{14}$ Lyotard's understanding of ecology is important. Not only does it problematise the utopianism or naivety in most systems-based theories of ecology, in which human beings are supposed to renounce their identity with ease, it also undoes arrogant ideas about human exceptionalism that one finds in Enlightenment concepts of subjectivity. For all its similarity with Lacanian notions of the real, Lyotard does not believe that one can banish the inhuman from the human. ${ }^{15}$ On the contrary, and paradoxically, the inhuman, for him, forms the core of the human, that 'thing' within us that links us to 'nature' and which transforms human existence into an experiment in/with immanence. The inhuman, in other words, is a marker of what we might see as our 'creatureliness', something which ties us to the fate and destiny of the planet itself, and which undoes the absolute binary that anthropocentric thinking draws between culture and 'nature'. Lyotard's theory of 'nature' is rooted in division, becoming and bifurcation. As opposed to the standard Romantic vision that emerges from Fichte and Hegel, there is no possibility, for Lyotard, of ever returning to a fixed origin or of re-establishing some lost harmony within the natural world. The best we can do is to try to accommodate ourselves to the anarchic 'unhomeliness' of the oikos, to give it a space to emerge. However, there is no guarantee of success. Everything remains indeterminate and contingent. 
16. This refers to Beckett's letter to the actress Jessica Tandy in which he explained that Not $I$ is 'to work on the nerves of the audience, not its intellect'. See Enoch Brater, Beyond Minimalism: Beckett's Late Style in the Theatre (Oxford: Oxford University Press, 1987), p. 23.

17. Elinor Fuchs, The Death of Character: Perspectives on Theater After Modernism (Bloomington: Indiana University Press, 1996), p.93.
Lyotard's view of ecology as a way of learning to live with the inhuman, both within the world at large and within the structures of subjectivity itself, has important consequences for how one might conceive of the ecological value of art and, in this specific instance, theatre. For if ecology is about allowing a space for irrecuperable strangeness to emerge (if not to speak), then ecological artworks have little to do, necessarily, with the representation of 'nature' or with engaging, directly and actively, in issues to do with environmental justice, such as climate change, species extinction, sustainability, resilience. Indeed, the most ecologically valid artworks may be those that allow a space for the inhuman to appear in the very realm (art) where human existence has traditonally been thought to find its most essential expression.

With regard to theatre, this means renouncing western drama's traditional obsession with reflection, and fashioning, instead, a mode of performance that would show spectators not what they are but what they are not. In concrete terms, this would be a theatre where Aristotelian dramaturgies, with their focus on constructing coherent dramatic actions unfolding in a linear pattern towards a designated end or telos, would be replaced with a subtractive theatre where time becomes a palpable and problematic force. The point here is not to represent an action, but to create an affective discharge, to engage in what we call after Beckett 'nerve work'. ${ }^{16}$ For, as Lyotard remarks, the oikos, the inhuman, is beyond cognition. We know it because we feel it in our bodies, because it touches us, because we are in it, like Lucky's speech in Waiting for Godot (1953) or the buzzing voice in Not I (1972). As such, and from this, I want to propose that theatre's ecological significance resides in the material charge of the theatrical medium itself, in the way in which an affective dramaturgical sculpting of time and space has the potential to disorder and reorder perception to the point where we are able to welcome in the troublesome guest, the oikos. This is a theatre, then, like Beckett's, which, to cite Elinor Fuchs, 'no longer defines itself, spatially, against an unseen outside', but which is best understood as a heterotopia or counter-site whose very presence throws the reality of the so-called real world into doubt. ${ }^{17}$ Which is precisely why I want to think of theatre in this essay not so much as a house but as a garden, a milieu in which our 'becoming inhuman' is cultivated.

\section{Beckett, Ecocriticism, and Ecology}

Such an immanent way of thinking about theatre transforms the way in which existing ecological readings of Beckett's work have tended to proceed, even when some of these readings, such as Theodor Adorno's, predate the arrival of ecocriticism on to the critical stage. In his complex 1958 essay 'Trying To Understand Endgame', Adorno proposes that Beckett's ecological importance is implicitly found in how he critiques 'the permanent catastrophe' that humanity has inflicted on the planet and on itself during the twentieth century. For Adorno, this is due to a constellation of historical events: the Holocaust, the development of a nuclear arsenal and ensuing arms race during the Cold War, and, in more 
18. Theodor Adorno, 'Trying to Understand Endgame', trans. by M. T. Jones, New German Critique, 26 (1982), 119-50 (p.122).

19. Greg Garrard, 'Endgame: Beckett's Ecological Thought', in Samuel Beckett Today/Aujourd' hui

23, ed. by Yann Méval, Dominique Rabaté and Sjef Houpermans (Amsterdam:

Rodopei, 2011) pp. 383-97 (p.395).

20. Samuel Beckett in an interview with Tom Driver, 1961, quoted in S. E. Gontarski, 'Introduction: Towards a Minoritarian

Criticism - The Questions We Ask' in The Edinburgh Companion to Samuel Beckett and the Arts, ed. by S. E. Gontarski (Edinburgh: Edinburgh University Press, 2014) pp.1-16 (p.13).

21. For other ecocritical readings of Beckett, see Paul Davies, 'Strange Weather: Beckett from the Perspective of Ecocriticism', in Beckett After Beckett, ed. by S. E. Gontarski and Anthony

Uhlmann (Gainsville: University of Florida Press, 2006), pp.66-78; and Paul Saunders, 'Samuel Beckett's Trilogy and the Ecology of Negation', Journal of Beckett Studies, 20.1. (2011) - 54-77.

22. James Knowlson, 'Beckett as Director: The Manuscript Notebooks and Critical Interpretation' in Modernism in European Drama: Ibsen, Strindberg, Pirandello, Beckett, ed. by Christopher Innes and Frederick J. Marker (Toronto: University of Toronto Press, 1998), pp. 212 27 (p. 220) general terms, by capitalism's complete reification of the world. In Adorno's view, Beckett shows us what it means to live in a world without nature, a world where no seeds sprout, a biosphere in ruins:

In Beckett, history devours existentialism ... After the Second World War, everything is destroyed ...; humanity vegetates along, crawling, after events which even the survivors cannot really survive, on a pile of ruins which even renders futile self-reflection of one's battered state. ${ }^{18}$

The contemporary ecocritic Greg Garrard adopts a similar tone to Adorno, but takes a different path, influenced, no doubt, by a fundamental shift in the object of environmental anxiety from nuclear catastrophe to climate change. As he has it, Endgame (1957) is a perfect play for a culture such as ours that is facing the uncertainties of climate change and species extinction. In Garrard's reading, Endgame does not so much foreshadow the end of the world as point towards a world that we are now currently living in, a world where the catastrophe has already happened, a world of limited resources that are running out, a Malthusian world. The horror of Endgame then is not about disappearance, for Garrard, but about endurance, the terror of living in a damaged, lifeless Umwelt where nothing changes or grows, the endless recurrence of the same, listless grey-black-grey horizon:

Endgame is literally, though not clearly, about both the end - of nature 'in the vicinity' of comfort, of kindness, of some semblance of peace or equality - and the grim elusiveness of any such reassuring finality ... Worse than the thought that 'it must be nearly finished' might be the hideous actuality of endurance. ${ }^{19}$

The critical readings proposed by Garrard and Adorno ${ }^{20}$ are certainly in tune with Beckett's own desire to find a 'form that accommodates the mess' of the twentieth century. ${ }^{21}$ And it is telling from an ecological perspective that Beckett, perhaps thinking of the Torrey Canyon oil spill off the coast of Cornwall in 1967, described Winnie in his 1971 production of Happy Days in Berlin 'as a bird with oil on its feathers'. 22 Arguably, even more so than in Endgame, Happy Days (1961), with its burning sun, allusions to fire storms and skin melting, ${ }^{23}$ as well as the key line about the earth losing its 'atmosphere', seems to take place in a planet without an ozone layer, a planet under threat. ${ }^{24}$ By deliberately refusing to invest in historically specific images, by keeping, that is, things strange and nebulous, Beckett appears to predict the environmental chaos that we are in today. Winnie's surreal burial in a patch of scorched earth is revealing in this context. For what the image communicates, albeit silently and evocatively, is the dark underside of 'anthropocene knowledge' knowledge that realises, all too well, that we are part of and dependent on the earth, no more so, indeed, than when we try to transcend it through technology. This contemporary meaning of the play is surely what is at stake in the striking scenography of Blandine Savetier's production of the play at the Comédie de Béthune in 2011. Here a peroxided Winnie, played by Natalie Royer, is entombed in a mound of black 
23. Samuel Beckett, 'Happy Days' in Samuel Beckett The Complete Dramatic Works (London: Faber and Faber Limited 1990) p. 154. All further references to the plays will use this source.

24. Ibid., p. 161

25. The size of the Trash Vortex is open to debate. Some reports believe it to be the size of Texas, others contend that it is more comparable to the United States of America.

26. Samuel Beckett, Endgame, p. 118.

27. Anna McMullan, Performing Embodiment in Samuel Beckett's Drama (London: Routledge, 2010); Colin Gardner, Beckett, Deleuze and the Televisual Event: Peephole Art

(Basingstoke: Palgrave Macmillan, 2012); Trish McTighe, The Haptic Aesthetic in Samuel Beckett's Drama (Basingstoke: Palgrave Macmillan, 2013); and S. E. Gontarski, 'Samuel Beckett in the Idea of Theatre', in The New Cambridge Companion to Samuel Beckett, ed. by Dirk Van Hulle (Cambridge: Cambridge University Press, 1994) pp-126-42.

28. McTighe, The Haptic Aesthetic, p.8.

29. McMullan, Performing Embodiment, p.1.

30. For more on Beckett's troubles with moles and wild boars in his garden, see James Knowlson, Damned to Fame: The Life of Samuel Beckett (London: Bloomsbury, 1997), pp. 460-61. polythene bin liners that bring to mind images of the terrible 'Trash Vortex', a gyre-like garbage dump that circulates endlessly in the middle of the Pacific Ocean, and which is composed of man-made plastics and toxic chemicals. ${ }^{25}$ Without ever making a direct allusion to the world, the image in Happy Days appears to think almost by itself, producing ecological connections and contexts, jumping backwards and forwards and to the side, but always, I think, reminding us, in some oblique but tangible way, of our interdependency, that there is no way of escaping - of exiting - the world. As Hamm puts it in Endgame: 'You're on earth, there's no cure for that'. ${ }^{26}$

These ecological readings of Beckett's theatre, for all their relevance, remain at the level of the symbolic. They alert us to hidden possibilities hermeneutic possibilities - within the dramatic text, and are founded, ultimately, on a logic of representation, a sign economy that points to an outside world that spectators recognise and make sense of. But what happens if we shift the focus of our attention and think of Beckett's work not so much in terms of ecological hermeneutics, but rather as an ecological practice in and by itself? The first point to note is how this turn from text to performance, from representation to affect, resonates with the work of critics such as Anna McMullan (2010), Colin Gardner (2012), Trish McTighe (2013) and Stan Gontarski (2015), who, in their different ways, are interested in the haptic or sensate quality of Beckett's plays. ${ }^{27}$ For these critics, all of whom are influenced, in one way or another, by Maurice Merleau-Ponty and Gilles Deleuze, the significance of Beckett's theatre is not found in making us think, but in making us feel, in how it challenges dominant models of knowledge, perception and perspective. McTighe, for instance, points out that, "'haptic" in Beckett's work does not only indicate contact and connection, it also describes disruption of space, time, and bodies, imaged in the formal structures that surround them'. ${ }^{28}$ And in the 'Introduction' to Performing Embodiment in Samuel Beckett's Drama, McMullan states that:

In an era in which commodified and technologized visual culture disseminates phantasmatic corporealities, [Beckett's] presentation of derogated, vulnerable bodies that struggle to appear and to speak continues to pose a challenge to contemporary culture and performance. ${ }^{29}$

Although no explicit ecocritical agenda is adumbrated by any of the critics mentioned above, the attention they accord affect offers productive insights for thinking through the ecological potential inherent in Beckett's theatre. In order, then, to tease out what that potential might be, and in the hope of bringing two different approaches to Beckett's work into a generative alignment for the first time, I propose for the remainder of this article to read Beckett's theatre metaphorically as a garden, a site where presentation is more important than representation and where the exceptional status of the human is placed in crisis.

But first, a word of caution. When I speak of exploring Beckett's theatre garden, I am not concerned with biographical details (Beckett's famous trouble with moles at his modest house in Ussy, for example), ${ }^{30}$ 
31. Beckett, Endgame, p. 111 . See also Winnie's reference to 'the back garden at Borough Green' in Happy Days, p. 142.

32. Leo Marx, The Machine in the Garden: Technology and the Pastoral Ideal in America (Oxford: Oxford University Press, 1964).

33. For a related critique of the essentialism inherent to Marx's garden metaphor, see Stephen Bottoms, 'The Garden in the Machine: Edward Albee, Sam Shepard, and the American Absurd' in Rethinking The Theatre of the Absurd, ed. by Lavery and Finburgh, pp. 77-104.

34. Robertsen Smithson, Robert Smithson: The Collected Writings, ed. by Jack Flam (Berkeley: University of California Press, 1996), p.194.

35. It is interesting to note the direct influence of Beckett's work in Smithson's geological vision of the world, his vital materialism. Ibid. pp. 37, 231, 327.

36. Beckett, Waiting for Godot, p.56.

37. Beckett, Endgame, p. 98

38. Steven Connor, Beckett, Modernism and the Material Imagination (Cambridge: Cambridge University Press, 2014), pp. 115-29.

39. Beckett, Endgame, p. 97.

40. Joe Kelleher, 'Recycling Beckett', in Rethinking The Theatre of Absurd, ed. by Lavery and Finburgh, pp. 127-46 $(\mathrm{p}-143)$. and neither am I much interested in teasing out specific references to flowers or weather in his work, such as, say, in Endgame, when Hamm dreams of 'Pomona' and 'Ceres', somewhere 'beyond the hills', where it is, perhaps, 'still green'. ${ }^{31}$ Likewise, I have no desire to argue for a sitespecific staging of Beckett's work in actual gardens. On the contrary, I am more preoccupied with reconfiguring theatre's architectural function as a site or location that has been subtracted, cut out, from the flux and continuity of the world and provided with walls, an enclosure of sorts, that would somehow mark it off from the chaos of everyday life. The point of this enclosure, as I see it, is not to reject or deny the world in an act of spurious aesthetic autonomy, but to find another way of engaging with it, of producing a sense of difference, an alternative spatio-temporal rhythm, perhaps. In Beckett's theatre garden, theatre is no longer the space for looking; it is a sensorium, a space where we are affected, corporeally, by the stuff that is placed in it, landscaped, we might even say. Finally, in contrast to Leo Marx's The Machine in the Garden: Technology and the Pastoral Ideal in America (1964), ${ }^{32}$ his classic study of how literature responded to industrialism's destruction of pastoralism in the USA in the nineteenth century, Beckett's garden shows no nostalgia for a lost wilderness. ${ }^{33}$ Like land artist Robert Smithson, Beckett knows that 'there is no escape from matter', ${ }^{34}$ not even in the theatre, considered historically, as the anthropocentric medium par excellence. ${ }^{35}$

\section{Beckett's Theatre Garden}

In keeping with Beckett's famously subtractive and minimalist mode of theatre, the theatre garden is an idiom that can do without drama, without conflict, without narrative; it is a space in which nothing - or almost nothing - happens, a location where, as in Waiting for Godot, the only thing that grows is a solitary leaf on a naked tree and where 'everything oozes'. ${ }^{36}$ Time slows down in Beckett's theatre garden and entropy, the gradual dissipation of energy, is perceived through the construction of an event in which all we can do, as spectators, is to follow 'something taking its course'. ${ }^{37}$ In this perpetual elapsing that never comes to an end, we experience what Stephen Connor has termed 'slow going', a painful temporality that leaves us exiled, undone, at the mercy of time itself. ${ }^{38}$ In Endgame, Hamm reminds us that theatre, in so far as it is a temporal art, is where 'we breathe, we change. We lose our hair, our teeth! Our bloom, our ideals! ${ }^{39}$ In the theatre garden, the abstract quality of Clov's impossible heap is now figured as a heap of decomposing stuff, materiality that, as a result of the passage of time, has lost its shape, its form, but which, for all that, still offers the hope that a new life might begin. This is a life in which, as Joe Kelleher argues in an essay on Happy Days, it is enough, simply, to be there, to affirm one's presence on the earth without looking for any transcendent meaning. ${ }^{40}$

This ontology of stubborn naivety, this affirmation of material existence, is certainly how performance theorists Bonnie Marranca and Allen S. Weiss think about gardens. In her neglected text 'Garden/Theater', published originally as the preface to American Gardening Writing 
41. Bonnie Marranca, 'Garden/Theater' in Ecologies of Theatre (Baltimore, MD: John Hopkins, 1996) pp.181-84 (p.182).

42. Ibid., pp.182-83.
43. Allen S. Weiss, Zen Landscapes: Perspectives on Japanese Gardens and Ceramics (London: Reaktion, 2013), p. 7

44. Ibid., p-8.

45. Connor, Beckett, Modernism and the Material Imagination pp. 199-202.

46. Lyotard, 'Oikos', p. 106.

47. Ibid., p. 107.
48. Beckett in Knowlson, Damned to Fame, p.197.

49. Ibid., p. 267
(1988), Marranca argues that of all the arts, theatre is the one that comes closest to gardening in the respect to which it leaves her 'feeling at home in the ephemerality of time' ${ }^{41}$ Marranca continues:

Really it is not so difficult to move from a theater to a garden. Each creates a world in space that celebrates pure presence, and the fabulous confusion of nature and artifice, which is to say, reality and illusion. At least one half of gardening is dreaming yourself into a new setting. ${ }^{42}$

If we interpret 'pure presence' materially rather than metaphysically, then Marranca's analogy is more than an abstract metaphor. For what it does is to establish a sensual homology between theatre and gardening that revolves around how both activities structure temporality. In each instance, human operators - the playwright, the gardener - structure time and space in such a way that the whole focus is on cultivating an awareness of transience, in celebrating the earth as it is.

Weiss proposes a similar argument in the ten points that make up his 2013 'Manifesto for a Future of Landscape'. According to Weiss, in Point Seven of that text, 'The garden is a hyperbolically ephemeral structure. Anachronism is of the essence, since a garden is all that it was and all that it shall become'. ${ }^{43}$ Likewise in Point Nine - and in language that draws attention, quite beautifully, to the intimate relationship existing between theatre and gardens - Weiss suggests that, 'the garden is a memory theatre, which must bear vestiges of its sedimented history, including traces of the catastrophes that it has suffered' ${ }^{4}$ For Weiss, gardens, like theatres, are instances of what Steven Connor, after Jean-Luc Nancy, might call 'radical finitude', places which have neither meaning nor telos, but which simply come into being and disappear again. ${ }^{45}$ While there is a certain melancholy here, there is also a joy, a pleasure, a way of recognising the inhuman world - the oikos - that we can never know or control. In the garden, as in the theatre, we cultivate strangeness and celebrate Lyotard's 'troublesome guest' who not only imposes 'distress' or 'suffering', 46 but is 'the Fremde [stranger] at the source of every invention, creation, and writing'. 47

That Beckett, too, was aware of art's capacity to cultivate a space for the inhuman, for disclosing that internal margin that divides us from ourselves, is evident in two letters he sent to Tom MacGreevy in 1934 and 1937, discussing the affect produced by the paintings - the landscapes of first Paul Cézanne and second Jack Yeats:

How far Cézanne had moved from the snapshot pueriles of Manet and Cie when he could understand the dynamic intrusion to be himself and so landscape to be something by definition unapproachably alien, an unintelligible arrangement of atoms, not so much as ruffled by the Reliability Joneses. ${ }^{48}$

What I feel he [Yeats] gets so well, dispassionately, not tragically like Watteau, is the heterogeneity of nature and the human denizens, the unalterable alienness of the 2 phenomena, the 2 solitudes, or the solitude and loneliness, the loneliness in solitude, the impassable immensity between the solitude that cannot quicken to loneliness and the loneliness that cannot lapse into solitude. $^{49}$ 
50. Liza Robertson, Nilling: Prose Essays on Noise, Pornography, the Codex, Melancholy Lucretius, Folds, Cities and Related Aporias (Ontario: BookThug 2012), p. 53 .

51. Lois Oppenheim, The Painted Word: Samuel Beckett's Dialogue with Art (Ann Arbor: University of Michigan Press, 2000).
52. Richard Schechner, 'Godotology: There's Lots of Time in Beckett', Modern Drama, 9.3 (1966) 268-76 (p. 269).

53. Jonathan Kalb, Beckett in Performance (Cambridge: University of Cambridge Press, 1991), p.159.

54. Steven Connor, Samuel Beckett: Repetition, Theory, Text (Oxford: Blackwell, 1988), p. 159 .

55. Ibid.
For Beckett, the experience of landscape that Cézanne and Yeats provide is not an experience of identification or reconciliation with 'nature', and neither it is an attempt to 'improve it' by reducing it to human scale, as Capability Brown, the eighteenth-century English landscape gardener, sought to do. (In Beckett's letter, the reference to the 'Reliability Jones' is, of course, a sarcastic pun on Capability Brown.) On the contrary, we gain, for Beckett, a more accurate, non-sentimental experience of the land through artworks that are deliberately stylised and formally experimental. This is because, Beckett implies, such work recalibrates our vision, and allows us to catch a glimpse into what the Canadian poet Lisa Robertson refers to as 'inexplicable opacity. ${ }^{50}$ If we can claim, as Lois Oppenheim does, that Beckett's theatre aesthetic is informed as much by fine art practice as by writing, then to be in Beckett's theatre garden is not to inhabit some illusory, mimetic garden, but to be made aware of the unapproachably alien quality of existence itself, to be left non-reconciled. ${ }^{51}$ Importantly, though, and in reference to my earlier point about medium specificity, Beckett discloses the alien presence of the inhuman in his theatre garden by producing a rhythm, creating a tempo, that slows perception down to the point where things and experiences that ordinarily go unnoticed are allowed to impress themselves upon us. In the process, we are weathered in the same way as the three anonymous characters that are trapped in the urns in Play (1963). We, too, have been enfolded in the temporal fabric of the work, attuned to a time of 'dis-appointment' that is always too slow or too late for consciousness.

\section{The Time of the Spectator}

In his article 'Godotology: There's Lots of Time in Godot', Richard Schechner shows how Beckett establishes two rhythms, 'one of the play and one of the stage'. ${ }^{2}$ Whereas the rhythm of the play concerns the relationship between playwright, directors and actors, the rhythm of the stage is the metatheatrical rhythm that includes the audience in its duration. Schechner's point about audience inclusion is underlined by both Jonathan Kalb and Steven Connor. For Kalb, Beckett's aim - and this is an avant-garde aim - is to make the spectator aware of 'immediacy', the sense in which the time of the performance is the performance of now, something that goes beyond mere representation. ${ }^{53}$ According to Connor, the goal is similar but different. By including us in the performance, Beckett does not so much make us present as absent, revealing our own inability to be on time, to coincide with the performance. In his reading of That Time (1976), Connor concentrates on the final words of the play 'no time gone in no time', and argues that the audience, too, has participated in a "stretch of "no-time", that is, the "non-time" of the dramatic representation, in which there is no real before or after, or even present tense, but only the representations of them'.${ }^{54}$ However, Connor is careful to caution that this 'non-time' is not a time of entertainment or illusion that will end once the performance has terminated. Rather, for Connor, 'we may also feel for a moment the anxiety that this theatrical "no-time" is more like our own lived time ... than we care to, or can 455 afford to, believe'. ${ }^{5}$ 
56. Samuel-Beckett, Footfalls, p. 399.

57. Ibid
58. Ibid., p. 400 .

59. Ibid., p. 401.
But how is this 'anxious no-time' constructed in Beckett's theatre garden? In what ways can it be seen as ecological? And how to write it? Because so much has already been written about Godot and Endgame, I intend to answer these questions by concentrating on Footfalls, one of Beckett's short, later pieces, which, on the surface at least, would appear to have little to do either with ecology or gardens. However, as I disclose below, this reluctance to represent is precisely what ties Footfalls so forcibly to the world, the very thing that provides actual experience of what it means to live in time. One final point or disclaimer: there is nothing special in choosing Footfalls to demonstrate my argument - most of Beckett's dramaticules would have served my purpose equally well.

Written in 1975, Footfalls, like all of Beckett's dramaticules, defies meaning and resists hermeneutic parsing. The audience is presented with a strikingly sparse stage image - a middle-aged women, with 'dishevelled grey hair', ${ }^{56}$ dressed in a tattered lace gown paces up and down on an illuminated strip in a darkened space, listening to the low, slow voice of her Mother $(\mathrm{V})$ that has been pre-recorded and broadcast over a speaker system. ${ }^{57}$ Throughout the performance one is never quite sure why May (M) is there, and the question, ultimately, is never resolved. There is neither back-story nor dénouement. Indeed, as the play unfolds, according to its own glacial pace and staccato rhythm, our confusion only increases, as we can no longer ascertain with any certainty the nature of the relationship between the two women, voice and body, mother and daughter. In the opening section of the performance, for instance, and despite the strangeness of the situation, a reflective or figurative logic just about holds. For here it is possible to understand the voice as a kind of auditory hallucination, a dialogue in the head, a phantasmatic Mother dreamt up by May as a kind of succour, a ghostly companion to aid her in her endless pacing, her insomniac inability to remain still.

V: Will you never have done? [Pause.] Will you never have done ... revolving it all?

M. [Halting.] It?

V: It all [Pause.]. In your poor mind. [Pause.]. It all [Pause.]. It all. ${ }^{58}$

Our attempts to make sense of the initial situation that we are presented with in Footfalls are thrown into doubt, however, in the second section of the piece, when dialogue ends and monologue takes over. While May continues, albeit at a reduced rhythm, to pace her small corridor of light, the acousmatic voice of the Mother attains a kind of autonomy, and provides some oblique information - but it is hardly much - into May's condition:

V: See how still she stands, how stark, with her face to the wall. [Pause.] How outwardly unmoved. [Pause.] She has not been out since girlhood. [Pause.] Not since girlhood. [Pause.] Where is she, it may be asked. [Pause.] Why in the old home, the same where she [Pause.] Where it began. [Pause.] It all began. [Pause.] ... When other girls of her age were out at ... lacrosse, she was already here. [Pause]. At this ... 
The shift from dialogue to monologue explodes dramatic conventions. It is impossible, now, to grasp, fully, the situation we are confronted with. For if the opening section still corresponded to a kind of reality, albeit a hallucinatory one, the voice's investment in narrative, along with her direct address to the audience, forecloses such a conventional if understandable reading of events in the play. Henceforth, there is nothing representational about the voice, and it cannot be accorded a place within a standard dramatic paradigm. Rather, the voice is free-floating, something that we have to accept for what it is, as opposed to what it might mean. In Footfalls, the causal logic of both Aristotelian and Brechtian dramaturgy is undone. In its place, Beckett, close to both Symbolism and Surrealism, asks us to accept a different stage, a theatre that has given up on reflecting a world that we supposedly know and where people and objects retreat and retain their mystery.

The mysteriousness of Footfalls is compounded in the final movement of the piece, when the recorded voice of the Mother disappears and the embodied voice of May takes over for what she calls the 'sequel':

M: ... Sequel. A little later when she was quite forgotten, she began to - [Pause.] A little later, when as though she had never been, it never been, she began to walk. [Pause.] At nightfall. [Pause.] Slip out at nightfall and into the little church by the north door ... ${ }^{60}$

As in Rockaby (1981), Not I and That Time, May's use of the third person pronoun deliberately blurs the space between subject and object, agent and recipient. We no longer know if May is referring to herself, her Mother, or to some other. Everything is as indeterminate and hazy as the 'semblance' that May purports to see in the churchyard at moonlight. Then, in a speech that both repeats and varies the structure of the Mother's monologue, May, as if from nowhere, and appearing, bizarrely, to assume some prior knowledge on the spectator's part, introduces a new fiction, narrates a different story:

M: Old Mrs Winter, whom the reader will remember, old Mrs Winter, one late autumn Sunday evening, on sitting down to super with her daughter after worship, after a few half-hearted mouthfuls laid down her knife and fork, and bowed her head. What is it, Mother, said the daughter, a most strange girl, though scarcely a girl any more ... ${ }^{61}$

Typically, the strange incident recounted by May is elliptical and unfinished. At its core, there is an absence, a gap, something that refuses to appear:

M: Amy, did you observe anything strange at Evensong? Amy: no Mother, I did not. Mrs W: Perhaps it just my fancy. Amy: Just what exactly, Mother, did you perhaps fancy it was? [Pause.] Just what exactly, Mother, did you perhaps fancy it was? [Pause] ... Mrs W: You yourself observed nothing ... strange? Amy: No, Mother, I myself did not, to put it mildly ... For I observed nothing of any 
62. Ibid., p. 403.

63. Ibid.

64. Ibid

65. David Williams,

'Geographies of

Requiredness: Notes on the Dramaturg in Collaborative

Devising',

Contemporary Theatre

Review, $20.2_{2}(2010)$ 197-202 (p.197). kind, strange or otherwise. I saw nothing, heard nothing, of any kind, I was not there. Mrs W: Not there? Amy: Not there. Mrs W: But I heard you respond. [Pause.] I heard you say Amen ... ${ }^{62}$

The story of Mrs Winters and her daughter, Amy (an anagram of May), has a performative function. It adds an additional layer of opacity to the play we are watching. Not only because the story's strangeness reflects the strangeness of the situation of Footfalls itself, but because it complicates further the relationship between May and her Mother. The very last lines of May's narrative, for example, are the same as those uttered by the Mother at the very start of the play:

M: Amy. [Pause. No louder.] Amy. [Pause.] Yes, Mother. [Pause.] Will you never have done? [Pause.] Will you never have done ... revolving it all? [Pause.] It? [Pause.] It all. [Pause.] In your poor mind. [Pause.] It all. [Pause.] It all. ${ }^{63}$

The narratalogical shifts, refrains and allusions in the play prevent us from assigning meaning. There is simply no point in trying to work out who May and the Mother are and/or what the status of their relationship is, be that phantasmatic or fictional. Rather, Beckett has done his utmost to present us with a situation that we must, if we want to respond to the performance, accept at face value. In Footfalls, what is important is not the narrative or story, but the rhythmic construction of the piece, the way in which it works as a totality, impressing itself upon us, entangling us in strangeness, in 'it all'. ${ }^{64}$

Things, of course, are even more complex when one moves from the play text to the performance text. In the physical unfolding of the piece, the mystery of the narrative is only one aspect of the work, something that rumbles away in background, existing at the very edges of consciousness. To watch Footfalls, as opposed to reading it, is to be caught in an immediate mood of melancholy, to be enveloped in the ambience of the piece, affected by the shuffling sounds of May's footsteps, the brilliance of the lights, the darkness of the shadows, the grain of the voice and the tangled tatters of the dress, its fragility. Meaning here is not communicated by words, but by the radiance of things, or perhaps more accurately by Beckett's ability to produce what we might call, after David Williams, a 'rhythmed assemblage', that is, a non-linear form of dramaturgy that includes the audience in its movement, as it makes its contingent and gratuitous passage across time and space. ${ }^{65}$ According to Williams, dramaturgy as 'rhythmed assemblage' is characterised by intensities, atmospheres and emotions: the aim is to produce significance through a kind of corporeal 'touch', not through deciphering abstract signs.

Beckett's ability to create a performance that simultaneously includes the audience in its pulse and beat is what makes his late plays properly environmental, that is to say, works in which we inhabit a world as opposed to simply looking at one that we already know. In the world of Footfalls, as we might also experience in a garden, actors are no longer human representatives that we identify with or know at the level of 
empathetic engagement or psychological recognition. Rather, they are things in themselves, objects that retain a sense of discreteness, and that serve no other purpose than their own being there. In that respect, Footfalls is not an abstract performance (as one might conventionally find it described), but a decidedly materialist one. Our inability to get behind the surface of the characters, to know and understand them, sensitises us to the play and sheen of surfaces, which, by the very fact of being brought into appearance overflow their discreteness and start to work upon our senses, affecting us, pulling us into the world of things. In Footfalls, as in Beckett's other dramaticules, visual perception is no longer something that moves out conically from the eye; on the contrary, it is something that moves inwards from the impress of the world, from the ability of matter to move us and so transform our modes of perceiving and thus operating in/on the earth.

Beckett's sculpting of time is crucial to his theatre of affect. Whereas dramatic theatre always seeks to deny its own immersion in time, to transcend the present by investing in narratives that would entertain us and so make us forget our painful grounding in the temporal, Beckett prefers to glue us to the present, allowing us to feel the passage of time itself in our bodies. In Footfalls, Beckett achieves this by investing in a logic of deceleration, slowing things down so that what is ordinarily imperceptible - the sound of shuffling feet, the swish of a wrap, the depth of shadows - is brought into consciousness. This slowing down of time does not allow us dominion over the moving surfaces that pass before our eyes by sharpening our attention and honing powers of concentration. Deceleration 'speeds things up', attuning us to the different speeds and intensities of the multiple things of the performance. Slowness here disturbs us, prevents us from sitting still. We are enervated and irritated: the performance resists; it produces friction and retains its autonomy. We are unable to dominate it. It escapes our desire to petrify it into meaning, to hold it in our gaze.

In Footfalls, the constant pausing of the voice, along with the interrupted pacing of May, gives rise to a syncopated rhythm. The performance draws us in only to thrust us back, to leave us shipwrecked somewhere in the middle of a beat. Like the slowness of the performance, the unevenness of the rhythm prevents you from losing yourself in an object, from becoming one with it. You connect and disconnect, advance and retreat, find yourself on a constantly shifting margin. In the same way that perception in a garden moves from one object to another without being captured and captivated by any one thing, so Beckett, in his theatre garden, is always concerned to disrupt spectatorial experience, to prevent it from being absorbed completely in the work. The point of this disruption, this désoeuvrement of what theatre should supposedly be, is to allow a space for the appearance of what most theatre is unable to bear: the boring, the banal, the thing that refuses to signify - the oikos.

The spatial conventions of theatre play an important part in Beckett's desire to produce ecological affect. Unlike durational video works that today are shown everywhere in the white cubes of art galleries, Beckett's garden theatre is located within a black box. You have to go through the performance, to sit with it, to find a way of dealing with its dilation of our 
66. Henri Bergson, Creative Evolution, trans. by Arthur Mitchell (Boston, MA: University Press of America, 1983), pp. 1-22.

67. Beckett, Endgame, p. 107.
68. Daniel Charles in Weiss, Zen Landscapes, p.ll.

69. Ibid. habitual temporal frame. That is where - that is how - it works best, as a kind of 'forced entertainment', we might say. In theatre, there is no way you can stop the performance, walk away, talk with someone else, exit the space, if it all becomes too much. This is time as endurance, in the double sense of that word - both time that escapes measurement, as in Henri Bergson's concept of durée, but also painful time, time without transcendence, or, what amounts to the same thing, time without the consolation of distraction. ${ }^{66}$ In Beckett's theatre garden, as in Endgame, there is, as Hamm says, 'nothing on the horizon', no vista to move towards. ${ }^{67}$ You are always rooted to the spot, to the impossible here and now.

It is no coincidence that the word dominating Footfalls is 'it', a pronoun for some unspeakable absence, a signifier of impossibility. The 'it' here is the same 'it' we find in French constructions such as il y a (there is), and il est temps (it is time). What this 'it' designates in Footfalls is the impersonal, ungraspable quality of time itself. The 'it' of the oikos, the 'it' that we don't want to admit to or experience, because we can't inhabit or possess it. 'It' is inhuman, impossible, it serves only to point out our difference; our failure to do anything else but 'to revolve', like May, around some empty centre. Nothing to be done in the vicinity of the 'it', this time beyond human time, this time that punctures mastery, this time where we intuit mortality, the necessary disappearance of things.

In this affirmation of transience, this cultivation of time, we find another parallel between Beckett's theatre and the art of gardening. According to Daniel Charles, 'the moss' that covers the rocks in the Zen Garden at Ryoan-Ji, in Kyoto, is the very thing that allows 'the place [to] cultivate and abandon itself to forgetfulness as a vital force, as the very force of time'. ${ }^{68}$ For Charles, moss is an ambivalent and deconstructive signifier, in so far as its 'work consists, in the very same movement, of affirming and annulling'. ${ }^{69}$ In the stony ground of Beckett's theatre garden, the things in Footfalls (lights, human bodies, clothes, voices) might be seen as kinds of moss or lichen that insist on their opacity, not simply at the level of signs, but at the level of experience, in their production of a time, an 'it' that simultaneously beckons us in and ejects us in the same moment. In this 'it', we feel discomfited, distracted by our attention and attentive through distraction. We are impoverished by 'it', simultaneously affirmed and annulled. In this garden, we feel what we might call 'the weight of the world', a strange sort of gravity that always places a barrier, a shadow, between us and things. Although we do not pace the boards, we, the spectators, ultimately, share May's predicament in Footfalls. We too, inhabit the shadowland, sit in the dark and experience the impossibility of escaping the world, of being unable to extricate ourselves from a narrow strip of light.

Ironically, though, it is here, in this inescapability, that the ecological meaning of Beckett's theatre resides. Its ability to remind us of the oikos, along with its capacity for instigating a corporeal and affective process, bears witness to everything that human beings, with their metaphysical obsessions with exiting the world, strive to repress and escape. Whereas environmentalist thinkers speak of changing recycling habits, of learning to adapt to a system that might delay the catastrophe, Beckett shows us what might emerge if we accept that the worst has already happened and 
70. Morton, The Ecological Thought, pp-38-50.

71. Jacques Derrida, The Politics of Friendship, trans. by-George Collins (London: Verso, 1995), pp. 64-65.
72. For more on weakness and ecology, see Carl Lavery, 'Introduction: Performance and Ecology - What Can Theatre Do?', Green Letters: Studies in Ecocriticism, 20.3 $(2016)-229-36$.

73. Beckett, Endgame, p.l10. that there is no solution to the ecological crisis. In this moment of ontological weakness and lameness, this acceptance that everything is already exhausted, a different kind of knowledge emerges. Here the oikos is no longer pushed away, forgotten, dispelled; it is admitted, allowed to exist, given a space to appear. Typically, Beckett offers neither explanation nor resolution for the appearance of this marginal other, this troublesome guest, so intimate in/to us that it always escapes our clutches. It is simply there as a 'strange stranger', as something we can't incorporate, a left over, an excessive remainder. ${ }^{70}$ However, the fact that the other is not only acknowledged but affirmed in Footfalls is the very thing that allows Beckett's play, I would argue, to hold out a sense of ecological hope. Crucially, though, no scenario is sketched out, no representation of what that hope might look like. On the contrary, the future is placed on hold, freeze-framed, stilled. But it is here in this stilling that the future, to use a French word so dear to Jacques Derrida, is posited as un avenir, a future that we won't ever know or be able to control, because like the oikos itself, it is always to a-penir, to come, a time, then, that eludes consciousness, cognition and capture, a time that is marginal. ${ }^{71}$

The theory of ecology that I am proposing in this article is difficult. I understand that is has nothing to say about the decisions that face us now with respect to the ecological crisis we are in, and which might well worsen in the years to come. Nevertheless, the fact remains that if we are to live differently on the earth then another mode of being, an alternative form of thinking, is necessary. This will not be done by fetishising nature or by looking for moments of harmony and balance. On the contrary, it is more important to explore moments of ontological difficulty and conflict that, as I suspect, will be impossible to resolve or transcend. However, it seems crucial that we at least acknowledge this impossibility as a basis for action, as a limit or ballast against the Promethean hubris of ecological problem-solving. Indeed, it might even be that the failure of a solution might ameliorate things by giving rise to more humble or 'weaker' ways of being human. ${ }^{72}$ As I have tried to argue in this article, by creating a theatre garden where we are undone in and by time, deposed and dispossessed on the earth, Beckett's theatre leaves us as helpless and indeterminate 'as a little bit of grit in the middle of the steppe' that knows not where its future will be. ${ }^{73}$ For me, this is what gardening with Beckett does, and is precisely the reason why his theatre exists as an ecological practice, something that allows you to live according to a different rhythm, in which humans and non-humans are caught in the vast and paradoxical endlessness of time's eternal transience.

In addition to changing our conceptions about where the ecological charge of Beckett's theatre resides, I hope that the garden analogy I have advanced in this article will have wider implications for the discipline of Theatre Studies in general. To suggest that theatre be approached as a garden challenges the engrained anthropocentrism of the medium itself, the sense in which theatre has always been regarded as the privileged domain of the human, the place in which audiences and performers come together to reflect on pressing social and political issues. Thinking of theatre as a garden rather than a house, however, discloses what most forms of theatre practice and criticism have tended to repress, if not 
74. See Baz Kershaw, Theatre Ecology: Environments and Performance Events (Cambridge: University of Cambridge, 2007), pp-314-18; and Stephen Bottoms's research project 'Reflecting on Environmental Change Through SiteBased Performance' (2010-13), http:// gtr.rcuk.ac.uk/pro jects?ref=AH H03921X/1 taccessed 18 April 2017). At its most basic, the argument here is that black-box theatre separates us from the environment by producing subjects who merely look at nature as a spectacle, and so have no corporeal or material relationship with it.

75. Gilles Deleuze, Cinema 2: The Time Image, trans. by Hugh Tomlinson and Robert Galeta (London: Continuum, 2005), p. 172 . actively foreclose: namely, that the human actor on stage is always already a part of 'nature'. If we accept an expanded view of ecology in which 'nature' and culture form part of a shared world, then there is no need to abandon the artifice of the auditorium or black box for a site-based or immersive aesthetic that would supposedly get us closer to the environment by situating itself within nature, as some of our most innovative ecocritics in Theatre Studies would have us do. ${ }^{74}$ Much better and more progressive, I think, to reconsider the black box as a type of garden, a site where everything and everyone is already 'nature', albeit with different capacities and possibilities. In the theatre garden to look is to be touched, to be affected corporeally by the materiality of the performance itself.

To think of theatre as a garden advances, in and by itself, an alternative view of the human subject, one that is in line with Lyotard's conviction that the human is constituted by the inhuman, haunted by the animal in the very heart of its so-called exceptional identity. In the theatre garden, the human is no longer portrayed as an exception to the world, a hero who can use rationality, will and language to transcend time and space. Rather, the actors and spectators who together make up the performance event are shown to be material organisms, whose modes of perception and ways of thinking are bound up with the physical processes of a planet that they cannot escape or master. In my attempts to imagine Beckett's theatre as a garden, I have attempted to argue for a way of doing ecology that, to borrow from Gilles Deleuze's writings on cinema, might allow us 'to discover and restore belief in the world, before or beyond words' ${ }^{75}$ Importantly, though, Footfalls, like all Beckett's work makes this affirmation of the world not through the movement of images on a screen, as Deleuze proposes, but through the shared co-presence of bodies living and dying together in an actual space-time enclosure, in the unfolding of something irreversible and inhuman - the cultivation of the oikos, theatre as garden. 


\title{
In Caves, in Ruins: Place as Archive at the Happy Days International Beckett Festival
}

\author{
Trish McTighe
}

1. Sarah Jane Scaife, Review of 'Happy Days: Enniskillen International Beckett Festival, 22-26 August $2013 \frac{\varepsilon}{2}$ Studies, 23.2. $(2014)_{\overline{\mathbf{z}}}$ 255-67.

2. Mel Gussow, Conversations with and About Beckett (New York: Grove, 1996), 83-92 (p. 84).
In a review of the 2014 Happy Days International Beckett Festival, Sarah Jane Scaife described the production of Not I (1972), set in the Marble Arch Caves just outside Enniskillen town, in the following way:

Entering the Marble Arch Caves was like being sucked into the belly of the mountain, bringing to mind many images from Beckett's prose writing, of long corridor-like tunnels, shapes and sounds near and far, of 'ultimate wall licks' (Fizzles), the moisture and drips of this visceral cavern like the stomach of Jonah's whale. We were led down hundreds of steps to get to the underground lake in the caves. We were then brought to three boats, where the ferryman told us to board one by one. The lights ahead created a haunting journey into Dante's Inferno; the lap of the water on the boats created the only sound. It was a journey for the senses. ${ }^{1}$

This role has become a signature one for the actor Lisa Dwan and is an astonishing accomplishment. Watching her perform deep underground, among the rock formations that attract droves of tourists to the site annually was a singularly haunting experience. Billie Whitelaw once described the role as 'like falling backward into hell'. ${ }^{2}$ It seems as though this Not I completed that gesture, landing audience and performer alike together in the dark belly of the play, as they shared in that sense of being swallowed by the earth and by time, surrounded by calcified limestone formations built up over aeons; a natural cathedral in the seemingly unending tunnels. The author who served as theme for that year's Festival was of course Dante; the caves playing the role that year as the infernal underworld. Dwan performed the play four times as part of the 'Inferno' experience in that year's Festival. Audiences, guided through the 'underworld' by ferrymen, watched from silent boats as Dwan's mouth- 
3. For a playful yet deeply considered account of the varieties of work and locations that the Festival has offered, see Nicholas Johnson and Brenda O'Connell, 'Three Dialogues on Enniskillen', The Beckett Circle, (Spring $2014)$, n.p. As well as insights into the productions they discuss, the authors offer the dialogue (which mirrors Beckett's Three Dialogues) as a novel form for engaging with the messy het erogeneity of a festival.

4. Sean Doran, unpublished interview with the author, August 2014.

5. Sophie Hunter, 'Why is Sophie Hunter taking Britten's Phaedra to a Beckett Festival?', The Guardian, 25 July $2015<$ http:// www.theguardian. com/music/2015/ jul/25/happy-dayssamuel-beckett-festival -enniskillen-benjaminbritten-phaedra> [Accessed 12 May 2016]. performance emerged from one of the natural cathedral-like spaces within the cave network. It seemed as though the darkness itself had been given a voice, echoing off the seemingly timeless stalactites.

It is this sort of audacious curation that has become a feature of the Festival, although it must be noted that Sean Doran, the Festival's director, is no stranger to such expansions beyond the frame of the traditional theatre space. His past projects included Wagner staged at Glastonbury Music Festival, experimental art works on the beach, and Aboriginal community sculptures in the desert of Western Australia for the Perth Arts Festival. In the 2014 Happy Days Festival some of the attractions included an abandoned church, which was the secret location for Catastrophe, while the monastic ruins on Devenish Island are frequently the site of readings and performances (I discuss one such event below). The Enniskillen sites used by the Festival are often at the fringes or margins of the town centre. They are temporally distant also. Reaching back into the past, they signal deep geologic time, as in the caves, or are human-made buildings that are now in ruins, as in the abandoned church. By contrast, some performances take place in more traditional proscenium theatre spaces situated in the town; these include the main Ardhowen Theatre and Portora Royal Hall. The festival concerts are held in Enniskillen's cathedral and churches, and the commercial spaces of the town embrace Beckett in their own ways, leading to themed products and services such as Beckett-inspired sandwiches and haircuts. Though most of the events do take place in or around the town centre, the marginal spaces remain vital and important sites within the festival context. And, as will be shown in the following commentary, they are an important aspect of the Festival's use of place.

\section{Place, Archive, and the Tourist's Gaze}

At roughly two hours' drive from Belfast and from Dublin, the Happy Days Festival takes place away from major metropolitan areas. This means that it lacks the range of institutional spaces in which to site work. Yet, this is considered 'a gift' by Doran, as the Festival must then innovate when it comes to space, extending its reach to the marginal, the forgotten and, often, the most picturesque. ${ }^{4}$ Ruins become important sites: Beckett's final prose piece Stirrings Still was presented in 2015 in an abandoned barn on a local estate. Doran also uses the Festival as a way to stage works less obviously connected to Beckett: a production of the opera Phaedra (also in 2015) took place in the abandoned Necarne Castle, for instance. Director Sophie Hunter's justification for its inclusion emerges from Beckett's interest in Racine and his lectures given on the topic at Trinity College- Dublin in the early 1930s. ${ }^{5}$ The affective experience of the Festival is one marked by journeys into these places and sites that are heavily encoded with human historical and epochal memory, even if Beckett's life and work might be only tangentially and temporarily linked to Enniskillen itself. I consider in the following commentary the idea of place, from land and cityscapes to geological formations, as a sort of archive containing a rich residue of history inscribed in various ways 
6. Nick Kaye, Site-Specific Art: Performance, Place and Documentation (London: Routledge, 2001), p.l.
7. Fiona Wilkie, 'Mapping the Terrain: A Survey of SiteSpecific Performance in Britain', New Theatre Quarterly, 18 (2002) $\mathbf{2}$ 140-60 (p. 150$)$.

8. Kaye, Site-Specific Art, p. 10 .
9. Patrick J. Duffy, 'Writing Ireland Literature and Art in the Representation of Irish Place', in In Search of Ireland: A Cultural Geography, ed. Brian Graham (London: Routledge, 1997), 64-83 (p.81).

10. Brian Singleton, 'ANU Productions and SiteSpecific Performance: The Politics of Space and Place', in That Was Us: Contemporary Irish Theatre and Performance, ed. Fintan Walsh

(London: Oberon, 2013), 21-36 (pp. 21-22) upon the landscape. This is in order that we might consider how sited performance pieces engage (or not) with the histories, human and nonhuman, shaping those sites. The purpose of the following therefore is to attempt to understand and characterise the relationship between the festival event and the 'local position', to use Nick Kaye's term, that it occupies. ${ }^{6}$ Within the genre of sited performance, place can offer theatremakers a rich repository, often acting as inspiration for, or genesis of, a performance. When performances draw on sites in this way, making direct use of the place as archive, the work is highly specific to that place, or so suggest the UK performance collective Wrights and Sites in their taxonomy of sited performance. They make the case that the term 'site-specific' should only refer to a performance created specifically for a site, 'sitegeneric' to a performance created for a series of similar sites, while 'sitesympathetic' refers to performance that physicalises an existing performance text within a particular site. ${ }^{7}$ As will be shown in the following, the Happy Days Festival productions tend to fall into the latter two categories. These sites offer a rich semantic backdrop for the performances of many of Beckett's texts yet may not really draw on site in the way that truly site-specific performance does; not truly engaging, in other words, with the archive of history that inscribes place. The article is concerned also with the ways in which the spectator of these performances is often positioned partway between aesthetic appreciator and tourist, where the gaze of the tourist always risks a 'writing over of place', as Kaye puts it, drawing on the work of Mark Augé. 8

In 1997 Patrick Duffy commented that the tourism industry in Ireland, one of the most rapidly expanding sectors of the time, 'is one of the most influential forces now shaping representations of identity, landscape and culture' with most of the narratives of Irishness - the myth of the West, the Anglo-Irish legacy, and even the northern conflict 'appropriated by the tourism industry'? This is visible in, for example, the Yeats summer school and festival, running since the late 1950s s $_{\mathbf{\mathbf { z }}}$ Belfast's black taxi tours and the Galway Arts Festival, to name but a few of the more well-known of the multitude of Irish events that muddy the distinction between cultural and touristic consumption. Given its location, however, Enniskillen does not fall easily into the category of mythologised Irish landscapes nor conflict commemoration; yet modernity has seen it become a tourist destination, a quiet fishing retreat for the most part. However, this quieter part of the world bears traces of less tranquil times. In fact, the existence of Enniskillen itself signals a more unsettled history. Indeed, it is this troubled history that the gaze of the Festival may be overlooking.

It is tempting first and foremost to see the use of site in this Festival as emerging amidst the more recent general trend towards sited work in Irish theatre. Some of this Irish sited theatre has been shown at Happy Days: Sarah Jane Scaife's Beckett in the City: Act Without Words II, for instance, was 'staged' outdoors in an Enniskillen underpass in 2013. Brian Singleton has traced the development of site-specific performance in Ireland, noting how many Irish theatre practitioners are moving beyond institutional boundaries in order to interact with sites. ${ }^{10}$ The work of Scaife and that of Dublin-based ANU Theatre Company, who specialise 
11. The Magdalene Laundries were a network of poorly regulated detention centres in Ireland for 'penitent' women. They were run by holy orders. Those who were committed to the laundries, many for life, were there for a range of reasons: infanticide, having had a child out of wedlock or in some cases for having been sexually abused or raped. The closure of the last existing laundry was as a recent as 1996 and many of those who were incarcerated have yet to see justice or reparations. These issues are dealt with at length by J,M. Smith in Ireland's Magdalen Laundries and the Nation's Architecture of Containment

(Manchester:

Manchester University Press, 2008); and in the film The

Magdalene Sisters dir. $_{\mathbf{1}}$ Peter Mullan tMiramax Films, 2002 .

12. Miriam Haughton, 'From Laundries to Labour Camps: Staging Ireland's "Rule of Silence" in ANU Productions" Laundry', Modern Drama -57.1 (2014) 65-93 (p.75)

13. Sarah Jane Scaife, 'Practice in Focus Beckett in the City', in Staging Beckett in Ireland and Northern Ireland, ed. Trish McTighe and David Tucker (Bloomsbury Methuen Drama, 2016), 153-67. in site-specific performances that map the spatial politics of Ireland's capital city, are obvious exemplars in this trajectory away from traditional theatre spaces. Can Happy Days, however, fit similarly within this framework? There is an overarching political intent in Scaife's work and in ANU's. As Miriam Haughton puts it, ANU's production of Laundry (2011), based on true stories of Magdalen Laundry survivors, ${ }^{11}$ uses a 'haunting historical landmark' in order that participants 'realize the importance attached to their individual presence at this event'. ${ }^{12}$ Although Scaife uses a-pre-existing Beckettian theatre text (Act Without Words II, Rough for Theatre I, and more recently Come and Go, Footfalls, Not I, and Rockaby), she also utilises site, creating new meanings and resonances in the text. ${ }^{13}$ Audiences are called upon to experience the material surrounds (cold, isolation, incarceration, neglect) that the frail, unhomed figures of Beckett's drama and the actors who play them experience, to be present in very particular and material ways. Although very different in terms of approach and content, Scaife and ANU do share the sense that once theatrical performance is taken beyond the institutional frame, its political aims and import might be reconceived.

While individual festival events might be readable in this way, it is less clear that this can apply to the Festival as a whole. With festivals in general, it is necessary to consider the relationship with the local economy and the ways in which a festival responds to matters of local identity and concerns. In other words, who participates in the festival? Who benefits from its presence in a specific place? How does the festival map onto the topographies of the town and its environs? This article will therefore seek to understand certain aspects of the sited practices of the Happy Days Festival in broad terms, even as I acknowledge that a complete analysis of such a multifaceted event is outside the scope of this essay and indeed may not yet be possible, given its comparatively youthful vintage. Rather, I present a case study of a single production, of Ohio Impromptu on Devenish Island in 2015 , as a representative example of the ways in which the Festival blends with a long history of tourism in the area, before going on to trace some of the complex histories apparent within Enniskillen's landmarks and cityscapes in order to think in broader terms about the Festival's relation to the notion of place as archive.

\section{Devenish Impromptu}

The principles of scarcity and novelty drive the Festival's use of site. The lack of performance spaces demands a creative engagement with site and, to handle the brevity of many of Beckett's works, the Festival employs a strategy of programming journeys to and from these sites. These journeys often utilise or gesture toward the tourist context in which they operate and in certain cases use tourist infrastructure or travel via well-worn trails. This is the case for events held, like the aforementioned production of Not $I$, in the Marble Arch Caves and Ohio Impromptu which this author attended in 2015. This was an evening performance sited on Devenish Island (from the Irish 
14. This is disputed by the nineteenth-century commentator J,E. McKenna, who makes the case that daim comes from the old Irish word for Druid or learned man (Dauv) and therefore believe the island's name should translate as 'Sacred Isle'. See James Edward

McKenna, Devenish (Lough Erne): Its History, Antiquities, and Traditions (Dublin: Gill, 1897), pp.9-10.

15. Helen Lanigan Wood, Enniskillen: Historic Images of an Island Town (Belfast: Friar's Bush, 1990), p.80.
Dáimbinis, apparently meaning Ox Island). ${ }^{14}$ To reach the island, we took the flat-bottomed river boat from a pier just outside the town centre. The boat is part of a network of ferries that bring tourists to the Lough Erne islands in the summer months. The journey took about 30 minutes and was an opportunity to view some of that river's unspoilt tree-lined banks. A few older farmhouses and recently built houses edge close to the water, but otherwise the view is little changed from the nineteenth century when the ferryboat The Lady of the Lake brought local tourists to the island for picnics. Helen Lanigan Wood's illustrated history of the region shows how The Lady of the Lake operated between 1896 and 1915, linking up with Sligo, Leitrim, and Northern Counties and Great Northern railways to provide tourist and travel services to local and surrounding areas. ${ }^{15}$ The Festival's use of sites such as Devenish and the ways it makes the journey to the site part of the experience of the performance brings the connection between tourism and the arts into sharp focus.

On our arrival on the island, half the attendees were brought directly to a small stone cottage; the other half were free to wander among the ruins of the monastic settlement. The performance itself took place in this darkened cottage (the site's tiny museum which preserves some of its finer stone carvings) set away slightly from the ruins of the Monastic church, the round tower and the gravestones. Frankie McCafferty played the Listener, Vincent Higgins the Reader. The production was directed by Adrian Dunbar. This short, spare playlet was written by Beckett for a 1981 symposium on his work at Ohio State University to celebrate the author's 75th birthday. Given its provenance, it is fitting work through which to ponder festivals and commemoration. The figures are seated throughout; the only movements are the knock, or 'staying' of the Reader's hands, when the Listener demands he repeat a passage or turn to a different page. The Festival's production managed to achieve a beautifully lit tableau, using a scrim to separate actors and audience, which had the effect of enhancing the white glow illuminating the figures. The chiaroscuro effect was a fitting rendition of the Beckettian palette, illuminating the figures in ghostly silhouette.

After the performance, we wandered among the island's ruins. There have been settlements on the site since the sixth century, when St Molaise founded the monastery there on the pilgrim route to Croagh Patrick, which is over 100 miles distance from Devenish, on the west coast of Ireland. Devenish endured Viking raids in $837 \mathrm{AD}$; it was burned down in 1157, only to flourish once again from the thirteenth to the sixteenth centuries. Among the items of interest is an intricately carved high cross dating from the mid-fifteenth century and the 115-foot-high round tower with Romanesque decorations. This all reads like the language of tourism, and it was strange to find these two experiences paralleled so closely within a single event. The stillness and quiet acceptance contained within Obio Impromptu seems on the face of it to be at odds with the more touristic experience framing the production. Tramping among the graves and ruins of the Devenish site, taking photographs and the obligatory sunset 'selfies' with the round tower in the background, seems out of place with this drama; the setting has tourism and art making 
16. Samuel Beckett, Collected Shorter Plays (London: Faber, 1984), p. 57.

17. Ibid., p. 287.

18. Ibid., pp. 287-8.

19. Ibid., p. 288 . uncomfortable bedfellows (though Beckett himself would no doubt have approved of the bar on the boat, which opened for the return leg of the journey).

There is not only a slight disconnect between site and performance, but also a certain dissonance between the activities of the tourist and the Beckett spectator. The former might be characterised as exploring, consuming, and recording place through the memento, the photograph; the generation, in other words, of memory. By contrast, Beckett's drama often involves the very opposite. Many of the figures of his dramas, partially realised, imagine being consumed by place, not consuming it; literally so in some cases, as May in Footfalls (1976) and the woman of Rockaby (1980), for instance, are half-swallowed by the darkness of the mise-en-scene. Krapp is consumed by the memory of the girl on the lake, the details of the place and his earlier 'farewell to love' are inescapable for him; other figures in the later drama seem similarly so. ${ }^{16}$ The voices of That Time (1975) bring forth waves of memories - particular times, certainly, but also particular places: the ruins where he hid as a child, the portrait gallery, the library. I am reminded also of the destruction of photographs in both Film (1965) and A Piece of Monologue (1979), acts that appear to be attempts to free the protagonist from the overwhelming tide of life's memories. The listening figure of Obio Impromptu (1980) is also consumed by memory, of the dear face, the one who has sent the Reader to bring comfort - even if the play stages a winding down of the story, and of the life to which the story refers. The Reader has come 'from time to time unheralded [...] to read the sad tale through again ${ }^{17}$; this performance, as the Reader describes, will be the final night, he will not come again: 'So the sad tale a last time told they sat on as though turned to stone'. The play ends with quietness, the two 'buried in who knows what profounds of mind' after the narrative has been reprised and revised into eventual silence. ${ }^{18}$

For all its touristic resonances, the site itself was part of the journey to and from the performance; if it had an effect, it was perhaps to generate a sort of quietness in the presence of what is no longer there, the sense of the ineffable in Beckett's work echoed by the ghostly absence of the island's former inhabitants, wrought by the weight of history in the surrounding stone monuments. Fittingly, then among the play's final lines is the following, 'so sat on as though turned to stone. The sad tale a last time told'. ${ }^{19}$

The figures' stone-like quietude is echoed in the stillness of the place, its time of conflict now long passed. Such a reading validates my point that individual productions may be set against place in ways that illuminate both site and text. Yet broader questions remain about the Festival's relationship to the tourism and culture industries of Ireland and Northern Ireland and its ability to engage with the region's complex history.

\section{Enniskillen, Plantation Town}

The Beckett Festival comes to this island town, rich in a history going back to the Neolithic period, to an area where farming and tourism are 
20. Lanigan Wood Enniskillen, p.5.

21. R.J. Hunter, 'Sir William Cole, The Town of Enniskillen and Plantation County Fermanagh', in Fermanagh History and Society:

Interdisciplinary Essays on the History of an Irish County, ed. Eileen M. Murphy and William. J. Roulston (Dublin: Geography, 2004), 105-46 (p. 128).

22. K.J. Rankin Theoretical Concepts of Partition and the Partitioning of Ireland (Dublin: Institute for British-Irish Studies, 2006), p.11.

23. Ibid. the current mainstays of the economy. As with much of the island of Ireland apart from Dublin and Belfast, Enniskillen saw little heavy industry (other than linen production, up to the nineteenth century). Enniskillen lies in County Fermanagh in the southwestern corner of Northern Ireland, about a 20-minute drive from the border with the Republic. Although some 8000 years of human settlement can be traced in the surrounding area, the town itself only came into existence through the Plantation of Ulster in the early 1600s. Created in 1612 by the charter of James I, it is one of 18 borough towns that were to be represented in the then Dublin Parliament. William Cole, from London, was appointed constable of Enniskillen Castle in 1609 and eventually became the sole owner of 60 acres across the island. His descendants became the Earls of Enniskillen. ${ }^{20}$ From this moment on, Enniskillen, a garrison town surrounded by farms planted by English and lowland Scots, English army servicemen and the remaining Gaels, was a mixture of peoples and cultures. The town came into being due to the plantation policy of urbanisation and modernisation and as such is an example of a market town built to increase trade and simultaneously increase the presence of the bourgeoisie. ${ }^{21}$ This purpose can be traced today in the layout of its streets with their open market spaces.

It was Fermanagh's complex 'mosaic' of Nationalists and Unionists, which could not be easily separated out, that made the debates about partition in the early twentieth century so difficult. ${ }^{22}$ Fermanagh became one of the counties whose inclusion in the proposed partitioned six (including Antrim, Armagh, Down, Fermanagh, Londonderry, and Tyrone) was debated at length. Like Tyrone, it did not have a Protestant majority. Partition was raised through a proposed amendment to exclude the four predominantly Protestant counties of Ireland Antrim, Armagh, Down, and Londonderry - from the 1912 Home Rule Bill. This would have left them outside territorial scope of the Irish Home Rule Parliament. ${ }^{23}$ The partition eventually included Tyrone and Fermanagh and came into being with the 1920 Government of Ireland Act and was to set the scene for the conflict that Northern Ireland endured for most of the latter half of the twentieth century. During the 'Troubles', Enniskillen was to become the site of one of the worst bombing atrocities by the this was the 1987 Remembrance Sunday attack in which 11 people were killed and 64 injured. The history of this town and region is therefore the history of plantation, partition, and conflict; these are the forces that have shaped its topographies, leaving their marks in various ways, from monuments, to architecture, to farming practices and land management.

There has been much written on the difference or distinction between the archive and the live, which translates often into the difference between text and embodied performance. ${ }^{24}$ Yet what might thinking of place as archive bring to the conversation when it comes, in particular, to sited work? As explored here in relation to Enniskillen, places carry traces of human and non-human forces: landscapes may not be documents, in the strictest sense of that word, but they do record the traces and imprints of the human life that covers and uses them. We might say that places document the past, even if the 'curatorial' practice of stone and earth is not driven by human intentionality battling the processes of
4. See for example Dian Taylor, The Archive and the Repertoire: Performing Cultural Memory in the Americas (Durham, NC: Duke University Press, 2003). 
25. C.Ó. Drisceoil, Mary Leenane, Stephen Davis, Barry

Fitzgibbon, and Mary Teehan, The Black Pig's Dyke Regional Project Report

Roscommon County Council <http:// www.roscommon coco.ie/en/Services/ Community/ Heritage/ Archaeology/TheBlack-Pig\%E2\%80\% 99s-Dyke-RegionalProject/> [accessed 28 January 2016]. See also Aidan Walsh, 'Excavation at the Black Pig's Dyke', Clogher Record, $\$ 4.1$ $(1991)_{2} 2-26$ (p-22.)

26. Art Ó'Broin, Beyond the Black Pig's Dyke: $A$ Short History of Ulster (Dublin: Mercier, 1995), p.7.

27. Wilkie, 'Mapping the Terrain', p. 150 .

28. James Knowlson Damned to Fame: The Life of Samuel Beckett (London: Bloomsbury, 1996), p. 26.

29. S.E. Gontarski and C.J. Ackerley, The Faber Companion to Samuel Beckett (London: Faber, 2006), pp. 450-51. decay. The place-archive emerges from the blind processes in which the earth encases the activities of the human, held tautly between preservation and decay; often, more is lost than is preserved. Limestone records the passage and trace of water, a force that has shaped the Marble Arch Caves in spectacular fashion, and fields 'remember' in their own way the work of generations of farmers. Like the archive, place and landscape appear to be permanent, seemingly exceeding in existence the events to which they form the backdrop. Yet the archaeological and geologic perspective would correct this view: places and their landscapes change, though this change is often imperceptible to the human eye. Places and archival documents are material entities whose only distinction might lie, therefore, in their differential rate of decay. In one sense, place is what happens beyond the limits of the archive, if the archive stands for pieces of the world whose natural pace of decay is interrupted and slowed by curation and preservation. Place equals that which is beyond the archive, subject to its own laws of preservation and decay, etchings in stone and earth, by chemicals, water. It is less clearly legible than the archive's documents and subject to more interpretation perhaps (though the difference is one of degree rather than distinction). Take for instance what is known as the Black Pig's Dyke, a supposedly defensive linear earthwork (a deep ditch sided by high banks) demonstrated to belong to the Iron Age ( $500 \mathrm{BC}$ to $400 \mathrm{AD}$ ) that skirts the border of County Fermanagh into County Leitrim between Lough Melvin and Lough MacNean Upper. Although recent excavation work now disproves the theory, ${ }^{25}$ it has long been read as metaphor for, and somewhat naturalised as, an ancient boundary partitioning Ireland north and south, a sort of justification for a longstanding national and cultural division 'written' in the landscape. ${ }^{26}$

For the most part, the sited work done at Happy Days tends to be of a site-sympathetic variety, ${ }^{27}$ where an existing performance text is physicalised within a specific site, as exemplified in the production of Ohio Impromptu. It uses history obliquely, drawing on the sensuous resonances of place without articulating explicitly the layers of history that I have glossed above. On the one hand, approaches such as this necessarily limit the capacity of the Festival to be able to speak to its spatial and political contexts. On the other, it reflects accurately the transitory quality of Beckett's own presence in that context. It is in this complex territory that we find a festival celebrating the life and work of an author whose main connection to the region lies in his years at secondary school in Portora Royal, situated on the outskirts of the town; Beckett himself a member of Ireland's Protestant minority, and later an émigré artist from its shores.

\section{Beckett and Enniskillen, at the Limits...}

Enniskillen lies not only at the limits of the Northern Ireland border, but also at the limits of the Beckett archive: the biographical basis for the Festival lies in, as we know, Beckett's attendance at Portora. Yet the Portora years lie at the limits of the consciousness we have of Beckett's life. These are his formative years and do not enter into his writing in any great way, as James Knowlson's biography notes. ${ }^{28} \mathrm{He}$ did not retain the same sympathy for Portora that he did for Trinity College Dublin, and later overtures for recognition from the school were ignored. ${ }^{29}$ However, 
30. Knowlson, Damned to Fame, p. 37; and Sean Kennedy, 'Samuel Beckett's Reception in Ireland,' in The International Reception of Samuel Beckett, ed. Mark Nixon and Matthew Feldman (London: Continuum, 2009), 55-74 (p-55).

31. Joseph Roach, 'All the Dead Voices: The Landscape of Famine in Waiting for Godot', in Land/Scape/ Theater, ed. Una Chaudhuri and Elinor Fuchs (Ann Arbor: University of Michigan Press, 2002), 84-93 (p. 92).

32. Gontarski and Ackerley, Faber Companion to Samuel Beckett, p-xv.

33. David Clare, 'The Gate Theatre's Beckett Festivals: Tensions between the Local and the Global', in Staging Beckett in Ireland and Northern Ireland, ed. Trish McTighe and David Tucker

(London: Bloomsbury: 2016), pp.39-50.

34. John Harrington, 'Festivals National and International: The Beckett Festival', in Interactions: Dublin Theatre Festival, ed. Nicholas Grene, Patrick Lonergan with Lillian Chambers (Dublin: Carysfort, 2008), 131-42 (p.137).

35. See Sean-Kennedy, 'Samuel Beckett's Reception in Ireland', in The International Reception of Samel Bechett, ed. Mark Nixen and Matthew Feldman (Lenden: Gentinuum, 2009), 5574 (p. 68). both Knowlson and later Seán Kennedy observe that Ireland's partition, during his second year at Portora, must have had some impact on his developing political awareness, even though he himself scarcely felt it impinged upon him. ${ }^{30}$ So the question might be, when it comes to a discussion of site and space at the Festival: How does the Festival relate to Beckett's lack of relationship, not only with the place itself, but also with its history - even if, as Joseph Roach puts it, history 'like so much else in the work of this most physical of playwrights, is made palpable, present to the senses even as absences - a silence, a stillness, an unbroken horizon'? ${ }^{31}$ Not only will a festival like Happy Days struggle to find direct connection between text and landscape; it is also the case that, as was asked of Eoin O'Brien's 1986 photographic book The Beckett Country, how is it to express Beckett's exilic distance from Ireland, not to mention partition and the region's exile from the rest of the island? ${ }^{32}$

Beckett was quite comfortably homed in Dublin by the Gate Theatre in the early 1990s. The 1991 Beckett Festival achieved a sense of the Irish connection within Beckett's work, without parochialising it, ${ }^{33}$ or without an over reliance on Irish stereotypes. ${ }^{34}$ The Gate's artistic director, Michael Colgan, saw the theatre's championing of the author as restorative, prompted by a lack of Irish presence at Beckett's 1986 birthday celebrations in Paris. ${ }^{35}$ This 'homing' or restoration also has a longer history in the performances of Jack MacGowran in the 1960s and 1970s, then Barry McGovern in the 1980s, with the prose adaptations that helped to highlight the 'Dublinness' of Beckett's writing. Given the biographical connections with Dublin and its surrounding landscapes, as so effectively traced in O'Brien's The Beckett Country, it is fair to say that the threads connecting Beckett to Enniskillen are not quite as robust.

Furthermore, moving Beckett 'to the country' presents a marginality reflected in the very marginality of Enniskillen itself. It might be worth acknowledging how the sense of what counts as 'marginal' is of course subjective; I am cautious to use the term here to indicate Enniskillen's proximity to the border, rather than reiterate an implied urban (and therefore cultural) centrality to either Dublin or Belfast. The region's landscapes are marked by remnants of pre-partition days and a gradual post-partition atrophying of connections between north and south: fragments of the bridge that once carried the Great Northern Railway line can be seen on entering the town from the east. Although this rail company did not go out of business until the 1950s, the financial support that might have saved it would have had to have come from both northern and southern governments - a cooperation impossible at that time. The ruined tracks can still be seen along the southwestern route between Sligo and the border, telling a tale of under-resourced infrastructure affecting roads as well. Driving west from Belfast, you notice how the road peters out from the well-maintained main road to Enniskillen, then the slightly narrower main road from Enniskillen to the border, to the much narrower country road that takes you from the border into Sligo, the nearest large town in the Republic. The road enters Sligo through one of its lesser (albeit highly scenic) arteries - almost through the back door, as if the southern town has forgotten (or tried to forget) the existence of one of its nearest northern neighbours. Through stifling the development of 
36. Thomas O'Reilly, Happy Days Festival Programme, August 2012.
37. Sharon Zukin, The Culture of Cities (Oxford: Blackwell, 1996), p.113.

38. ‘Carnivals for Elites? The Cultural Politics of Arts Festivals', Progress in Human Geography 22.1. (1998)-54-74 (p-64).

39. Emer Sheerin qtd. in G. Smyth, Space and Irish Cultural Imagination (Basingstoke: Palgrave, 2001), p.31. transport links, partition increased this sense of marginality and remoteness. Without partition, Enniskillen might have been a much busier hub connecting Sligo and Dublin with Belfast and Derry, rather than, as it is for many holidaymakers, a retreat of lakes and green fields away from the urbanised east. Yet it is here that Doran stakes his claim to the creation of a cultural hub out of which the Beckett, Friel and Wilde festivals will emerge (the inaugural Friel Festival took place in 2015 in Donegal).

\section{Happy Days and the Place-Archive}

Given this historical backdrop, what conclusions can be drawn about the relationship between the Happy Days Festival and the place-archive? Some may see the Festival not only as a cultural event in itself, but also as a way to also showcase local tourist amenities. As Thomas O'Reilly, Chairman of Fermanagh District Council puts it in the 2012 inaugural programme:

By using venues in and around the island town of Enniskillen, the festival will showcase our waterways, landscape, buildings and streets as a hub for arts, culture and sport. Whether you are familiar with Enniskillen or not, you find unique events in unique places and a warm welcome to all. ${ }^{36}$

Such a relationship between the tourist economy of a place and its cultural events is to be frequently observed in the context of international festivals and the use of place for these ends demands interrogation. Many commentators, deeply influenced by Pierre Bourdieu's writings on culture and capital, see festivals and cultural celebrations as ideologically inflected and reflecting for the most part the interests of specific social classes and groups. As Sharon Zukin writes, we can no longer simply think of culture as a reflection of material civilisation but rather as a tool in the hands of patrons who often compete over the 'definition of symbols and the space to put them', using 'images not only as salable commodities but also as the basis of tourist and real estate markets and visions of collective identity'. ${ }^{37}$

Stanley Waterman has explored how place as well as art is consumed in festivals and 'prestige projects and place-marketing do not necessarily contribute to cultural regeneration and are more inclined to benefit the local middle-class and cultural tourists'. ${ }^{38}$ Festivals can often be part of the spatial rebranding of places, in ways that do not benefit those most in need. Parts of Fermanagh are in line for urban regeneration and one has to wonder if this Festival, like so many cultural touristic ventures, as Emer Sheerin puts it, relies upon 'a very selective and exclusively aesthetic representation' of the region, in which there is a 'constant attempt to discover what is visually appealing and exotic' while ignoring poverty and conflict. ${ }^{39}$ In terms of cultural events and their relationship with place, a connection can be drawn, therefore, between festival attendee and tourist observer. Denis Cosgrove sums up the problematics of placeconsumption beautifully when he articulates the distinction between those who perceive space as landscape (and consume it as such) and 
40. Denis E. Cosgrove, Social Formation and Symbolic Landscape (Madison: University of Wisconsin Press, 1988), p. 19 .
41. Judith Rugg, Exploring Site-Specific Art: Issues of Space and Internationalism (London: I.B. Tauris, 2010), p. 124 .

42. Dean McCannell, The Tourist: A New Theor of the Leisure Class (Berkeley: University of California Press, 1999 [1976]), p. 83.

43. Ibid., pp.80-81.

44. Rugg, Exploring SiteSpecific Art, p. 49. those for whom the land forms the surrounding of their daily lives: 'The insider does not enjoy the privilege of being able to walk away from the scene as we can walk away from a framed picture or from a tourist viewpoint'. ${ }^{40}$ The erasure of conflict, poverty and their historical precedents are a wider problem of place consumption, as is - and this is highly specific to places which have been affected by partition and conflict - an inability or unwillingness to engage with that unsettled history. It may be that festivals force us to ask difficult questions about the ways in which sites are used in contemporary theatre practices, inside and outside festival contexts. Thinking of place as an archive of sorts demands that we think of how the place-text is being utilised and imagined under these conditions; in other words, whether or not individual artworks or the festival as a whole are responsive to the traces of history embedded in the landscape. And more importantly, the links that this Festival (and indeed many festivals) has with the tourism industry.

It may be too soon to say if these problems of ideology and inequality apply to the Happy Days Festival. It tends, as with many such festivals, to follow along the tracks laid down for tourists and showcases sites as much as it showcases art, and this leaves it open to some of the same critiques directed at the tourism industry. Tourism suffers from, as Judith Rugg puts it, a 'resituat[ion of] place as benign and free of conflict. Tourism as a form of 'place reframing', for Rugg, involves a sort of 'enforced coherence [...] of regeneration, redevelopment, urban planning or tourism'. ${ }^{41}$ Dean McCannell's seminal work on the subject indicates that tourism offers a sort of inoculation against the past: 'the effect of preservation is to make the present more unified against the past, more in control of nature, less a product of history'. ${ }^{42} \mathrm{He}$ observes how modernity has transformed nature from 'cruel alternative to community life' to a 'place of play', from something we must fight to something we must preserve. ${ }^{43}$ Rugg argues that site-specific art can work against the constructions of the place through tourism narratives, and reveal rather than conceal conflict. ${ }^{44}$

Individual works in the Festival might respond to site aesthetically, but - at least so far - do not attempt to unearth the historical content of sites, to access and utilise the cultural loci of memory. Like the biographical connection of Beckett himself to the area, the Festival floats atop a complex history of plantation and partition. Not unlike visitors to the Marble Arch Caves, who are strictly prohibited from touching the rock formations because this can alter the pattern or even stunt the growth of the calcified rock, the Festival might be similarly traceless. It hovers, rather, somewhere on the spectrum between site specificity and site responsiveness and the 'transitory topographies' that characterise festivals of this nature. ${ }^{45}$

The question of the Happy Days Festival's relationship to place is part of a broader set of questions that must be asked of all festivals and cultural events: Who benefits, culturally and economically? How is the placearchive, its history, landscape, conflicts and partitions, being used? What, if anything, is being forgotten in that use of place? And, in these acts of commemoration as the performance of a writer's legacy, we might ask, following Nicholas Johnson: What art work (indeed, what other authors) becomes elided, while other works become celebrated icons of 
46. 'A Theatre of the Unword: Censorship, Hegemony and Samuel Beckett', in Ireland, Memory and Performing the Historical

Imagination, ed. Christopher Collins and Mary P. Caulfield (Basingstoke: Palgrave Macmillan, 2014), 36-54 (pp. 36-7). the canon? ${ }^{46}$ The Happy Days Festival is still in its infancy. It is perhaps too soon to ask it to answer to all the questions that have been raised here. At only five years old at the time of writing this piece (2016), it is perhaps too newly in place to deal in a meaningful way with the placearchive on which it rests. Yet it presents an opportunity for critics and commentators to observe the process of a festival's embedding in place. As observers, we have a responsibility to be aware of the issues at stake and aid in documenting the Festival's activities, while being cognisant of the historical realities that are always already embedded in the landscape and which precede the artistic practices of the Festival.

To end on a speculative note, it may be that the tentative connection between Beckett's work and Enniskillen is exactly what resists a sanitising or embalming of history within touristic representations of place. Work like the production of Obio Impromptu discussed here presents the tourist experience side by side with the aesthetic quietude of Beckett's theatre, allowing a dissonance to stand between the two. This echoes the dissonance (but not disconnection) that is to be found between art and the economy, and may provide a blueprint of a fault-line along which other dissonances - such as the remnants of local conflict, embodied geographically in the partitioned island - may be mapped. For the Festival, time - and place - will tell. 


\title{
'Demented Particulars': Traces of Godot and the Provincial Theatre Archive
}

\author{
Sinéad Mooney ๑
}

1. Elin Diamond, 'Performance in the Archives', Theatre History Studies, 28 (2008), 20-26 (pp. 22-23).

2. Diamond, 'Performance in the Archives', pp. 22-23.

3. Jacques Derrida and Eric Prenowitz, 'Archive Fever: A Freudian Impression', Diacritics 25.2 $(1995)_{\mathbf{2}}$ 9-63 (p-14).
A visit to the Beckett International Foundation's archive at the University of Reading recalls Elin Diamond's account of the archive as ritual performance as she recounts a 2006 visit to consult archival material at the Fales Collection at New York University's Bobst Library. There is the quasibureaucratic, quasi-religious ritual of presenting appropriate credentials: signing in, being told the rules, the ritual decontamination of her belongings before entering the archive, the filling of slips, and, finally, the handing over of the carefully preserved and presented material:

The archive assistant slides the outsized envelope of loose papers and places it flat on his arms and, as though holding a priestly stole, slowly walks to me. I rise at his approach. To take the envelope from him, I have to extend my arms and bend at the knee, an inadvertent curtsy. ${ }^{1}$

The historian Carolyn Steedman reminds us that the modern European public archive came into being in order to solidify and memorialise first monarchical and then state power, all of which is recalled for Diamond in 'my awkward curtsy as the file passes from king to subject, from magistrate to citizen, from the Fales librarian to me'. ${ }^{2}$ This power is bequeathed in turn to the scholarly archive, reinforced by the scholarly, rather than juridical, laws that turn mere objects or writing into the evidence for this or that truth. The scholarly archive still, for Diamond, reeks of such ceremony. If the historical archives, which have figured most strongly in the recent theorisation of the archive, are the most obviously implicated in regimes of power, all archives are implicated in what Derrida, in Archive Fever, calls 'archontic power', derived from the first archons, or guardians of the archive. ${ }^{3}$

This essay uses the contrast between the holdings of the prestigious Beckett International Foundation archive at the University of Reading 
4. Carolyn Steedman, Dust (Manchester: Manchester University Press, 2001), p.69.

5. See Peter Fifield, Introduction to the special isstre -Beckett Out of the Archive', Modernism/Modernity $18.4(2012)_{\overline{2}} 673-79$. and the traces left by early productions of Waiting for Godot in the less obviously valuable archives of regional theatres as a starting point for a more materially minded production history of the play in its early English incarnations outside the major theatrical centres. In considering the play less as an aesthetic object than as one theatrical property within the repertory system, as registered by publicity ephemera, account books, and funding and casting correspondence, it attempts to achieve a fuller understanding of the immediate conditions in and through which theatrical performances are produced, and to read in archival traces elements of the materiality of past performances.

The Reading Beckett archive, the world's largest collection of Beckett papers - and in 2013 the purchaser at auction of the manuscript notebooks of his early novel Murphy, until then the last significant Beckett manuscript still in private hands, for the sum of $£ 962,000$ - necessarily participates in such prestige. An archivist's author, Beckett preserved his own manuscripts, proofs, diaries, and notebooks for decades, donating many to friends who were also scholars of his work, leading to an extraordinarily complete archive, accessible to scholars, distributed across numerous institutions in several countries, as well as, centrally, at Reading. That the archive is always a record of loss is a truism, a name for 'the many places in which the past (which does not now exist but which did actually happen, which cannot be retrieved but which can be represented) has deposited some traces and fragments'.- ${ }^{4}$ However, during Beckett Studies' archival turn - when Beckett scholarship based on theoretical readings was superseded by textual and genetic criticism using the manuscripts in the archive - one could be forgiven for losing sight of this loss entirely, such was the emphasis on the aura of power and presence of the Beckettian archive. Such was the emergence of 'new' work from the Beckett archive that began to be published posthumously (as unpublished manuscripts such as Eleutheria and Echo's Bones, which had been set aside but, crucially, preserved, during Beckett's lifetime), that it seemed as if Beckett were more alive than he had been since his death in 1989.

Authorial intention in the form of preservation and donation is clearly central to the Beckett archive, with its focus on primary materials, in which authorial errors and false starts are in a sense 're-authorised' by their donation, and the archive in turn derives its considerable authority from the powerful intervention of the author, who donated much of the material. Much has been made of the ironic revaluation of what Beckett, who consistently deprecated his work, considered rubbish - drafts, failures, botched or abandoned work, although, of course, his published oeuvre also features works bearing names such as 'Fizzles' and 'From an Abandoned Work' - via the transformative act of its archivisation. For, as Peter Fifield argues in his introduction to a special issue of the journal Modernism/Modernity on the significance of the archive in Beckett studies, the archive cannot hold anything worthless. ${ }^{5}$ Its positivity infects every item it touches, so that even the author's outright rejections are made valuable by inclusion. Like religious relics, initially valueless human remains, hair, teeth, burial clothes, are made sacred by the system of belief that decrees them relics; the rubbish bin becomes the reliquary. 
My project, however - a study of early English productions of Waiting for Godot (1953), outside the major theatrical centres - focuses, not on Beckett's manuscripts, or on alterations to the performance texts, but on what happened to Godot in production when it was licensed for repertory after its debut at the Arts Theatre Club, move to the West End and subsequent regional tour. I found myself working at some distance, geographically and psychologically, from the prestige vested in the Reading Beckett archive, where documents are collected under the sign of Sam, and made valuable by its imprimatur. I was working primarily in the archives of regional theatres, many of them located in provincial city or county records offices, where Beckettian traces are incidental to larger narratives of the institutions themselves and productions past, where you read for the traces of Godot productions amid vast, often uncatalogued or undated boxes containing details of financial squabbles, minutes of Annual General Meetings, promptbooks, press cutting scrapbooks and ephemera, all in various states of preservation. My experience has been far more akin to that described by Carolyn Steedman, who, taking a sceptical approach to heroic notions of 'archive fever', notes that scholarship on Derrida's essay has remarkably little to say about the 'ordinariness, the unremarkable nature of archives', and the everyday disappointments to be found in record offices and repositories; 'There is the great, strandless, brown, slow-moving river of Everything, and then there is its tiny flotsam that has ended up at the particular record office you are at work in. ${ }^{6}$ If the narrative of the scholar in the well-catalogued, beautifully preserved Beckett archive seldom affords the deep-seated excitement of a genuinely new discovery, it is nonetheless a narrative of what, in the opening part of 'Archive Fever', Derrida presents as the image of the arkhe, a place where things begin, where power originates, and its workings are inextricably bound up with the authority of beginnings and starting points. ${ }^{7}$ The counter-narrative of the scholar searching the fileboxes in county records offices for Beckett productions is one of a different kind of experience. Far away from the privileged space that the Beckett archive accords to all marks and traces of the Beckettian oeuvre, the dustier traces of Godot in provincial theatre archives are far more akin to unreclaimed, unauthorised archival residue.

Archives preserve records of value to a community because that community has felt that these values had a place in the future. Records of Godot are differently valued in the archive of a regional theatre, preserved in a county council records office, compared to their status in the Beckett International Foundation collection, in which they figure as aspects of a specifically Beckettian narrative. In one sense, in a regional theatre archive they are aspects of a larger account of an institution; in another, the records themselves, consisting of ephemera, yellowed newspaper cuttings, accounts of conventionally 'invisible' backstage work and finances, are different by their nature from the drafts and working materials of

8. See Arjun Appadurai, The Cultural Life of Things: Commodities in Perspective (Cambridge: Cambridge University Press, 1988), p. 8 Beckett's career. The material arrives at the different archives having travelled through a series of different 'regimes of value', in Arjun Appadurai's term, moving from commodity to gift, and - in the case of the theatre archive - from theatrical metonym to part of a collection, as evidence of a lost performance. ${ }^{8}$ What, then, can the undifferentiated, 
9. David Pattie, 'The Stuff of Performance: Beckett, Marginalia and Theatre Programming', paper given at Staging Beckett at the Margins, University of Chester, 11-12 September 2014
10. Sinéad Mooney, " "Radish, One Per Night"s: Early Godots in the Regional Theatre Archive', paper given at Staging Beckett and Contemporary Theatre and Performance Cultures, University of Reading, 10-11 April 2015.

11. Marvin Carlson, Places of Performance: The Semiotics of Theatre Architecture (Ithaca: Cornell University Press, 1989), p. 2.

12. Michael Leigh, 'Century Theatre: A Personal View of its raison d'être'. Programme note for all 1971 summer season productions, Century Mobile Theatre archive, Leicestershire Records Office. Much of the Century material, as in other archives referred to in this article, does not have individual call numbers, but they will be supplied where possible. uncatalogued, 'lesser-value' theatrical archive offer the scholar that the organised prestige of the Beckett archive cannot?

In a conference paper, 'The Stuff of Performance: Beckett, Marginalia and Theatre Programming', David Pattie makes an important distinction, arguing that conventionally, within single-author literary studies, archival research is centripetal, circulating around the figure of the author, whereas in theatrical archival research, a centrifugal force draws the scholar in other directions, away from authorial intent, out into the theatre, and the irretrievable past, the record of lost performances and past backstage theatrical work. 9 This is key to the work I have been doing, which is less interested in the performance texts of Godot, or in innovations in production, than in the way in which even an avant-garde play such as Godot - still trailing the controversy of its origins in Paris and London, once it was licensed for repertory playing in the provinces became subject, as any other play, to a form of cultural and civic judgement, assimilation or commercial commodification. How did Godot fit within local theatrical, cultural and economic structures, and within regional and national debates about theatre in the two decades after its London premiere? What productions were staged alongside Beckett's play, and how did its reception alter over time as the play stopped being perceived as a bulletin from the continental avant-garde and gained 'modern classic' status? Was the play 'read' differently by regional audiences who were, by and large, encountering the play in repertory, and was the play's potential for any kind of disarticulating interrogation undercut in being performed by a familiar local company with an ongoing relationship to its regular audience? I became interested, looking for the traces of this 'worldlier' Godot, in the archives of provincial theatres, amateur and professional, in the ways in which an iconic play inserts itself into the larger public world in which it is produced, and so becomes less an inscrutable modernist artefact than a play subject to the ordinary strictures of contemporary theatrical norms and to prior material exigencies. ${ }^{10}$

As Marvin Carlson has argued, 'The way an audience experiences and interprets a play [...] is by no means governed solely by what happens on the stage.' ${ }^{11}$ Godot's production history, as much as the play's move from French to English, from Parisian 'little theatre' to London's West End and regional tour in the mid $1950 \mathrm{~s}$, becomes the story of a financially successful theatrical property in the regions of England during both the demise of the repertory system, and the rolling out of public subsidies from the Arts Council and local authorities. Andrew Leigh, the general manager of Century Mobile Theatre, writing in 1971 for a programme note about the world in which Century first toured in four ex-military trailers pulled by a tractor, wryly evokes a post-war theatre world where 'the Provinces' were

still torn between a JB Priestley-style Variety circuit no 1 and 2 tours all meeting at Crewe station on Sunday afternoon on the one hand, and on the other the sight of a hundred-odd 'weekly reps' sustained by actors living on four pounds a week [...] crumbling before the onslaught of Hollywood in the cinema $[\ldots]$ and cinema's own murderer about to appear out of the dark 40 s - Television. ${ }^{12}$ 
This is a somewhat cartoonish retrospective from the 1970s, but the meanings of early productions of Godot in the regions of England are profoundly entangled with the lingering demise of the repertory system, the structures of theatrical organisation and funding, and the impact of programming requirements and the cultures associated with particular theatres on the work produced by those theatres, and on the way in which it was understood by their audiences.

\section{Rematerialising Godot}

The theatre archive is particularly rich in accumulations of circumstantial evidence, what Beckett's novel Murphy terms 'demented particulars', and as such corrects scholarly tendencies to attribute a play's cultural and ideological impact to the playtext alone. It allows for a form of 'rematerialisation' of Godot. Yet if all archives are records of loss, this loss is exacerbated within the theatrical archive. Peggy Phelan, famously, writes:

Performance's only life is in the present. Performance cannot be saved, recorded, documented, or otherwise participate in the circulation of representations of representations: once it does so, it becomes something other

13. Peggy Phelan, Unmarked: the Politics of Performance (London and New York: Routledge, 1993), p.146.

14. Fifield, p. 674 than performance. ${ }^{13}$

Although performance itself exists only as memory, dream or recollection, the archives are full of its material remains - the costumes, properties, set models, sketches and drawings, sound recordings, photographs and documents left behind once the performance is over. In the archives in which I have worked, researching performances from before the advent of video recordings made for the purpose of archiving, these were as likely to consist of box office receipts indicating daily takings for ice cream, chocolates and programmes during a run of Godot, correspondence about lost props, or pleas for Arts Council funding as production materials. Within Beckett studies, such remains tend to be overshadowed by the incontestable authority of Beckett's own theatrical notebooks and other, more curious material remnants. Peter Fifield notes that the '[s]cribbles on whiskey labels and disposable tablecloths are particularly special: archival showpieces where Benjamin's aura can still get a good foothold [...] the low is again made high by the author's touch. ${ }^{14}$ By stark contrast, the traces encountered in provincial theatre archives are different creatures entirely.

Between the Beckett archive and the theatre archive is a tension between the insistence, in the latter, on the materiality (as opposed to textuality) of the theatre, and the act of reading, which is usually understood, in the Beckett archive, to involve the interpretation of playscripts and their authorial addenda. The theatre archive signals more strongly the non-textual, physical materiality and ephemerality of the raw theatrical event now vanished. One can, further, in the theatre archive's favour, refer to Beckett's own preference for the 'demented particulars' rather than grand synthesis, as is made clear in an entry in his German Diaries written in 1937. Here he writes ' $[\mathrm{w}]$ hat I want is the straws, flotsam, etc., 
15. Cited in James Knowlson, Damned to Fame: the Life of Samuel Beckett (London: Bloomsbury, 1996), p. 244 .

16. Andrew Sofer, 'Spectral Readings', Theatre Journal 64 (2012) - 323-36 (p.330).
17. Ric Knowles, Reading the Material Theatre (Cambridge: Cambridge University Press, 2004), p. 3 .

18. Knowles, Re the A There P. 53 . names, dates, births and deaths, because that is all I can know $[\ldots][\mathrm{T}]$ he pure incoherence of times and men and places is at least amusing. ${ }^{15}$ In such flotsam the undifferentiated mass of many regional theatre archives is particularly rich.

Andrew Sofer borrows the term 'dark matter' from physics - the 'secret ingredient that holds our world together', but whose existence can only be inferred - and translates it into theatrical terms. Theatrical 'dark matter' denotes 'the invisible dimension of theatre that usually escapes detection'. If theatre traffics by its nature in the corporeal, it also conjures the incorporeal, or invisible - 'offstage spaces and actions; absent or unrepresented characters; the narrated past', among others. ${ }^{16}$ Godot himself, an offstage presence, nowhere seen but everywhere intuited, is an obvious instance, but I want to extend this 'dark matter' into the conventionally invisible theatrical world of backstage theatre and discourses surrounding and supporting productions of Godot, invisible phenomena that nonetheless structure an audience's experience.

What remains in the archives of these lost early Godot productions is most often a scrappy, achronological matter of photographic stills, ephemera and prompt-books: a record of a lost material reality. Viewing Godot within the context of the theatrical archive allows for a greater cultural materialist emphasis on the conditions of production and reception that shape meaning and which do, in a sense, represent something of the unconscious of much theatre. The theatrical archive allows the Beckett scholar to see a Godot which, if not actually diminished by its status as one play among others, programmed between a new West End success and the Christmas musical, for which actors are cast, box office receipts taken and subsidies sought, is at least encountered in something of the crowded complexity of its various conditions of production and reception - within the unforeseen interstices among the different elements of what Ric Knowles dubs the 'hermeneutic triangle' of theatre: conditions of production, performance text and conditions of reception. ${ }^{17}$ Each element consists of complex and coded systems, working in concert or in tension with one another to produce whatever meaning the performance has for specific audiences. The traces of a 'worldlier' Godot in the theatre archive allow for a fuller understanding of the immediate conditions in and through which theatrical performances are produced, allowing for a broader reading of the material context of some Godot productions.

Knowles notes that the two topics of discussion most prominent backstage in green rooms and theatre bars - money and working conditions are as largely absent from the discourses of theatre criticism as audience amenities and the physical and discursive spaces through which audiences 'read' productions. ${ }^{18}$ One of the most significant things about an encounter with the theatrical archive is the extent to which this is rectified. Promptbooks, constructed during rehearsal to be used in performance for prompts, lighting cues and timings by the stage manager - the printed performance text usually annotated in pencil, with lines cut, additional movements, cues, dressing room calls for offstage actors - offer the most vivid single instance of how the traces of performance persist in the archive, of how performative writing, or rewriting, takes on lasting material form. If (at least in the period before routine video recording became 
19. Promptbook dated 30 May 1969. Godot's cast were Jeffrey Shankley, Des

Macnamara, Jonathan Mallard, Paul Henry (best known for playing Benny in a longrunning UK soap opera Crossroads) and Roderick Smith. The production was directed by Michael Simpson. Birmingham Repertory Theatre Archive (Birmingham Central Library). MS 978/2/6/165. Page references are to Waiting for Godot (London: Faber, 1965 ).
20. Promptbook for 1974/1975 Birmingham Repertory Theatre Studio Godot, Birmingham

Repertory Theatre archive (Birmingham Central Library). Page references are to Waiting for Godot (London: Faber, 1965). the norm) theatrical stills sell performance in the marketplace as press images by acting as a synecdoche for the live theatre which cannot be experienced otherwise, the promptbook is an embodied kind of document which inscribes the time-bound behaviours of actors' bodies and theatrical technologies.

A Birmingham Repertory Theatre Godot promptbook dated 30 May 1969 - perhaps put together by Jonathan Kemp, who is listed as stage manager in a handwritten cast list inside the book's cover - is typical in having text pages from the 1965 reprint of Faber and Faber's small-format paperback edition pasted on the verso, with the recto pages containing pencilled moves, diagrammed choreography, with occasional sketches of stage positions of the tramps in relation to one another, and the mound, a map of actorly and directorial work arrived at in rehearsal. ${ }^{19}$ The interventions in the performance text recorded by the stage manager are not extensive, in many cases constituting a minor alteration (Vladimir's 'Worse than the pantomime' is altered to 'Worse than the theatre' (p. 35); 'Sanctimonious cow' is added to Vladimir and Estragon's exchange of insults ( $\mathrm{p}$. 75)), there is the addition of a stage direction (when Pozzo says 'You took me for him', the pencilled instruction is 'Pozzo takes a step towards them'; and Lucky 'rises from sag' when Vladimir says 'How do I know?' and when Estragon says 'It's the chafing' (p. 25)). The most significant intervention is that Lucky's monologue has been cut significantly, and that the Boy, seated in the audience 'rises' at his 'Mister!', gradually makes his way to the foot of the stalls and onto the stage when Vladimir says 'Will you approach!', and is centre stage at 'You have a message from Mr Godot?' (p. 49) before making his exit again through the audience. In Act 2, it is specified that the Boy 'rises from C5' and 'goes onto stage at the left' (p. 91). A handwritten stage manager's document remains from a later production in 1974, under the headings Actors/Set/Props/Effects, breaking the two acts down, line by line, into significant movements, objects needed, light and sound effects: 'Boot business for Estragon'; 'Hat business for Vladimir'; instructions that the rope must be long enough to get Lucky to centre stage before Pozzo enters. Slight as they are, they allow the reanimation of a past performance, fleshing out rhythms and timings, showing us the play in production as palimpsest, subject to material exigencies and to continual rewriting. Different hands and inks or pencil suggest later, postrehearsal additions, or alterations during the run, showing us performance in process.

A promptbook for a later Birmingham Rep Godot (produced in the theatre's new studio space in 1974 and revived in 1975, the same promptbook serving for both) has far fewer textual alterations, Lucky's monologue is uncut, and virtually all of the annotations are lighting cues, calls for actors, giving front of house notice that it is five minutes to the interval when the Boy is being questioned about working for Godot ( $\mathrm{p}$. 51), and prop placements - during the interval, a reminder for the leaves to be added to the tree, and that the boots are to be downstage centre, the hat downstage right when the Act II curtain rises. ${ }^{20}$ Minor as these annotations are to the published playtext, reading these material echoes resembles eavesdropping on one side of a conversation, fragments of a 
21. Barbara Hodgdon, 'Material Remains at Play', Theatre Journal, 64. $(2012)_{\mathbf{2}} 373-88$, $(\mathrm{p}-374$.

22. $\mathrm{DD} / \mathrm{NP} / 2 / 1 / 298$. Nottingham Playhouse archive (Nottinghamshire Records Office).

23. DD $/ \mathrm{NP} / 2 / 1 / 298$. Nottingham Playhouse archive (Nottinghamshire Records Office).

24. Bert O. States, Great Reckonings in Little Rooms; On the

Phenomenology of Theatre (Berkeley: University of California Press, 1985), p.198.

25. Steedman, Dust, p.7.

26. Richard Schechner, Between Theatre and Anthropology (Philadelphia: University of Pennsylvania Press, 1985), pp. 36-37. larger narrative of performance process, intimations, almost of a theatrical unconscious, or what Barbara Hodgdon calls the 'the minority language of rehearsals', the unofficial seldom-seen jargon of backstage. These remains address the question of how live performance persists in the archive, leaving traces that, in this instance, make the unseen working conditions of the stage manager and backstage staff discernible - and the dark matter of theatre visible as industry. ${ }^{21}$

The promptbook for the Nottingham Playhouse's 1971 Waiting for Godot, starring Donal McCann, Peter O'Toole, Niall Toibin and Frank Middlemass, directed by Frederick Monnoyer, lists, as is typical, the precise timings of the curtains up and down for each act for each performance. $^{22}$ The final performance timings on the last page of the book are ornamented with a pencil sketch of the tramps and the tree, and a pencilled note: "The curtain falls on "Waiting for Godot" and Brian and Helen go on the dole again! (But not for long one hopes). Adieu and thank you. ${ }^{23}$ Brian and Helen are unidentified, but, as backstage staff though clearly not permanently employed by the Playhouse - inscribing themselves into a celebratory, valedictory moment in self-consciously, even mockingly theatrical language; here, they conjure up another curtain call that extends or exceeds the performance's run. This instance of the intrusion of the invisible 'industry' of the theatre into the performance's finale recalls Bert O. States's remark that the curtain call is 'a seam in social nature $[\ldots]$ a beginning and an ending, a return and farewell', a transitional moment where character disassembles in favour of actor, not quite performance, not quite non-performance. ${ }^{24}$ The author of the promptbook is similarly inside and outside the theatrical frame. Carolyn Steedman, reading Derrida, notes that the grammatical tense of the archive is "the future perfect - "when it will have been", a record of what is past that nonetheless gestures towards the future'. ${ }^{25}$ Time is endemic to Godot, locked into the play's structure, the fathomless; repetitive days and the tramps' vain attempts at killing time. As a playscript is ripe for repetition in the sense of re-staging (in Richard Schechner's wellknown claim, '[p] erformance means [...] twice-behaved behaviour ${ }^{26}$ ), the promptbook, the archival remains of intervention into the performance text, always, ironically, gestures towards future performances, which is particularly germane to this play in which 'nothing happens, twice'.

Godot's obsession with time is, further, ironically mirrored in the promptbook's obsession with precise timings, regulatory mechanisms, prompting, and the exact picking up of cues by actors, sound and lighting technicians, and stage hands. It is the stage manager, the end user of the promptbook, who assumes responsibility for the regulatory and managerial running of rehearsal and performance, in the ironic position of policing the correctness of the run of an experimental play such as Godot, hailed as reinventing drama, but not necessarily the theatrical system in which it was produced.

Typed loose sheets inserted into the 1974/75 Godot promptbook - a hole-punched text in a ring-binder - demonstrate an invisible policing system regulating the run. These consist of stage manager's reports, handwritten on typed standard forms, one per performance. As well as 
27. Stage Manager's report of

10 March 1975

inserted into prompt-

book for 1974/1975

Birmingham

Repertory Theatre

Studio Godot

(Birmingham

Repertory Theatre archive)

28. Stage Manager's report of

19 March 1975 and

26 March 1975

inserted into prompt-

book for 1974/1975

Birmingham

Repertory Theatre

Studio Godot

(Birmingham

Repertory Theatre

archive). noting exact timings for both acts and interval, and brief remarks on the size, lateness or responsiveness of the audience, they are also a record of late entrances, fluffed lines, missed cues and props, and scenery and technical malfunctions: a typical entry in the 'notes' on the show report form for the revival on 10 March 1975 reads:

Cork in bottle broke. Lucky took bottle off. Lucky's hat came off again during the speech, Mr Smith [the actor playing Estragon] replaced it, and Lucky wound up again to continue speech but unfortunately the hat came off again. A lot of lines cut short especially during Act Two. Dropped hat during swapping session in Act Two. Pretty deadly audience. ${ }^{27}$

In some notes the tone is wry and collegial - 'Stool broke after kick. Everybody corpsed but the audience were very good. "I weakened a little towards the end. You didn't notice?" caused a general outbreak again' or 'Mr Poyser's [the actor playing Pozzo] description of the audience "Another lot from rent a corpse" 28 - in others a more obviously authoritarian tone, perhaps with the aim of maintaining discipline and continuity throughout the run, as when John Savident, playing Pozzo in the 1974 run, is repeatedly noted as having gone on 'without a collar or tie' due to an error by Wardrobe, or the litany of missed cues and late entrances. The imposition on Godot of this quasi-managerial discourse borrowed from the world of business and management sits oddly with the highly patterned but ungoverned world of the play, but looks back to the strictly regulated world of the lower end of repertory theatre in the 1950s. John Osborne, who joined one of Harry Hanson's squad of companies, the Court Players at the Palace Theatre, Camberwell, in the early 1950s, wrote that Hanson's companies 'were dreaded as the last funk hole for any actor':

Fluffs and dries were entered into a book by the stage director and other misdemeanours, if committed enough times, ensured the sack, administered literally according to the Hanson Book. He was the theatre's Gradgrind and his theatres were administered like workhouses of despair ... [t]he company were docile, like prisoners without heart or spirit. [...] We committed our lines as if we were sewing mailbags. No one dared fudge them or forget a move. ${ }^{29}$

Something of this recognition of the power dynamics possible within certain theatre systems inheres in Beckett's dramatic vision of compulsory performance and ill-learnt lines as pensum stammered out by resigned, unpersonable actors for a demanding, dissatisfied audience, culminating in his conception of theatre as totalitarian regime in Catastrophe (1982). For all Catastrophe's origins in Beckett's sympathy for the imprisoned Czech playwright Václav Havel, its vision of a director and assistant mercilessly manipulating the body of a mute and largely dehumanised actor disconcertingly evokes the Foucauldian docile bodies of 'theatre's Gradgrind' and the tightly regulated surveillance of some elements at least of the repertory system. The theatre archive's Godot here shows the 'wrong side' of the theatrical weave, making the circumambient theatre industry more 
30. Letter from Braham Murray to Michael Anderson, London Artists Ltd,

21 January 1967. DE $5067 / 4 / 1$. Century Mobile Theatre archive (Leicestershire Records Office).

31. Magaret Ramsay Ltd, Repertory List, DE 5067/4/1 (Century Mobile Theatre archive).

32. Hughes Massie Copyright Agents, Repertory List, DE 5067/4/1 (Century Mobile Theatre archive). visible than the play, which emerges only in the interstices of prop lists and timings.

\section{Century Mobile Theatre's Godot}

Century Mobile Theatre's 1967 Godot - the only play in the theatre's repertory to be presented both in the theatre's winter season at the Manchester University Theatre and on its Bowness-WindermereKeswick summer touring circuit in 1967 - figures in the theatre's archive, uncatalogued and partial, held at the Leicestershire County Records Office, less as aesthetic object, or performance text than as a reliable financial property or as a single play within a crowded repertory season. Century Theatre was a mobile touring company which initially operated out of Hinckley in Leicestershire from 1952 on four ex-military trailers pulled by a tractor and setting up a 200 -seater theatre in parks, recreation grounds and bombsites; later it ran seasons at the University Theatre, Manchester and summer tours of the north-west, with longer stops in Cumbria. However, despite the touring, and Century's cooperative ethos - it had no board of directors, and all employees were shareholders in the limited company - this was a traditional repertory scenario, as evidenced by a January 1967 letter from the artistic director Braham Murray to the actors' agency London Artists Ltd, asking it to set up auditions for a cast for the coming season: Godot features on the provisional list of plays from which auditioning actors are asked to prepare audition pieces. ${ }^{30}$ In the same bundle is a 1958 repertory list from Margaret Ramsay Ltd (Repertory and Amateur Department), London WC2, listing plays to be released for repertory production at the end of its London runs - Relatively Speaking by Alan Ayckbourn and Spring and Port Wine by Bill Naughton - and listing 'London and New York successes, together with prizes won, which theatre they were currently running at, numbers of juvenile, male and female actors required, and the number of sets'. ${ }^{31}$ A similar document from Hughes Massie, Copyright Agents, London WCl, offers licensing for 'plays by promising new authors' if any repertory company 'likes to vary its season with an occasional new play [...] A preference between comedy, drama, thriller, etc. should be indicated, together with the cast available and some note of scenic possibilities'. ${ }^{32}$ Most repertory theatres could simply not afford to produce significant amounts of experimental work unless it was also sensational or had sufficiently broad popular appeal to draw crowds in an increasingly competitive theatrical marketplace - Godot, despite its aura of 'difficulty' could do both; it was cheap to stage, and came with proven West End marketability. This in some sense explains its relative popularity as a programming choice, as it moved seamlessly from 'new play' to 'modern classic' status within the repertory system.

The 'work' of production surrounding the play as it was toured by Century emerges strongly in one of the other most obvious elements of the Century archive; a series of letters and postcards about props - chiefly missing boots, wigs, a beard originally intended for Lucky but discarded as unworkable in rehearsal, and Pozzo's fob watch, which Century failed 
33. Unsigned letter from Century's Stage Manager to Bapty and Co., London, 19 June 1967. DE 5067/4/1 (Century Mobile Theatre archive).

34. Andrew Sofer 'Spectral Readings', p. 324 .

35. Alice Rayner, 'Presenting Objects, Presenting Things', in Staging Philosophy: Intersections of Theatre, Performance and Philosophy, ed. by David Krasner and David Z. Salts (Ann Arbor: University of Michigan Press, 2006), pp.180-202 (p.181).

36. Birmingham Repertory Theatre Studio Waiting for Godot promptbook, 27 March 1974/ 19 March 1975 (Birmingham Central Library).

37. Box Office Takings, DE $50672 / 5$. The takings show clearly how much of a shoestring operation Century was - on 21 July Godot took 10 pounds 11 shillings, on 22 July 1967, 18 pounds and 3 shillings, rising to a height of 33 pounds, 15 shillings and 6 pence on 4 August (Century Mobile Theatre archive). to return to the hire company, all pursued by a series of increasingly irate letters from London suppliers addressed to a field in the Lake District. ${ }^{33}$ Weather-beaten and difficult to read, these communications materially construct Godot around its paradigmatic central objects - and script the behaviours of stage managers, dressers and props masters, making invisible labour visible. A determinedly anti-naturalistic modernist play, when evoked via its vanished props, can suggest the ways in which drama however opposed to the 'fourth-wall' realism Beckett considered egregiously conservative and conventional - bears a distinct and intimate relation to material reality. In the theatre, for Andrew Sofer, we are arrested by things, not codes; '[n]ot unlike a Star Trek transporter accident, theory dematerialises theatrical matter and never reconstitutes it quite as it was before'. ${ }^{34}$ For Alice Rayner, 'stage props, as paradigmatic objects, constitute the worldliness of the stage [...] properties in all senses, they give their material attributes to an otherwise empty space and in turn populate that space' ${ }^{35}$ As such, the theatre archive is inscribed with the concrete materiality of all these vanished props, for instance, the so-called 'expendables' that needed to be replaced or replenished for each performance (in the Birmingham Rep Studio's 1974/75 Godot, these were 'Tabacco [sic]; England's Glory matches; turnips; carrots; chicken; burnt sugar for wine' ${ }^{36}$ An invisible agency rather like a theatre props master eternally resupplies Winnie with her necessaries in Happy Days (1961), as her burnt parasol and broken mirror are magically replaced for each new 'happy day'. Here, material theatrical practice informs Beckett's vision; the repeatability of the theatrical run, the caretaking function of the invisible backstage functionaries, the predicament of an actor trapped in an uncongenial role, are literalised and made metaphors for 'going on.'. Similarly, the rematerialisation of Godot's objects reminds us of the quality of 'thereness', of visibility, that initially attracted Beckett to the theatre, even as he immediately worked to subvert it.

The Century Godot also becomes visible in the archive as a financial property. Godot featured prominently in its ambitious repertoire for years, perhaps for the same, practical as well as aesthetic, reasons that made it appeal to Roger Blin in Paris in 1952; its small cast, simple set and rudimentary props. Its box office takings are documented on daily receipts, down to the takings from ice creams and programmes; in the 1967 season, which is best documented in the Century archive, Godot outperforms Synge's Playboy of the Western World and Noel Coward's Private Lives in the winter/spring season at Manchester University by some way, but, while it does better than David Halliwell's Little Malcolm and his Struggle Against the Eunuchs, on the Cumbrian summer season, it is significantly outperformed by Edward Albee's Who's Afraid of Virginia Woolf? and Richard Brinsley Sheridan's The Rivals. ${ }^{37}$

More striking than the box office takings, however, is Godot's emergence as a theatrical property within a system that was, by the late 1960s, heavily reliant on Arts Council subsidies. Fraught Arts Council correspondence figures often within the archive; a letter of 11 April 1967 from Stephen Croft, a drama officer at the Arts Council, replying to a request from Braham Murray, its artistic director, for an extra $£ 5000$ - Century had been funded in the season ending April 1968 to the tune of 
38. Letter from Stephen Croft to Braham Murray,

11 April 1967. DE 5067 2/5 (Century Mobile Theatre archive).

39. Braham Murray, letter to J. Hodgkinson of 3 June 1967. DE 5067 2/5 (Century Mobile Theatre archive). In 1968 he set up the 69 Theatre Company at the University of Manchester where they produced plays until 1972, then The Tent inside the Royal Exchange, which would become the Royal Exchange Theatre. See Braham Murray, The Worst It Can Be is a Disaster (London: Methuen, 2007).

40. David Bradby, Beckett's Waiting for Godot (Cambridge: Cambridge University Press, 2001), p. 68.

41. Nottingham Playhouse programmes. DD/2706/ 3 (Nottingham Playhouse archive)
$£ 30,500$ - says that he will attend Century's Council of Management meeting and asks that two seats for Godot at the Manchester University Theatre be kept for him on the previous night. ${ }^{38}$ The appeal was ultimately unsuccessful; just after the end of the Godot run, a resignation letter from Braham Murray to the Drama Director of the Arts Council, offered as a reason for his resignation that the 'odds are pretty hopeless' and that the 'reorganisation and the money we need are beyond your powers at the moment'. ${ }^{39}$ The Godot of the Century Theatre archive emerges, even in the context of a cooperative touring theatre company, as a play situated within the framing discourses of public funding. Far, by the end of the 1960s, from the 'avant-garde play of dubious Franco-Irish origins' that the Arts Council refused to support when it was in search of a London theatre in 1954, Godot nonetheless finds itself inscribed inside a system increasingly dependent on such funding. ${ }^{40}$

\section{Ephemera}

A series of Godot productions at the Nottingham Playhouse is interesting to consider in terms of theatrical ephemera's proscenial role and its alterations over roughly the first 25 years of Godot's production history. The Nottingham Playhouse had productions of Waiting for Godot in 1957, 1962, 1971 and a 1983 co-production with the York Theatre Royal. The 1957 and 1962 productions have the standard sixpenny programme of the repertory theatres of their day. ${ }^{41}$ Typically, in the 1950s, programmes were flimsy documents containing little beyond cast, order of scenes, producers and suppliers of props. Their standardised format, with the theatre logo, and listings of regular cast and crew more prominent by far than the name of the play, literalises the sense of the loyal regular audience of a successful repertory company such as the Nottingham Playhouse. The demise of the first night curtain speech over the course of the 1950s - a practice that saw the author literally on stage, addressing the audience - the programme increasingly became prominent as it began to hold commentary by the writer, contextual information to aid the audience's understanding, appreciations by director or designer, and so gradually became a document designed to shape the audience's understanding of the play.

We can see this in action within the Nottingham Playhouse archival ephemera. Initially, in the 1957 programme, there is no place at all for the author, who is conspicuous by his absence; instead, the theatrical experience is firmly embedded in the ongoing life of a provincial repertory theatre of the late 1950s and its surrounding civic culture, which is manifest in the copious local advertising in the programmes. Again, this shows Godot as an economic process; the play is part of a theatrical economy, generating revenue and requiring advertising, pulling in paying audiences or not. In both the 1957 and 1962 programmes, the majority of space is given over to advertising for local businesses; the play is perhaps the least prominent element of the programme text. Advertising in theatre programmes, often ignored, is a sightline into the economic and cultural life of a theatre and a city; as well as the inevitable cigarette 
42. Programmes for Nottingham Playhouse's 1957 and 1962 productions of Waiting for Godot, DD $/ 2706 / 3$ (Nottingham Playhouse archive).
43. Press cuttings book 1956-57 season. DD NP 2/4 (Nottingham Playhouse archive).

44. Nottingham Evening News 'Around the Theatres',

23 July 1957. Press cuttings book 1956-

57 season. DD NP 2

4 (Nottingham

Playhouse archive). advertisements ('Deliciously mild Puria tipped - 10 for 1'7d'); there are ads for the Moulin Rouge restaurant, Trinity Square ('Parties catered for a modest inclusive charge'); the AK Austin garage on Mapperly Road and the local Co-operative Film Society). ${ }^{42}$ The presence of the board of the Trust which oversaw the running of the Nottingham Playhouse and other similar theatres - often made up of local community leaders and business owners - comes into view as another corollary to the play, setting up potential tensions between aesthetic risk or social critique and adherence to certain moral or financial standards.

In the considerable pre-publicity of the local newspapers, presented in the press cuttings books kept in the Nottingham Playhouse archive, there is the acknowledgement that the 1957 Godot was controversial when staged at the Arts Theatre club in London two years earlier, but the effect is muted and altered, domesticated to its specific local context, by announcements of the other plays surrounding it in that season's programming - ranging from Peter Ustinoff's Romanov and Juliet (Ustinoff had just become an associate artist of the Playhouse), and Noel Coward's South Sea Bubble to Wycherley's The Country Wife and a thriller, Murder Without Crime - announcements in the local press of a new actor joining the repertory company for the summer season, the acknowledgement that the local College for the Blind has lent the production Pozzo's basket, and the announcement that Godot will be the final production of John Harrison, the departing director of productions at the Playhouse whose farewell is included in the Godot programme. ${ }^{43}$

The local press notes that, on the last night, while the character of Godot never arrived - still in 1957 a matter that was noted by reviewers John Williatt, chairman of the Nottingham Theatres Trust, appeared on stage with the actors to give a speech praising Harrison, the departing director. Here, when the long-expected figure appeared, at the end of the 1957 Nottingham Playhouse run, Godot was in fact a local theatre board member, breaking the 'frame' of the proscenium arch by representing on stage the civic mechanisms at work in the theatre. The effect was in essence to defuse what was obviously still considerable audience puzzlement at the play by retrospectively recasting Godot as the 'difficult' swansong of a popular departing director of productions. That Godot was scheduled for a single week only, polite reviews that largely avoided discussing the play and confined themselves to praising the cast's performances and Voytek's set (the Nottingham Evening News reviewer opined that Mr Beckett had 'gone around a mental ward to collect some of the speeches', but commended Raymond Lee's performance as the Boy as 'charming, ${ }^{44}$ ), and the obvious mismatch between the actors of a traditional repertory company and the all-male casting requirements of Godot, all suggest interpretative problems for companies that hadn't as yet quite solved the tensions between a loyal local repertory audience and its expectations, the pragmatics of marketing and avant-garde drama.

In the Nottingham Playhouse Godot ephemera, it is possible to see a work undergoing a process of assimilation at a time when theatrical ephemera itself was undergoing a period of transition. The 1962 production had a programme with more acknowledgement of the play as a phenomenon and discussion piece, a brief paragraph on the first page 
45. Programme note, 1962 NP Godot. DD/ $\mathrm{NP} / 1 / 5 / 2 / 137$ Nottingham Playhouse archive)
46. Gareth Lloyd Evans, 'National Provincial', Guardian Arts (18 October 1962). DD NP $2 / 4$

(Nottingham Playhouse archive)

47. The Guardian Journa (27 November 1962). Nottingham Playhouse press cuttings book 1962-63. DD NP $2 / 4$

(Nottingham Playhouse archive)

48. Programme of the 1983 Nottingham Playhouse-York Theatre Royal Godot. DDNP 2/1/299 (Nottingham Playhouse archive).

49. Alice Rayner 'Presenting Objects, Presenting Things', p. 181 engaging with the initial London audience's reactions, now eight years in the past, while acknowledging that 'Beckett's popular successors, Pinter and Simpson, have made it easier for present-day audiences to understand Godot ${ }^{45}$ The press cuttings, archived alongside the programmes make it plain that the 1962 Nottingham Playhouse Godot was received in terms of a contemporary debate raging about the new National Theatre and its relationship to provincial theatre, and the fear that the new London theatre would divert resources, human and financial, from the provinces. A press cutting pasted alongside theatrical stills of Godot argues that

it is precisely because a good deal of the vitality of theatre lies outside of the metropolis that the second factor is so ironic, dangerous and incipiently depressing $[\ldots]$ the myth that you can only find good theatre in London, and that any playwright or actor is not proved until, like Dick Whittington, he shakes the provincial mud off his shoes and makes his pile in London. ${ }^{46}$

There is also press coverage of the actors doing somewhat anomalous publicity, posing in full costume on the street, perhaps because Godot was again only staged for a week as a late interpolation because the schedule of the theatre needed to be rearranged after the actor Daniel Massey had to leave for 'an important TV engagement' (likely to have been his appearance in the ITV Play For the Week Under Western Eyes), cutting an Osborne/Waterhouse double bill from its planned run of three weeks to two. ${ }^{47}$ Godot was to be followed by a modern Welsh comedy, Gwyn Thomas's The Keep (a London transfer from the Royal Court), and then the musical Salad Days, that year's Christmas show. Godot in repertory, far from sweeping away the theatrical status quo, would continue to rub shoulders with comic and verse plays, Victorian melodrama, social realism, European classics in translation, Shakespeare, Restoration comedy and the Christmas pantomime.

Nothing of this local cultural specificity remains in the programme of the 1983 Gregory Doran-directed Nottingham Playhouse coproduction with York Theatre Royal, perhaps in part because it was a co-production between Nottingham and York theatres. ${ }^{48}$ The modern theatre programme has been born, with a knowing sense of its own style as an aesthetic and interpretative object. One of Jane Brown's iconic photographs of Beckett fronts the programme, which clearly now costs considerably more than sixpence, but the image is knowingly tampered with; clown's make-up scribbled on, graffiti-style, in red pen, as is the title of the play - suggesting a fresh, irreverent approach to a text that has now achieved sufficient status as a classic to elicit a certain qualified impertinence and to require a new approach. Although it aspires to invisibility, the programme can subtly carry considerable ideological weight, and, as a central component of the traces of Godot in the theatre archive, such 'stuff' can throw light on the economic and cultural relations of production, audience construction and reception, and the material conditions of performance. Like stage props, they indicate 'the worldliness of the stage'. 49 
I have tried in this article to suggest that the different, less obviously 'valuable' holdings of regional theatre archives can add substance to a more materially minded or 'worldly' production history of Godot, in considering the possibilities both of rendering visible the 'dark matter' of the playhouse, and of reading in archival traces elements of the nontextual materiality of long-past performance. This essay has sketched briefly, how, from the traces left by early Godots in provincial theatre archives, we can see some of the ways in which conventionally invisible factors frame, contain and contribute to the ways in which audiences understand theatrical productions. The offstage figure of Godot himself, a dramatic trope of felt absence, acts as a figure for the impact of ghost presences - the circumambient discourses of funding, publicity, backstage work, the rehearsal room - whose substance, nonetheless, constitutes a carapace around the play, and the ghosts of long-vanished props and bodily movements in a concrete stage space, whose traces persist in the archive. The matter which persists in the records of regional Godots - the messy or insignificant 'stuff' of theatre - registers the way in which conventionally disregarded elements of theatre set unstable, experimental, 680 politicised meanings in motion.

\section{ORCID}

Sinéad Mooney (D) http://orcid.org/0000-0001-8055-6292 


\title{
Beckett and Darkness: The Drive to and the Flight from...
}

\author{
Andrew Lennon
}

1. Billie Whitelaw, 'Introduction to Not $I$, in $A$ Wake for Sam, $B B C, 10$ January $2013_{2}$ Available at: <https://www.you tube.com/watch?v= M4LDwfKxr-M> [accessed 1 March 2016].

2. Linda Simon, Dark Light: Electricity and Anxiety from the Telegraph to the X-Ray (Orlando, FL: Harcourt Books, 2004).

3. Ibid., p-2.

The reactions of audiences to intense blackouts during some of Samuel Beckett's short plays have been noted since Billie Whitelaw recalled spectators attempting to flee the auditorium during her 1973 performance of Not I (1973). ${ }^{1}$ Similar responses, aligned to the conditions of complete darkness, are still produced in audiences over 40 years later, and they are the focus of this discussion. By highlighting the creation of intense blackout, how it can provoke such reactions, and an alternative form of darkness in Beckettian theatre, the aim is to elucidate links between the conditions that spectators endure, and Beckett's work. The conditions of complete darkness are the result of a withholding of illumination, so my discussion begins with some considerations of the impact of light.

In her monograph Dark Light, Linda Simon charts the fluctuating social anxiety surrounding the advent of electricity in the second half of the nineteenth century. ${ }^{2}$ The book considers the wide-ranging impact of electrification, from the domestic light bulb to electro-shock therapy. It culminates with the development of X-ray technology, pioneered by Wilhelm Röntgen's 1895 print of his wife's hand. Röntgen's image demonstrated how the unseen light of X-ray technology makes visible that which is imperceptible. Simon's broad discussion suggests that beyond simply illuminating 'public and private spaces', at that time light 'implied moral illumination', and encouraged an enlightenment 'of the spirit and the mind'. ${ }^{3}$

Luigi Manzotti's 1881 La Scala staging of Excelsior is cited by Simon as an example of the cultural encouragement to support these technological innovations. Manzotti's ballet depicts the character of Light defeating Obscurantism (or Darkness, as it is varyingly referred to) for the advancement of other allegorical characters, such as Civilisation, Peace, and Cosmopolitanism. After opening to wide acclaim in Milan, Excelsior toured Europe and the Americas extensively before returning to Paris to coincide with the Universal Exhibition of 1889. According to Alan 
4. Alan Riding, 'Arts Abroad', New York Times, 15 January 2002 <http://www nytimes.com/2002/ $01 / 15 /$ arts /artsabroad-in-an-1881-ba let-optimism-as-itused-to-be.html> [accessed 24 November 2015].

5. George Dorris, 'Review: Two Balletic Sensations: Excelsior and the Ballet of the Nuns', Dance Chronicle- 23.3 (2000) $\overline{2}$ 329-37 (p. $330)$.

6. Simon, Dark Light, $\mathrm{p}$. 271
7. Martin Welton, 'The Possibility of Darkness: Blackout and Shadow in Chris Goode's Who You Are', Theatre Research

International, 38.3 (March 2013) $4-19$.

8. The light we can see is also limited to what wavelengths have been reflected into our eyes after other various wavelengths of colour have been absorbed by the surface they strike. Therefore, the reflection of the red wavelength of light into the auditorium means we see red lips on stage as red.

9. Welton, 'The Possibility of Darkness', p. 5 .
Riding, the production 'spoke for an era', ${ }^{4}$ against the backdrop of what George Dorris defined as 'a celebration of Positivism, showing the advances that mankind was making through science and industry'. Simon's description of Excelsior gives a sense of the dramatic intention of the La Scala production:

The spirit of Darkness lurks in the corners of each scene, awaiting an opportunity to wreak havoc [...] but Light manages to triumph, and in the end engulfs Darkness and all that it represents; ignorance, barbarism, ruthlessness, and death. Light will unite the warring countries of the world, light will bring peace and tolerance, light will bring endless prosperity. ${ }^{6}$

Although these claims are hyperbolic articulations of what light could grant the contemporary spheres of social cohesion and economic growth, they do perhaps give an insight into the potential of human progress observed at the time, and the near-endless possibilities imagined in a world at the turn of electrification. The lofty assertions of Excelsior's personified light have, to a degree, been attributed in the present day to natural light. In his article 'The Possibility of Darkness', Martin Welton discusses the British Parliament's 2010 Daylight Saving Bill debate on the benefits of an additional hour in the United Kingdom's time zone, so daylight stretches longer into winter evenings. ${ }^{7}$ Although somewhat less utopian than the claims of Excelsior, Ministers argued that the benefits would significantly improve the quality of national life, leading to reductions in road traffic accidents, crime, and obesity, while boosting the economic and cultural landscape.

Simon's and Welton's examples hint at the notion that light is endowed with a unique, civilising and pervading sense of order, that will encourage individuals and communities to prosper. However, such attributes are not innate to light. They are presumed to be results of the presence of light, which itself is only determinable from the traces of that which it illuminates. Light itself is not something we actually see. We see in light, but we do not see light itself. When in the theatre you observe a beam of light striking the stage, and its shaft travelling overhead, you are actually seeing the result of heated photic energy (photons) reflecting and refracting via multitudes of tiny particles in the air. ${ }^{8}$ Whether X-ray light, or daylight, illumination is a process of invisible energy rendering visible form. Equally important, though, for the purposes of this study, is the notion that we can still see in the dark, albeit what we see is the absence of light. As Welton suggests, this inverted act of vision distorts the position of object and viewer through a displacement of distance and focal point:

Seeing in the light (or at least doing so clearly) demands a necessary distance between the eye and the object it regards [...]. By contrast, the visual experience of darkness is one of proximity. It is right there in front of you, and the pleasures and terrors of the dark surely rest on the collapse of distance as result. ${ }^{9}$

The collapse of distance is taken forward in this article, via what are termed excesses of darkness in recent productions of some of Samuel 
10. For broader discussions on contemporary practice that foregrounds darkness and the limitation of light, see Theatre in the Dark: Shadow, Gloom and Blackout in Contemporary Theatre, ed. by Adam Alsten and Martin Welten (London: Bloomsbury, 2017).

11. Not I, Rockaby, Footfalls, dir. Walter Asmus, viewed when touring to

the Birmingham Rep Studio, Birmingham, UK, $16-20$ September 2014

12. Beckett's Ghosts: That Time, A Piece of Monologue, Breath and Not I, dir. Jason Byrne, Amanda Coogan, and Jimmy Fay, Project Arts Centre, Dublin, 13 22 April 2006

13. All That Fall, dir. Max Stafford Clark, St. Michael's College, Enniskillen, 22 July 2 August 2015.

14. It can be cited in var ious forms from numerous works such as Play, That Time Footfalls, Rockaby, and Obio Impromptu.

15. David Addyman, 'Rest of Stage in Darkness: Beckett, his Directors, and Place', Samuel Beckett Today / Aujourd'bui, 22 $(2010)_{2} 301-14(\mathrm{p}$. 312)

16. The reference to the Foucauldian common locus is Addyman's, as he discusses the tension between the indefinable or ambiguous nature of the Beckettian narrative space and the real physical space which is increasingly hidden.
Beckett's short plays. This discussion focuses on particular moments of blackout which bring into collision (literally in some cases) notions of spectator vulnerability with audience cohesion. The desire for absolute blackout in some productions, this turn (or return) to darkness, is popular in performance beyond the dramaticules and radio plays of Beckett, but this is not a broad study of such work, though common issues may also be identified. ${ }^{10}$

This investigation foregrounds three case studies; the Royal Court's 2014 production of Not I, Footfalls (1976), and Rockaby (1982) performed by Lisa Dwan; ${ }^{11}$ a 2006 performance of four short plays entitled Beckett's Ghosts by Bedrock Productions at Dublin's Project Arts Centre; ${ }^{12}$ and Out of Joint's All That Fall (1957) at the Enniskillen Happy Days Festival 2015. ${ }^{13}$ Having attended these productions, my study is focused on how they created their blackouts, the experience of their darkened environs, and the reactions they produced. The first two case studies achieved a complete darkness that is not always accomplished, and produced in audience members reactions that are of note to this study. The third case study is distinct because its darkness was generated through the blindfolding of audience members, and is employed in this study as an innovative counterpoint to the total blackouts utilised in the first two examples. This discussion will suggest how darkness as part of a Beckettian aesthetic does not limit communication, but rather can reveal new considerations of the performance space, of the self, and of Beckett's work. By investigating the precise limitation of light in the context of these productions, I will argue that the making invisible of the entire performance space (that extends to the designated area for an audience) can elicit a physical, emotional, and psychological response in the spectator. By withholding light, and not directing it, these productions in different ways, make aspects of that which is invisible, visible.

\section{Harnessing Darkness}

The precise manipulation of light is a prerequisite in many of Beckett's dramas and his own vision for the production of his work. From the constrained illumination of Mouth in Not I (alongside the almost imperceptible Auditor), or the detailed lighting cues and levels prescribed in the exhaling flow of Breath (1969), to the staccato photic violence of Play (1963), various processes of light limitation offer nuanced potentials to examine the resultant excesses of darkness. David Addyman notes that 'rest of stage in darkness' is a repetitive Beckettian direction that suggests a disappearance of the stage itself. ${ }^{14}$ For Addyman, this problematises the notion of the stage as a literal place - firstly because its narrative space often 'defies imagination', and secondly, because the physical space is increasingly made to vanish. ${ }^{15}$ Distilling this problem by arguing that darkness is not the same as placelessness, Addyman states that the attempt to disappear the common locus of the stage is thwarted both by its persistent physical presence, and by Beckett's penchant for discussing and remembering place linguistically and aesthetically. ${ }^{16}$ Summarising this tension in Beckett's 
17. Addyman, 'Rest of Stage in Darkness', $\mathrm{p}$. 312. Emphasis in original.
18. Herbert Blau, To All Apperances: Ideology and Performance, (London: Routledge, 1992), p. 55. The culmination of this sen tence in Blau is, 'of the drama of Chekhov'. I have chosen to edit this out to avoid confusion, but to clarify,

Blau drew into relation Chekhov and Beckett to demonstrate their work urges individuals, in Blau's terms, to think better than they do (Chekhov), and think better than they can (Beckett).

19. S.E. Gontarski, 'Introduction:

Towards a

Minoritarian Criticism

- The Question We

Ask', in The Edinburgh

Companion to Samuel Beckett and the Arts,

ed. by S.E. Gontarski

(Edinburgh:

Edinburgh University

Press, 2014), pp. 1-13

(p.10).

20. Welton, 'The

Possibility of

Darkness', p. 5 aesthetic, Addyman resolves that 'the repetition of this stage direction, which is after all an attempt to abolish the stage and the theatre - to void them - underlines that the negation of place has to take place in some place - upon the stage'. ${ }^{17}$

The generating of complete and prolonged darkness in productions enables a broadening of the confines of this tension, beyond the physically framed or spatially articulated stage, to encompass the space of the spectator. Under such conditions, Addyman's concept of Beckett's attempt at a negation of location takes place in the whole performance space, as opposed to only upon the stage. Therefore, by examining contemporary productions in consideration of the collapse of this separation of stage and auditorium, via Welton's assertion of the collapse of distance that darkness creates, we may engage new ways to perceive the whole performance space within a Beckettian aesthetic. The productions discussed in this article enable an acute questioning of Beckett's writings as potentially part of a rejection of this divide, and arguably hypothesise a common locus that is not physically bound by a stage area. Herbert Blau hinted at Beckett's originality in the act of negation when he stated that 'Beckett's practice occurred, with a certain virtuosity, in the space left empty, the precipitous silences'. ${ }^{18}$

The disappearance or making invisible of the stage area can be described as an activation of darkness. It is not simply a negative result of the lack of light, but rather a precise withholding of illumination; a harnessing of darkness that registers with an audience. This withholding of light in Beckettian theatre arguably confronts the spectator with an uncanny sense of nothingness, much like some of Beckett's protagonists. Of particular interest for this study are responses to the various environments produced through practices that withhold light. This involves questioning how excessive darkness might spark a sense of fragility within a spectator plunged into complete blackout, or ignite a kind of cohesion between spectators as a community of individuals, facing a void of Beckett's creation. A 'community of individuals' is the term I offer for moments when visual traces of the collective audience body are not present, and individuals can only reference their own presence within these darkened experiences. Patrons are obviously aware they are not alone in the auditorium; however, such assurance is diminished in prolonged blackouts when one cannot locate a visual sign for their own body, let alone those of fellow spectators.

The experience of excessive darkness is about more than the conditions of physical blackout. It concerns what occurs unseen in such darkened moments, and what is seen, felt or thought by individuals in the nothingness. This drawing together of the visual and the psycho-emotive is arguably present in Beckett's oft-cited emphasis that he was less concerned with the intelligibility of Mouth's words in Not $I$, and instead striving for 'a piece that may work on the nerves of the audience, not its intellect'. '9 Welton's crisp assertion that 'what and how one sees is not entirely separate from what and how one feels' similarly draws in sensorial and emotive responses to visual stimuli. ${ }^{20}$ Therefore, the practical issue of what and how we see requires explanation in productions that employ an excess of darkness. 
Closing one's eyes is the avoidance of the act of seeing - as well as an individual choice, which must also be taken into consideration. Being blindfolded (which has its own peculiarities, as I will discuss later) is the act of being made to not see, when seeing is possible. Complete blackout can be taken as the removal of all possibility of visual signs; however, even in such conditions one is still seeing, but observes that there is nothing to see, or, only nothingness to be seen. ${ }^{21}$ Moreover, in an environment of complete blackout, one may be seeing in a keener sense than if there was some light polluting the dark, as instincts of self-preservation attempt to physically situate the body within such conditions. Stanton B. Garner Jr. contends that the 'sheer predominance' of darkness in Beckett's late plays, such as Not I and Rockaby, enables it to acquire 'a pressing visual weight', as it 'frames illumination'. 22 However, in protracted moments of complete darkness there is no contrast with illumination to make that distinction between an area of focus and a surrounding void. The 'weight' of such darkness is due to the excessive nature of its totality.

Tracing an excess of darkness as also an excess of nothingness, draws focus to a kinship between minimalist art of the late 1960s and Beckett's short prose. This is a connection elucidated by Lucy Bell, who argues that Beckett's increasingly pared-down linguistic style retains an 'irreducible residue' that 'always-already lies beyond interpretation, beyond meaning, beyond theory': ${ }^{23}$

His [Beckett's] works communicate precisely in their refusal of communication, denotation and meaning: through their inherent excess. Because their lack of communication is also an excess over communication, they are conditioned by the paradox of minimalism, encapsulated by Ludwig Mies van der Rohe's famous motto: 'less is more'. ${ }^{24}$

Developing this train of thought within the tangible environs of the theatre, there can be no greater less than nothingness, but no more darkness than complete blackout. The achievement of such blackouts is not easily established (as discussed below), yet it engulfs spectators so completely that their focus can turn almost completely inwards. The only perceptible boundaries for spectators in such conditions are those that can be felt, the materials which bound up bodies, such as skin, clothing fabric, and the chair in which they sit. Witnessing reactions to the complete withholding of illumination that overwhelms the entire performance space, brought into focus the need to examine excessive darkness, and how it communicates through the act, the achievement, and the unity of nothingness.

\section{'Going Dark'}

'Going dark' is a common cry of the stage hand, deputy stage manager (DSM), or lighting technician, bellowed before a sudden decrease in the stage and auditorium lighting levels, to ensure no one is harmed as a consequence. But is it never truly 'dark'; some semblance of light still exists. The sources of such nuisance illumination can range from 
emergency exits signs or working lights in the wings, to the prompt desk off-stage or access lights in the auditorium. When a fastidious drive to complete darkness, part of Beckett's vision for some of his work, is pursued by productions of his dramas, then meticulous preparation is undertaken to manage all light sources. Common precautions are that every doorframe should have blackout curtains behind them, to stop light spilling through the edges. Emergency exit signs should be removed or unplugged, and LED standby lights hidden with black foil. Glow tapes on the auditorium steps are covered. A gel called neutral density should shroud the screen of the lighting control desk to limit the effect of its pollution. In short, every light source is nullified as far as possible. This list may seem like the idiosyncratic ramblings of a lighting enthusiast. However, it is this attention to detail in creating a stygian darkness, where we are forced not to see, that enhances both the minutia of what it is we are forced to see, and the affect that an excess of darkness can have upon spectators. In this extreme preparation, this more, is the nothingness, the less, achieved; that is to say, through precise limitation can communication become clearer. This maxim is equally applicable to the exacting requirements of a performance of Mouth, as it is for the meticulous limitation of light.

\section{Sight and Light: The Royal Court Production}

As the house lights dim at the opening of the Royal Court production of Not I, Footfalls, and Rockaby performed by Lisa Dwan, I expect the entire performance space to be plunged into complete blackout. To test this, I lift my hand in front of my face and see no outline; I turn my head left and right, knowing that a moment ago people were visible each side, but see no silhouettes. For a person who has spent several years lighting the stage, this is a pleasure of visual negation that is rarely accomplished; although I recognise that for some, such an experience is far less gleefully sought or received. This 'velvety' darkness holds for a deliberately elon-

25. Victoria Finlay, 'Interview: Actress Lisa Dwan on Performing Samuel Beckett Monologue Not $\Gamma$, South China Morning Post, 14 February 2014 <http://www.scmp. com/lifestyle/arts-cul ture/article/ $1711836 /$ interviewactress-lisa-dwan-per forming-samuel-beck ett> [accessed 10 March 2015] gated length of time. ${ }^{25}$ Sniggers and whispers die away. Distance and closeness, absence and presence, community and isolation (or perhaps freedom) exist simultaneously in this stygian gloom. In its midst the spectator is left to navigate their own mental journey, among a community of individuals in the space.

When darkness surrounds multiple individuals in Beckett's dramas What Where (1984), for example - they appear as at some indefinable meeting point, yet still separate and distant. This is part of the role of darkness within a Beckettian aesthetic: it separates, it individualises, and it forces an inward turn, in the dramatis personae and, arguably, in the spectator. An excess of darkness disconnects an audience from each other, in a similar way to how light and dark onstage can demonstrate a separation between characters (May and her mother in Footfalls), or even a separation within characters (Mouth and her body in Not I).

This focus on the individual provokes a specific kind of engagement with darkness, particularly through the sensitivity to light with which Beckett's theatre conversant. For example, in his discussion of Chris 
26. Staged in the Turbine Hall, TATE Modern, London, during Miroslaw Balka's 2010 How It Is installation. The audio track of the performance is available online at <http://www.tate. org.uk/context-com ment/audio/experi ences-dark-who-youare $>$ [accessed 4 February 2016].

27. Welton, 'The Possibility of Darkness', p. 6

28. Ibid., p. 6
29. Vladimir Nabokov, Speak, Memory: An Autobiography Revisited (London Penguin Classics, 2000), p.17.

30. Samuel Beckett, The Complete Dramatic Works (London: Faber \& Faber, 1986), p. 83

31. Siobhan Murphy, 'Pitch-black Theatre Experience at Royal Court Provokes a Sense of Panic', Metro, 14 January 2014 <http://metro.co.uk/ 2014/01/14/pitchblack-theatre-experi ence-at-royal-courtprovokes-a-sense-ofpanic-4262756/> [accessed 10 March 2015]
Goode's Who You Are which utilised the TATE's shadowy Turbine Hall to offer a sense of blackout (but not a total blackout), ${ }^{26}$ Welton highlights the audiences' 'specific and peculiar reality of their being together in darkness'. ${ }^{27}$ This communal experience of the 'quasi-darkness' common in theatre, is not what is foregrounded in total blackout of The Royal Court production. ${ }^{28}$ The excess of darkness before Not I focuses attention away from fellow spectators, and challenges an individual's awareness of their bodily self. As discussed, patrons in the darkness can instinctively attempt to situate their physical self during the blackout. This can be manifest in acts such as touching the confines of the theatre seat. It can take a visual and mental form, as eyes search for a flicker of light. It culminates in an aural awareness of the abnormally loud noise that breathing and movement creates. Eventually, as silence increases in the darkened space of the Royal Court production, the reverberations of one's heartbeat seems to register as a sound, through the body's increased pulse. The nothingness of this physical darkness combines with an aural emptiness. The displacement of physical surroundings makes every action potentially fraught, destabilising the potential of one's agency, as you cannot approximate any sense of distance with which to undertake an action with certainty.

The darkness can trigger an inward turn in the spectator, and the intensely private affair of one's experience within this environment, I would argue, evolves in one of two ways. Firstly, as a fear-induced repulsion from the darkness, manifest as discussed via the search to visually situate one's body in space. Secondly, as a foreboding anxiety that light will suddenly intrude on this privacy and expose you, mid-action, midthought, mid-sentence. The dark, therefore, threatens through its excess, yet its antithesis - light - threatens through its absence; this paradoxical relationship does not work in reverse.

Spectators in the elongated opening blackout of the Royal Court production, can justly presume that the performance will begin and light will re-enter, although exactly how long they will be left in darkness is uncertain. The end of the blackout, however, does not signal the end of excessive darkness in the production; audiences are re-plunged into, and re-confronted by, the same indeterminate black void between each of the three plays. This structure demonstrates an affinity with Vladimir Nabokov's expression that, 'our existence is but a brief crack of light between two eternities of darkness, ${ }^{29}$ a statement echoed by Pozzo before his final departure in Waiting for Godot (1956): 'They give birth astride of a grave, the light gleams an instant, then it's night once more'. ${ }^{30}$ Although this article does not focus on a production of Godot specifically, tracing such affinities aids the discussion of darkness as part of a wider Beckettian aesthetic.

Although reviewers of the Royal Court production persistently dwell on the deployment of darkness, even noting that 'closing your eyes makes no difference, ${ }^{31}$ it is a reasonable postulation that other senses can be heightened during these blackouts. Therefore, what little rustling, fidgeting or buzzing that persists in these darkened moments, seems unnaturally loud. Moreover, this strange amplification induces an increasing stillness, pertaining to a simple logic - if you remain still, what can 
32. The term 'notion of the stage area' is used because the stage is physically hidden. Although the stage area persists, it signifie more than its physical limits, when the space is not defined by light.

33. Finlay, 'Interview'

34. Whitelaw, 'Introduction to Not I.

35. Birmingham Rep Studio, 20 September 2014.

36. So far, attempts to garner the Stage Manager's Reports for this tour have not been successful.

37. Anthony Lane, 'The Boards: Chatterbox' The New Yorker, 29 September 2014 <http://www.newyor ker.com/magazine/ 2014/09/29/chatter box $>$ [accessed 10 March 2015].

38. Hannah Hiett, 'Not I Previewed: "The most Stressful, PanicInducing, Amazing Hour...", The Lowry Blog, 18 September 2014 <https://thelow ryblog.wordpress. com/2014/09/18 not-i-previewed-themost-stressful-panicinducing-amazinghour/> [accessed 10 March 2015]. possibly go wrong? The danger posed by disrupting this darkness underlines the (albeit invisible) exposure of the individual, and reflects the collapsing distance between the notion of the stage area and the auditorium. ${ }^{32}$ A desire to be absorbed into the darkness is instinctively one of self-preservation, yet the lack of light is still both unsettling and stifling. The pressure, or weight, of this darkness is arguably released by the performance start, when spectators are confronted by a different kind of pressure - the incessant jabbering of Mouth.

For the performer of Not I, there is an even greater inducement of a stygian environment via various bodily restrictions: these include the fastening of the torso to a frame or chair, the precise securing of the head's position (vital for the success of lighting Mouth), the blindfolding of eyes, and the use of earplugs. Lisa Dwan attests to a heightening of the senses in this restrained state, while also highlighting what reactions intense darkness can incite: 'the dark can produce panic attacks. People often rush out, and even though I can't hear or see, I know if there's a disturbance in the audience; I can smell it'. ${ }^{33}$ Such audience reactions warrant exploration, as explained at the beginning, because they have been evident since the first Royal Court production of Not $I$, as Whitelaw recalled in an introduction to the television version of the play:

There was no escape, because we killed all the lights, we broke all the rules, and took the lightbulbs out of the exit lights and took the lightbulbs out of the ladies' loo-lights because people tried to escape into the loo. ${ }^{34}$

I have physically experienced such flights from darkness twice. The first instance occurred during the opening blackout of the Royal Court's 2014 production, in a performance at the Birmingham Rep. ${ }^{35}$ A spectator violently pushed past my legs in an attempt to leave the auditorium, nearly falling over. As they fumbled to the exit they caused a patron to scream, presumably as they bumped into them as well. A second person collided with me while leaving during the three-minute blackout between Not I and Footfalls. Anecdotal evidence from Rep employees points to another panic attack occurring at a matinee earlier in the same week. ${ }^{36}$ Either this panic attack is the same one referred to in The New Yorker's preview of the production, or there are other such instances as Dwan's account references. ${ }^{37}$ After its short run at the Birmingham Rep, the production moved to Manchester's Lowry. As part of the production's marketing, a promotional review by Hannah Hiett renamed the experience of witnessing the performance 'the most Stressful, Panic-Inducing, Amazing Hour'. Hiett described a notice given just before the performance:

Before the lights went down, an announcement was made: The emergency exit lights would be switched off, every leak of light will be blocked. If you can't handle it, please don't run, keep calm, stay in your seats until the first short piece was done and there would be a three-minute blackout before the next piece began. If you had to get out, please go then. ${ }^{38}$ 
39. Beckett, The Complete Dramatic Works, p. 138.

40. Ibid., p. 203 .

41. Ibid., p.307.
Such a disclaimer could in equal measure alleviate stress or, as Hiett's title suggests, encourage the very panic it seeks to avert. This pre-show announcement proclaims a contract the audience are obligated to and, therefore, casts shame upon those who would break the agreement by leaving at any time other than the recurrent blackouts. Moreover, such a disclaimer alludes to a sense that the audience do not own the darkness they inhabit and are immersed in; rather it seems to suggest the darkness has authority over them, through the affects it produces from the body that can be both emotional and physical. The announcement predicts tangible responses from an expectant audience, but still asks that they restrain these reactions so as not disrupt the performance or the experience of others. This excessive darkness is, therefore, imbued with an affecting physicality that envelops the whole performance space through the collapsed distance between the stage and the auditorium.

\section{Sight and Light: Project Arts Centre}

In opposition to a collapse of distance that darkness can invoke, some Beckettian works employ light to harshly expose the limitations of a space by defining it. For example, the 'blazing' light upon Winnie in Happy Days (1961), ${ }^{39}$ the 'dazzling' description called for in Act Without Words I (1958), ${ }^{40}$ and the alternating 'strong spots' of Play which trigger 'immediate' responses from the urn-dwelling speakers. ${ }^{41}$ In each of these examples, the light offers a false sense of liberty through its advantage of making visible a part of that world. Yet the visible spaces of each example are still riddled with varying kinds of confinement, from a mound, to the off-stage wings, or a trio of urns. The varying excesses of darkness employed by some short works create an equally stark focus, but one that is centred on the confinement of the individual, not the confinement of space. The second flight from darkness I witnessed attests a little more to this tension between the use of light and dark within a Beckettian aesthetic.

To coincide with the 2006 centenary of Beckett's birth, the nowdefunct Bedrock theatre company produced an evening of short works entitled Beckett's Ghosts at Dublin's Project Arts Centre. This production comprised, in running order, A Piece of Monologue (1979), That Time (1976), Breath, and Not I. Upon entry spectators were greeted by red curtains, which both concealed the stage area of the black box space and acknowledged traditional or 'safe' theatrical fare, in contrast to the sparse dramaticules that would be revealed over the course of the performance. A slow fade to complete darkness was followed by a prolonged blackout submerging the audience for an indeterminate period. The glowing curtains were a final trace of a defined performance area, before total darkness consumed the space, collapsing the distance between auditorium and stage. There was no warning or safety disclaimer for this production. Many of the precautions of light limitation, as laid out previously, were employed. The curtains could be heard parting in the darkness and $A$ Piece of Monologue began as light slowly grew inside the globe lamp stage left, illuminating half of Speaker's face. 
Unlike the Birmingham Rep performance, a disturbance occurred in the Project Arts Centre immediately after the period of darkness, as the presence of light returned. Whispers and uncertain sounds of talking grew to shouting from the back of the auditorium. This increased to a scream as a reluctant patron protested at volume that they wanted to leave. The single auditorium door opened via a sliding mechanism that the patron was unable to operate in the dim light, presumably compounding the physical (and mental) entrapment they were attempting to flee. Even the end of the blackout (that is, the start of Speaker's monologue), and the relief that illumination granted the upstairs studio, was not enough to yield the spectator's need to take flight from the performance space. Whatever affect had been caused by this state of darkness, the intrusion of light could not placate.

The patron's screams during the opening of the performance led the production staff to turn all the house lights to full, for fear of an injury occurring. This action immediately destroyed the ocular sensitivity that had been cultivated as it illuminated the entire space, and obliterated any sense of a collapsed distance. While exposing the exact proximity of the globe lamp to Speaker, it also made evident the corner of the bedstead that was part of an incomplete structure. Moreover, this photic intrusion laid bare the vulnerability of the actor when the moment of performance had been dazzlingly shattered.

The lack of precision from the house lights, their excess, gave nothingness a new and unwanted level of detail. The indiscriminate light exposed the harsh reality of very little: the few props that existed on stage, the shallow divide between the auditorium and the stage (a division made apparent when the curtains closed in full light), the propinquity of spectators to each other, and their reactions to the unfolding events. The unplanned visibility of the patrons problematised their position solely as spectators, due to the unconsciously self-reflexive nature of this lit moment, and the shattering of the performance contract. The patrons were no longer spectators to a performance, but also witnesses to an eruption of fear in the performance space. Unlike the Royal Court's production, in the abruptly illuminated environs of the Project Arts Centre, patron apprehension no longer simply resided within a stygian darkness, but was momentarily directed towards potentially unobserved changes in this suddenly altered performance space. The light rendered in detail all the component parts of the black box space. The darkness had not only concealed these details, but given them the potential to become other than what they appeared when exposed to fluorescent scrutiny. In this way, the efficacy of the precise implementation of darkness was reinforced by its stark obliteration, strengthening the notion that darkness is not simply an absence of light, but has its own presence. Darkness in such instances is not only an obscuring of the physical elements of the performance space, but must be considered a precise withholding of illumination for the purposes of establishing its presence; this presence lingers in its affect and is not altogether faded by the intrusion of light.

Considering these varying reactions, it is arguable that if darkness as part of a Beckettian aesthetic affects spectators to the extent that some need to physically remove themselves from it, then this has implications. 
For the producers of such work, this poses issues of ethical responsibility about how complete darkness is utilised and how risks are mitigated, because, as in both examples above, even the intrusion of light was not enough to diminish the effects of excessive darkness. Within Beckett's theatre the presence of darkness has a potency, and the precision of Beckett's demands for its implementation attest to his appreciation of this. My final case study will consider the production of an alternative kind of darkness - one without such dramatic consequences, but arguably no less potency within the confines of Beckettian drama.

\section{Sight and Sound: Happy Days Festival 2015}

The separate flights from darkness outlined above speak to the precise application of light and dark in communicating a theatre of the nerves or senses. But what of a different kind of enforced darkness? This third example examines a physical restraint of vision, as opposed to an allpervading darkness. Out of Joint's All That Fall, presented at the Enniskillen Happy Days Festival 2015 and directed by Max StaffordClark, staged Beckett's radio play in a manner that foregrounded the aural experience. In 2011 Dublin's Pan-Pan Theatre Company produced an internationally acclaimed version of $A l l$ That Fall, which littered rocking chairs throughout the performance space and used a wall of lights to complement the sound of trains arriving and voices approaching, among other purposes. In contrast, Stafford-Clark returns the play to an almost completely auditory experience through the visual confinement of individually blindfolded patrons. As stated, this kind of darkness is an act of being forced not to see, as opposed to being asked to see nothing. All That Fall is another of Beckett's plays that is conspicuously tied to an oftquoted and famous direction, ${ }^{42}$ given by the author in correspondence to in referring to the quency with which this quotation is used, and also the reductionism that can be a problematic when such citations become almost synonymous with works; however, it would be remiss not to include it given the subject-matter of this article. The problematics of such continued close associations is a separate debate.

43. Everett C. Frost, 'A "Fresh Go" for the Skull: Directing All That Fall, Samuel Beckett's Play for Radio', in Directing Beckett, ed by Lois Oppemheim (Ann Arbor: University of Michigan Press, 1994), pp. 186-219 (p-191). Emphasis in original.

\section{Barney Rosset in 1957:}

All That Falling specifically radio play, or rather radio text, for voices, not bodies $[\ldots][\mathrm{n}$, the reduced visual dimension it will receive from the simplest and most static of readings ... will be destructive of whatever quality it may have and which depends on the whole thing's coming out of the dark. ${ }^{43}$

It is important to note that Out of Joint's production was never totally dark, but instead created a kind of middle ground between total blackout and Beckett's call for a radio text 'coming out of the dark'. Out of Joint's promotional material specifically referenced Beckett's intent for the work, and attempted to enact it by making the actors' bodies invisible to the audience members (no longer 'spectators'). This forced patrons to engage with an aural landscape defined by the physical movement of the actors' words through the performance space. This journey becomes clearer when we understand the staging of the piece.

Inside the assembly hall of St. Michael's school, the triangular performance space was defined by the seating layout for the audience. Two triangles of chairs faced each other, a smaller triangle inside a larger one, 
44. Beckett, The Complete Dramatic Works, p. 172.
45. Ibid., p-180.

46. I experienced this while blindfolded however, I cannot attest to other such singular interventions between an actor and a patron in this performance. and it was the space in between these triangular formations that created the 'country road' upon which the performers walked, and where Mrs Rooney's narrative journey becomes a sonically realised one. ${ }^{44}$ In the performance I attended, most of the audience conformed to sit on the outer row of chairs - the larger triangle - facing inwards. It was as though we were about to 'watch' a performance in the middle of this three-sided stage, despite it being clear from the blindfold issued upon entry that the restriction of sight was a prerequisite of attendance. We were asked to don our blindfolds prior to the entry of the actors and while these visual restrictions did enforce a sense of darkness, they did not completely block out all traces of light within the space, which remained on for the duration of the performance.

The pathway between the triangular seating banks added to the sense of motion within the performance and the narrative. Moreover, it aided the establishment of a sense of proximity to the performers and their words, which instead of coming out of the dark, actually come into the enforced dark of the blindfolded patron. Logical judgements were possible about where along the triangular trail a voice was coming from; I cannot say definitively, but I doubt mine was the only blindfolded head that turned to face a voice as it spoke. Proximity was discernible in exact detail when actors touched audience members. One such moment was when Tommy commented sardonically, 'that's the thanks you get for a Christian act', 45 and tapped the shoulder of the audience member he was sat next to, to demonstrate their invisible agreement in the matter. ${ }^{46}$

In the blindfolded darkness of Out of Joint's production, there was arguably a lessened propensity for patrons to have to leave a performance, because all one had to do was remove the eye-mask to alleviate the enforced darkness. Although there was little mention of precautions needed in terms of exiting the space, the chinks of light visible at the edges of your blindfold were a constant reminder of this easy escape from the dark. However, while there was a comparative physical safeness to this performance, that does not belie the commonalities which can be traced across all three case studies; specifically, between a spectator's engagement with a sense of selfhood in these darkened moments, a collapse of distance within the whole performance space, and the productions' explorations of varying kinds of darkness significant to the aesthetic of Beckett's work.

In Stafford-Clark's All That Fall, the body of each spectator was always visible within the space hidden by the blindfold - this lit space that should only be inhabited by the actors; that was part of the performance contract, and a reversal of theatrical norms. This self-imposed darkness within a wider illuminated environment is clearly different from the all-encompassing blackout of the previous case studies. Yet this environment was appropriate for Out of Joint's production, which attempted to embed the audience within the aural world of the play. The implementation of darkness in this instance creates a kind of theatre that plays to the senses, as opposed to playing on the senses, and in doing so confronted Beckett's scepticism of staging All That Fall, via the removal of the visual performance space.

The lit bodies of fellow blindfolded patrons in Enniskillen allude to the community of voices coming out of the darkness that Beckett suggested; this 
47. Graley Herren, 'Facing the Darkness: Interrogations Across Genre in Samuel Beckett's What Where', Midwest Quarterly, 43.3 (Spring 2002) 322-36 (p-327)

48. Beckett, The Complete Dramatic Works, p. 83.

49. Ibid., p. 435 .

50. Eric P. Levy, Trapped in Thought: A Study of Beckettian Mentality (Syracuse, NY: Syracuse University Press, 2007), p.36.

51. Ibid., p. 28.

52. With reference to the emptiness of the stage, see Les Essif, Empty Figure on an Empty Stage (Indiana: Indiana University Press, 2001), pp. $74-78$, for a discussion specifically about Not I. See Terry Eagleton, 'Beckett and Nothing', in Reflections on Beckett: A Centenary Celebration, ed. by Anna McMullan and S.E. Wilmer (Ann Arbor: University of Michigan Press, 2009), pp-32-9, for a discussion of how nothingness in Beckett can be seen as a 'profoundly political notion' ( $\mathrm{p}-38$ ), considered in the light of Adorno's assertion of the barbarity in postHolocaust art. un-visible audience arguably has a dual presence as real-world patrons and narrative inhabitants. Audience members could observe fellow patrons by simply removing their blindfold, and by virtue of this agency - equally granted to all - a subtle threat exists that individual audience members could unwittingly be observed. Being subject to the potential gaze of others is made cogent during pre- and post-show states, when blindfolds are not worn and the focal point for each patron are the members of the audience seated opposite. Although removing the blindfold would infringe on the performance contract, the darkness it enables - which is not an excess, which is not total, which the patron can control - is employed to create the nothingness that is filled up with aural information. This alternative darkness supports Beckett's narrative, as well as his notion for the reception of the play.

It is arguable that Beckett's aversion to any staged reading of All That Fall concerned both the failure of the words to come out of the dark, as well as the negation of individual renderings of the text; that is, the characters would take the form of readers upon the stage. In the Royal Court and the Project Arts Centre productions, darkness (and light) intermittently intrude in the performance space. However, Out of Joint create a darkened space that ends at the extremity of each individual patron's body and lasts for the entire performance. In this sense, the darkness in Enniskillen was more individually defined, although responses to it were performed in full light.

\section{Lights Up: Conclusion}

The varying kinds of darkness employed in productions of Beckett's short works offer aesthetic avenues to explore what the author described as his artistic task, that is to 'find a form that accommodates the mess'. ${ }^{47}$ If we consider this to be simply the mess of life, the detritus of accumulation, then Breath is perhaps the visual zenith of this task. As a slither of theatrical existence where 'the light gleams an instant', Breath elucidates a repetitive trope of Beckett's short works, to conjure images of lives lived and lost, the mess of memories being struggled with and the violence of their eruption, repetition, and recognition. ${ }^{48}$ However, finding a form for the mess may be equally accomplished in the spewing diatribe of Mouth or W's last gasps for 'more' in Rockaby. ${ }^{49}$ In relation to Beckett's prose, Eric P. Levy argues that there is an aesthetic of lessness where 'reductive repetition eventually achieves a mimetic sparseness almost beyond expression'. ${ }^{50}$ Levy suggests that an external nothingness, a void, can invert the projected vision of a protagonist into a 'perception of inner emptiness'. ${ }^{51}$ We might easily translate external nothingness as a manifestation of inner emptiness, into the aesthetic language of darkness on stage. ${ }^{52}$ However, this discussion has sought to balance questions of what the nothingness of darkness does, with the importance of how it is precisely implemented (and received) in performance, and how it can alter the entire performance space. The purpose has been to illuminate how and why the potency of darkness, and the making present of nothingness as part of a Beckettian aesthetic, might offer valuable insights into the work and its reception. 
53. Beckett, The Complete Dramatic Works, p178.
Darkness within a Beckettian aesthetic is purposeful and brings forth nothingness as a something to be considered, as a presence that can impact a spectator and a performance space. However, to reappropriate Addyman's phrase, even the negation of space has to take place in some space - at least in Beckett's theatre. Whether the author literalises nothingness as Mr Slocum gazes 'through the windscreen, into the void' ${ }^{53}$ or describes it via Pozzo's account of the immense darkness before and after life, or calls for its visualisation through a disembodied Mouth floating in blackness, the precise use of darkness as a literal and physical language by Beckett, and those entrusted to produce his works, places the spectator (or listener) into an arena of self-confrontation. This arena does not provoke simple or even consistent resolutions.

If so inclined, we could dismiss each flight from darkness as a fear of the dark itself, or as anomalies to the common reception of the work. We could say these audience members were simply not enjoying it - clearly, screaming to leave the auditorium is a good indication of this. However, this study does not seek to trivialise patrons who take flight from excessive darkness, nor does it discount these responses as pure anomaly. I would venture instead that there is some affect, or some internal interrogation, that is brought on by excessive darkness and that is not quenched by the light granted after prolonged blackout. In the communal blackouts an individual is confronted with their sense of selfhood, mirroring characters in Beckett's dramas. Out of Joint's arguable adherence to the spirit of Beckett's work created many iterations of darkness that were individually defined. Through this, patrons in Enniskillen were locked into a dialogue with their experience of the narrative, as well as of the performance conditions. The precise implementation of darkness when employed within Beckettian drama - in whatever manner it is pursued - can create kinds of theatre that play on and with the senses. In such environments processes of logic and reason can be, momentarily, disrupted. However, the collapse of distance that darkness encourages can offer different ways to conceive the entire performance space, particularly when considering Beckett's appreciation of light and dark in performance. While Out of Joint's methods are obviously unsuitable for many productions, darkness in that performance was a strategy employed to harmonise the text, the performance, the space, and the spectator, and perhaps that is a useful consideration for how excesses of darkness might be implemented in future. 